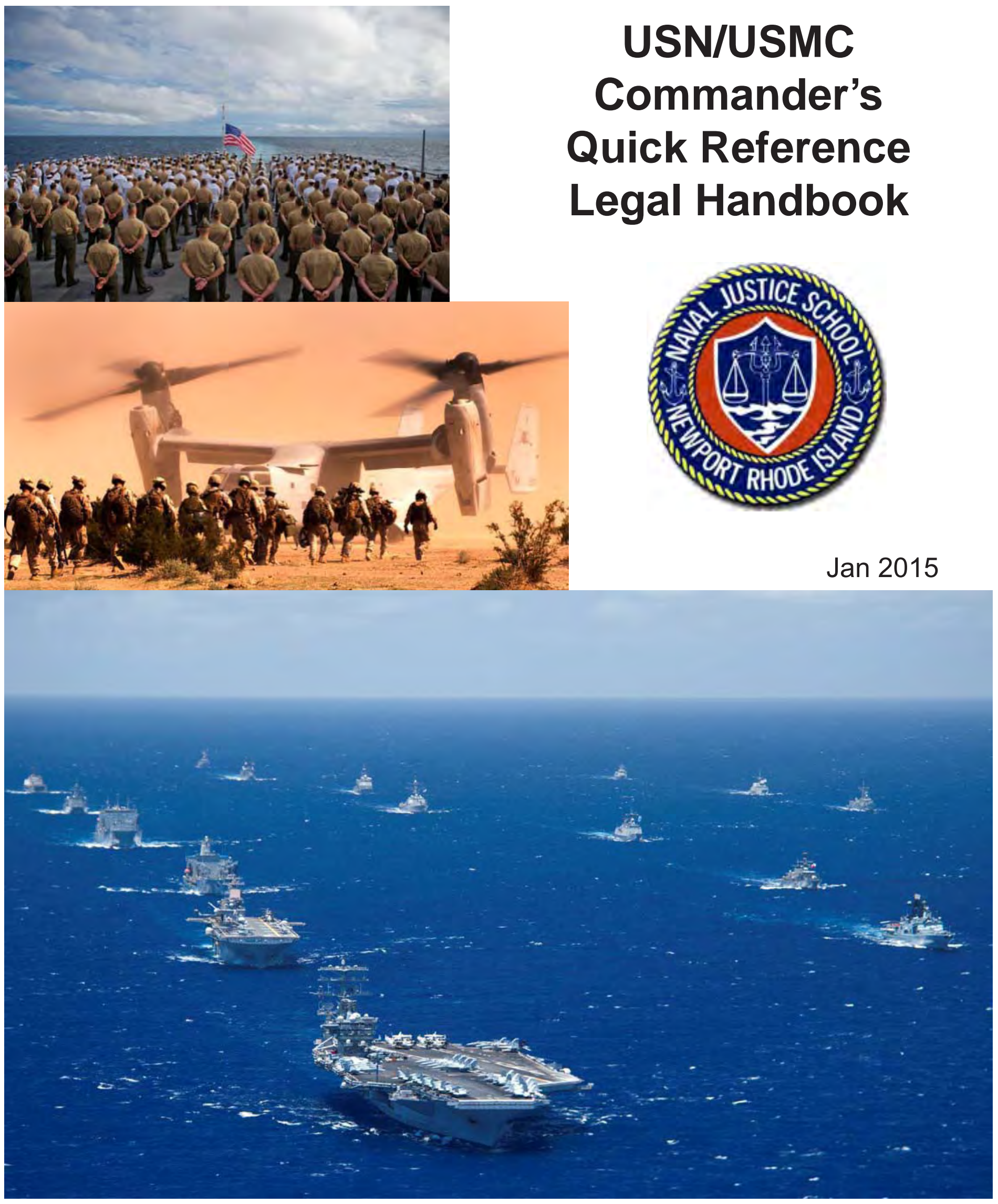




\section{Report Documentation Page}

Form Approved

OMB No. 0704-0188

Public reporting burden for the collection of information is estimated to average 1 hour per response, including the time for reviewing instructions, searching existing data sources, gathering and maintaining the data needed, and completing and reviewing the collection of information. Send comments regarding this burden estimate or any other aspect of this collection of information,

including suggestions for reducing this burden, to Washington Headquarters Services, Directorate for Information Operations and Reports, 1215 Jefferson Davis Highway, Suite 1204, Arlington

VA 22202-4302. Respondents should be aware that notwithstanding any other provision of law, no person shall be subject to a penalty for failing to comply with a collection of information if it

does not display a currently valid OMB control number.

\begin{tabular}{|c|c|}
\hline $\begin{array}{l}\text { 1. REPORT DATE } \\
\text { JAN } \mathbf{2 0 1 5}\end{array}$ & $\begin{array}{l}\text { 3. DATES COVERED } \\
\mathbf{0 0 - 0 0 - 2 0 1 5} \text { to 00-00-2015 }\end{array}$ \\
\hline \multirow{3}{*}{$\begin{array}{l}\text { 4. TITLE AND SUBTITLE } \\
\text { USN/USMC Commander's Quick Reference Legal Handbook }\end{array}$} & 5a. CONTRACT NUMBER \\
\hline & 5b. GRANT NUMBER \\
\hline & 5c. PROGRAM ELEMENT NUMBER \\
\hline \multirow[t]{3}{*}{ 6. AUTHOR(S) } & 5d. PROJECT NUMBER \\
\hline & 5e. TASK NUMBER \\
\hline & 5f. WORK UNIT NUMBER \\
\hline $\begin{array}{l}\text { 7. PERFORMING ORGANIZATION NAME(S) AND ADDRESS(ES) } \\
\text { Naval Justice School,360 Elliot Street Bldg 360,Newport,RI,02841 }\end{array}$ & $\begin{array}{l}\text { 8. PERFORMING ORGANIZATION } \\
\text { REPORT NUMBER }\end{array}$ \\
\hline \multirow[t]{2}{*}{ 9. SPONSORING/MONITORING AGENCY NAME(S) AND ADDRESS(ES) } & 10. SPONSOR/MONITOR'S ACRONYM(S) \\
\hline & $\begin{array}{l}\text { 11. SPONSOR/MONITOR'S REPORT } \\
\text { NUMBER(S) }\end{array}$ \\
\hline
\end{tabular}

12. DISTRIBUTION/AVAILABILITY STATEMENT

Approved for public release; distribution unlimited

13. SUPPLEMENTARY NOTES

14. ABSTRACT

15. SUBJECT TERMS

16. SECURITY CLASSIFICATION OF:

\begin{tabular}{c|c|c|}
$\begin{array}{c}\text { a. REPORT } \\
\text { unclassified }\end{array}$ & $\begin{array}{c}\text { b. ABSTRACT } \\
\text { unclassified }\end{array}$ & $\begin{array}{c}\text { c. THIS PAGE } \\
\text { unclassified }\end{array}$
\end{tabular}

17. LIMITATION OF ABSTRACT

Same as

Report (SAR)

\begin{tabular}{c|l}
$\begin{array}{c}\text { 18. NUMBER } \\
\text { OF PAGES } \\
\mathbf{1 6 6}\end{array}$ & 19a. NAME OF \\
& \\
&
\end{tabular}




\section{***NOTICE TO USERS OF THIS GUIDE ***}

This reference, like all reference material, is meant as a guide and is not, by itself, authoritative legal or regulatory information. Statutes and service regulations always supersede contradictory guidance that may be contained in this reference.

The legal and procedural information contained in this guide are current as of the date of distribution to the recipient. However, given the large volume of information contained in this reference, portions of this guide are subject to change on a regular basis, sometimes with little notice or time for revision. Therefore, Naval Justice School advises the reader that some of the information in this publication may become out of date or superseded by more recent guidance, including more recent publication of this reference.

Under all circumstances, commanders - whether utilizing this guide or not - are strongly urged to contact a judge advocate to seek personal guidance in handling all legal issues that may arise in execution of command responsibilities. While this guide serves as a useful tool to spot and develop solutions for legal issues, it is not a substitute for the informed advice of a judge advocate. 


\section{TABLE OF CONTENTS}

Section I: $\quad$ Military Justice and Sexual Assault Prevention and Response $\quad 1$

NCIS Reporting and Military Justice Investigations 2

Processing Sexual Assault Allegations 3

$\begin{array}{ll}\text { Sexual Assault Initial Disposition Authority (SA-IDA) } & 6\end{array}$

Questioning/Interrogating Suspects and Article 31(b) Rights 9

$\begin{array}{ll}\text { Search and Seizure } & 11\end{array}$

$\begin{array}{ll}\text { Court-Martial Types and Convening Authority } & 13\end{array}$

$\begin{array}{ll}\text { Court-Martial Basics } & 15\end{array}$

$\begin{array}{ll}\text { Pre-Trial Restraint } & 17\end{array}$

$\begin{array}{ll}\text { Pre-Trial Agreements } & 19\end{array}$

$\begin{array}{ll}\text { Post-Trial Review } & 21\end{array}$

$\begin{array}{ll}\text { Victim/Witness Issues } & 23\end{array}$

Section II: $\quad$ Administrative Corrective Measures and Non-Judicial Punishment 26

Non-Punitive Measures to Correct Misconduct or Poor Performance 27

$\begin{array}{ll}\text { Non-Judicial Punishment Basics } & 29\end{array}$

$\begin{array}{ll}\text { Non-Judicial Punishment Procedures and Proceedings } & 31\end{array}$

Non-Judicial Punishment Clemency Action 33

Non-Judicial Punishment Appeals $\quad 35$

Section III: $\quad$ Administrative Investigations $\quad 37$

$\begin{array}{ll}\text { Investigations under the JAGMAN } 38 & 38\end{array}$

$\begin{array}{ll}\text { Death Investigations } & 41\end{array}$

Reporting Requirements for Loss or Compromise of Classified Information 43 
Section IV: $\quad$ Claims $\quad 45$

$\begin{array}{ll}\text { Claims Overview } & 46\end{array}$

Section V: $\quad$ Administrative Separations and Officer Misconduct 47

$\begin{array}{ll}\text { Enlisted Administrative Separation Basics } & 48\end{array}$

Enlisted Administrative Separation Boards $\quad 54$

Officer Misconduct and Separations 56

$\begin{array}{ll}\text { Detachment for Cause } & 58\end{array}$

Section VI: $\quad$ Command Urinalysis Program 59

$\begin{array}{ll}\text { Command Urinalysis Program Overview } & 60\end{array}$

Section VII: $\quad$ Physical and Mental Health Issues 64

HIV Issues $\quad 65$

$\begin{array}{ll}\text { Mental Health Evaluations } & 67\end{array}$

Section VIIl: $\quad$ Sexual Harassment, Fraternization, and Hazing 68

$\begin{array}{ll}\text { Sexual Harassment Response } & 69\end{array}$

$\begin{array}{ll}\text { Fraternization Overview } & 71\end{array}$

$\begin{array}{ll}\text { Hazing Prevention and Response } & 73\end{array}$

Section IX: $\quad$ Freedom of Expression $\quad 75$

Speech, Religions Accommodation, Political Activities $\quad 76$

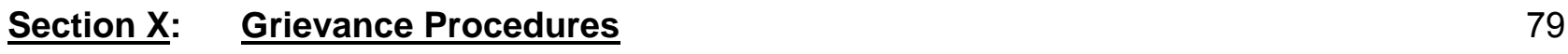

$\begin{array}{ll}\text { Mast and Complaints of Wrong } & 80\end{array}$

Hotline Complaints (IG) and Whistleblower Protections 82

$\begin{array}{lc}\text { Congressional Inquiries } & 83\end{array}$ 
\begin{tabular}{ll} 
Section XI: & Information Access \\
\hline
\end{tabular}

Freedom of Information Act (FOIA) $\quad 85$

Privacy Act and Personally Identifiable Information $\quad 87$

$\begin{array}{ll}\text { HIPAA } & 89\end{array}$

Section XII: $\quad$ Relations with Civilian Authorities 90

$\begin{array}{ll}\text { Civilian Jury Duty } & 91\end{array}$

$\begin{array}{ll}\text { Cooperation with Civilian Law Enforcement Authorities } & 92\end{array}$

Repossession of Personal Property on Installations 95

Service of Process/Subpoenas $\quad 96$

$\begin{array}{ll}\text { Customs Responsibilities } & 98\end{array}$

$\begin{array}{ll}\text { Foreign Claims } & 99\end{array}$

Foreign Criminal Jurisdiction and Status of Forces Agreements 100

Section XIII: Foreign Relations and Overseas Marriages 101

$\begin{array}{ll}\text { Liberty Risk } & 102\end{array}$

$\begin{array}{ll}\text { Marriages Overseas and Marriages to Foreign Nationals } & 103\end{array}$

Section XIV: Legal Readiness 104

$\begin{array}{ll}\text { Legal Assistance } & 105\end{array}$

$\begin{array}{lc}\text { Pre-Deployment Legal Readiness } & 108\end{array}$

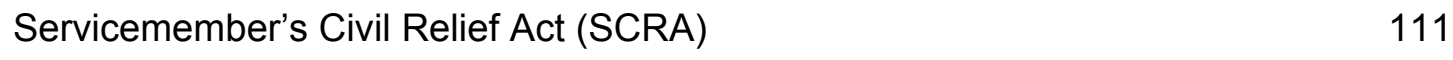

$\begin{array}{ll}\text { Dependent Support } & 114\end{array}$

$\begin{array}{ll}\text { Paternity Complaints } & 116\end{array}$

$\begin{array}{ll}\text { Indebtedness Complaints } & 117\end{array}$

Family Relationship Issues, Domestic Violence, Family Advocacy Programs $\quad 119$ 


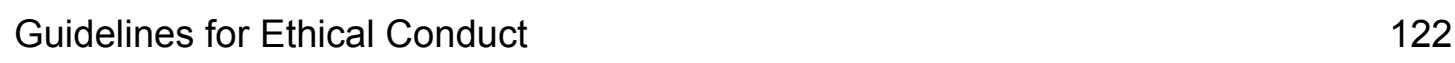

$\begin{array}{ll}\text { Commercial Dealings between Servicemembers } & 123\end{array}$

$\begin{array}{ll}\text { Conflicts of Interest } & 124\end{array}$

$\begin{array}{lr}\text { Fundraising } & 126\end{array}$

$\begin{array}{lr}\text { Birthday Ball Fundraising } & 128\end{array}$

$\begin{array}{lr}\text { Gambling } & 129\end{array}$

$\begin{array}{lr}\text { Gifts between Employees } & 130\end{array}$

$\begin{array}{ll}\text { Gifts from Outside Sources } & 131\end{array}$

Use of Government Property 133

$\begin{array}{ll}\text { Outside Employment } & 134\end{array}$

$\begin{array}{lr}\text { Political Activities - Military Active Duty } & 135\end{array}$

$\begin{array}{ll}\text { Private Organizations and Spouses Clubs } & 136\end{array}$

$\begin{array}{lr}\text { Travel Benefits } & 138\end{array}$

Command Coins, Recognition, Retention Items $\quad 139$

GLOSSARY OF COMMON ACRONYMS USED IN THIS PUBLICATION 140

$\begin{array}{lr}\text { APPENDIX } & 144\end{array}$ 


\section{SECTION I:}

MILITARY JUSTICE

AND

SEXUAL ASSAULT PREVENTION AND RESPONSE 


\section{REFERENCES:}

(a) MCM (RCM 303)

(b) JAGMAN (Chapter II)

(c) SECNAVINST 5430.107 (series)

(d) SECNAVINST 1752.4A (series)

(e) DODI 6495.02

\section{COMMAND INQUIRY:}

Suspected offenses may come to command attention in a variety of ways (e.g., shore patrol, civil law enforcement, or phone call, etc.) The commanding officer (CO) must conduct some form of inquiry into reported offenses that may be tried by court-martial per reference (a). The degree of inquiry will depend on the nature, validity, and seriousness of the complaint. See reference $(b)$.

\section{MANDATORY REFERAL TO NCIS:}

Reference (c) mandates that certain incidents be referred to NCIS whether occurring on or off base and regardless of civilian investigation involvement. These incidents include:

- Actual, suspected, or alleged major criminal offenses (punishable under the Uniform Code of Military Justice (UCMJ) by more than 1 year of confinement);

- Non-combat deaths when the cause of death is not medically attributable to disease or natural causes;

- Fires or explosions of unknown origin affecting Department of the Navy (DON) property or property under DON control;

- Theft or loss of ordnance or controlled substances;

- Disappearance of a command member;

- All instances of suspected fraud against the government within DON (e.g., theft of government property, bribery, false claims for pay, etc.); actual or suspected acts of espionage, terrorism, sabotage, assassination, and actual, suspected, or attempted defection of DON personnel;

- Internal security incidents, such as loss, compromise, or suspected compromise of classified information and national security cases; and

- Suspected sex-related offenses as defined under Articles 120 and 125 of the UCMJ.

WHEN NCIS DECLINES TO INVESTIGATE:

$\mathrm{NCIS}$ may, at its discretion, decline to conduct or continue any investigation, but shall expeditiously inform the effected command. A command may then request assistance from the local base security department or appropriate authority or pursue a command investigation pursuant to reference (a). 


\section{PROCESSING SEXUAL ASSAULT ALLEGATIONS}

REFERENCES:

(a) SECNAVINST 1752.4A (series)

(b) MCO 1752.5B

(c) MCO 3504.2 (series)

(d) OPNAVINST 1752.1 (series)

(e) SAPR CO Checklist (www.sapr.mil)

(f) DoDD 6495.01

(g) DoDI 6495.02

(h) NAVADMIN 272/12 and MARADMIN 624/12

(i) MCO $5800.16 \mathrm{~A}$

(j) SECDEF Memo of 14 Aug 2013

(k) 10 U.S.C. $\S 1565(b)$

(l) MARADMIN 583/13

\section{GENERAL INFORMATION:}

- The Department of Defense defines "sexual assault" as the intentional sexual contact, characterized by use of force, physical threat, abuse of authority, or when such sexual contact is made when the victim does not or cannot consent. It includes rape, nonconsensual sodomy, and indecent assault regardless of gender or spousal relationship [see reference (g)]. References (b) and (c) provide specific detail specific policies, provide guidance, and identify command responsibilities for handling sexual assault allegations.

- Sex-related crimes are prescribed under the Uniform Code of Military Justice in Articles $120-120$ c and 125. Understand that the definition of "sexual assault" from the Sexual Assault and Prevention (SAPR) program is not the same as the legal definition of sexual offenses as punishable crimes under the UCMJ.

COMMANDER'S RESPONSIBILITIES: Commanders must have a thorough knowledge of reference (a) to fully understand the scope of their responsibilities, and those of the personnel under their command, when handling sexual assault allegations.

- Leadership is the key to sexual assault prevention and response;

- The commander's role in prevention is to establish a climate that confronts the beliefs and values that contribute to behaviors which facilitate sexual assault, to establish clear standards for personal behavior, and to hold offenders accountable;

- As leaders commanders must be keenly aware of and sensitive to the climate of their units;

- Commanders must continuously educate their personnel on how to prevent incidents of sexual assault, while also encouraging victims and witnesses to report these incidents when they occur; and

- Be aware that sexual assault victims are physically, mentally, and emotionally traumatized and wounded.

- See Sexual Assault Initial Disposition Authority section below for additional command responsibilities.

REPORTING REQUIREMENTS FOR SEXUAL ASSAULT INCIDENTS: Commanders shall immediately report all actual, suspected, or alleged sexual assaults to the Naval Criminal Investigative Service. Therefore, commanders must not conduct independent command 
investigations into alleged sexual assaults in order not to potentially compromise an $\mathrm{NCIS}$ investigation into any sexual assault allegations.

In addition to normal OPREP/SITREP requirements, commands must report to Echelon II commanders within 24 hours of receiving a report of an incident of sexual assault and submit follow-up reports at least monthly until resolution [see reference (f)]. The following types of incidents must be reported as noted:

- Sexual assaults, including rape, forcible sodomy, assault with intent to commit rape or sodomy, and indecent assault.

- Sexual assaults occurring in areas of Navy control regardless of the victim's or perpetrator's military status, military affiliation, or nationality.

- Incidents involving sexual assault victims who are family members and victims and alleged perpetrators who are active-duty naval Servicemembers or of another service assigned to a naval command regardless of the location of the incident.

- Incidents involving sexual assault victims who are under age 18 or married to the perpetrator should be reported through the family advocacy program [see DOMESTIC VIOLENCE/FAMILY ADVOCACY].

\section{ADDITIONAL REQUIREMENT FOR REPORTING TO SEXUAL ASSAULT INCIDENTS:}

- USN: Per reference (h), within 30 days of a report of a sexual offense, a commander must make contact with the first flag in the chain of command in person, via video teleconference, or via phone to give the flag officer a command assessment of the situation.

- USMC: Per reference (h), a Sexual Assault Prevention and Response 8-day brief must be submitted electronically to the victim's commanding officer for unrestricted reports. Note: This brief need only be submitted if the victim is an active-duty adult. Reference (i) details a commander's responsibilities in further detail. Generally, commanders must ensure that sexual assault victims are treated fairly and with sensitivity, that information related to the victim is handled in a confidential manner, that the victim has access to necessary services, and that the victim receives monthly updates on the status of his/her case. Commanders should consult with their staff judge advocates and a victim advocate for further guidance.

CARE FOR SEXUAL ASSAULT VICTIMS: In cases of sexual assault, the specialized concerns and issues (physical, mental, and emotional) surrounding such assaults require all personnel involved in the case to give additional consideration to the sensitive treatment of such victims. Avoiding actions or treatment that makes the victim feel re-victimized is crucial to the well-being of the individual concerned. Additionally, references (a) and (b) expressly prohibit releasing the name of any sexual assault victim to the media without the victim's consent.

VICTIM ADVOCATES: The Navy and Marine Corps have victim advocates available through the Family Services, Sexual Assault Prevention Program. Victim advocates possess specialized training in assisting victims of sexual assault. Commanders should be receptive to recommendations made by victim advocates on behalf of victims. Victim advocates may recommend that the commanding officer issue a military protective order, that the victim reside in a "safe house" for a short period of time, or that the victim requires a level of assistance beyond what the victim advocate can provide, requiring a commander's authorization.

VICTIM'S LEGAL COUNSEL (VLC): Per reference (j), on 14 Aug 2013, the Secretary of Defense directed that each service immediately implement a victim legal advocacy program to 
provide legal and representation to victims of sexual assault. On 1 Jan 2014, the Navy and Marine Corps established a VLC Organization (VCLO). The mission of the VCLO is to provide legal advice and representation to the victims of certain crimes. A VLC (judge advocate) will be detailed to advocate on the victim's behalf by providing legal counsel throughout the investigation and court-martial process. References (j) through (I) provide additional guidance on a victim's eligibility for VLC services. Contact a staff judge advocate in order to determine whether a particular victim is required to meet a VLC.

\section{ADDITIONAL CONSIDERATIONS:}

- The Secretary of the Navy will provide guidance to commanders regarding their ability to take appropriate action to remove or temporarily reassign a Servicemember accused of committing a sex-related offense from a position of authority or from an assignment. This may not be used as a form of punishment but is intended to promote good order and discipline within the unit and to protect the victim if he/she is in the same unit as the accused.

- A defense counsel must now request, via the trial counsel, to interview the victim of a sex-related offense. The victim has the right to have the trial counsel or a VLC present for the interview with the defense counsel. 
REFERENCES:

(a) Policy

i. NAVADMIN 195/12

ii. MARADMIN 372/12

iii. JAM Practice Advisory (1-14)

(b) Reporting requirements

i. $\quad$ NAVADMIN 272/12

ii. MARADMIN 624/12

(c) Expedited transfer

i. $\quad$ NAVADMIN 132/12

ii. MILPERSMAN 1300-1200

iii. CMC/MFC-3 LOI dtd 28 Jun 2012

iv. MARADMIN 227/12

(d) Commander's Checklist (www.sapr.mil)

(e) MCO 5800.16A

(f) OPNAVINST 1752.1 (series)

POLICY: Per Secretary of Defense (SECDEF) policy, any report of offenses under the Uniform Code of Military Justice, Article 120 (rape, sexual assault of an adult), Article 125 (forcible sodomy), or Article 80 (attempts of rape, sexual assaults, or sodomy) shall now be referred to the 0-6 Special Court-Martial Convening Authority (SPCMCA) or higher court-martial authority in the chain of command for initial disposition of the allegation(s). This person will be the SAIDA [see reference $(a) i]$.

USMC POLICY: While the USN follows the SECDEF policy, the USMC is broader and requires all crimes under Article 120, including sexual-contact crimes, as well as all crimes under Article $120 \mathrm{~b}$ (all sexual crimes against children), also be elevated to the higher convening authority [see reference (a)ii].

SA-IDA RESPONSIBILITIES: If you are a SA-IDA, you have all options to direct or dispose of a case that are available pursuant to Rules for Court-Martial 306 [for USMC policy, see below and reference (a)iii]. Prior to making any disposition decision, the SA-IDA must consult with a staff judge advocate. The following options are available to the SA-IDA:

- Take no action: the case will be dismissed, and the SA-IDA will work with the local Sexual Assault Response Coordinator to complete reporting requirements.

- Court-martial warranted: If the SA-IDA believes the case may warrant a court-martial, then the SA-IDA may convene an Article 32 investigation and then potentially forward the matter to a General Court-Martial Convening Authority (GCMCA), who will determine whether to refer charges to a court-martial. A SA-IDA may convene a special courtmartial for charges other than rape or sexual assault of an adult, rape or sexual assault of a child, forcible sodomy, or attempts thereof.

- Administrative action: in the USMC, the SA-IDA must make the decision to initiate administrative separation proceedings when appropriate. The SA-IDA in the USMC can also direct the accused's immediate superior to notify the accused of administrative separation processing initiation. If the accused's immediate superior is also a SPCMA, the SA-IDA can direct the SPCMCA to convene the administrative separation board [see reference (a)iii].

- Non-judicial punishment. 
- $\quad$ Forward for disposition. In the USN, the SA-IDA may determine that the matter should be forwarded to a subordinate or senior authority for disposition, to include any disposition action available to that authority under Rule for Court-Martial 306 . In the USMC, the SA-IDA cannot forward a case to a subordinate command for disposition [see reference (a)iii].

SUPPORT TO THE SEXUAL ASSAULT PREVENTION AND RESPONSE (SAPR) PROGRAM (Formerly SAVI): Commands must be prepared to prevent and respond to allegations of sexual assault. Establish an atmosphere of zero tolerance of sexual assault and rape [see enclosure (4) of reference (f)].

RESPONSIBILITIES OF THE COMMANDING OFFICER (CO): Whether the CO is the SA-IDA or not, if a $\mathrm{CO}$ is the immediate commander of the accused or victim, the $\mathrm{CO}$ must be familiar with and follow the requirements of the Commander's Checklist [see reference (d)].

- Military Protective Orders (MPOs): This is still the responsibility of the accused's and/or victim's CO, respectively, to implement if necessary. COs are encouraged to consult with a staff judge advocate and NCIS prior to issuing a MPO if feasible.

- Victim/Witness Assistance Program (VWAP): Ensure that the victim has been advised of his/her VWAP rights under Department of Defense policy and as enumerated in DD Form 2701.

- Investigations: Ensure that NCIS is immediately notified upon the receipt of an unrestricted report of sexual assault. The command is not to initiate a command investigation

- Responsibility to the victim: Ensure the victim's safety, as well as the victim's access to all needed SAPR and medical resources.

- Responsibility to the accused: Ensure that the accused's due process rights are not violated, he/she has access to appropriate legal resources, and has access to any necessary medical assistance.

EXPEDITED TRANSFER: If a victim, who has made an unrestricted report of sexual assault, requests an expedited transfer, then the $\mathrm{CO}$ has 72 hours in which to make a decision as to whether the mission can support the request. For the USN, the factors to consider when making this decision can be found in reference (c)ii.

- USN: Per reference (c)ii, if the CO denies the request for expedited transfer, there will be an automatic appeal of the denial to the GCMCA in the chain of command.

- USMC: Per reference (c)iv, if the CO denies the request for expedited transfer, then the victim may appeal the decision if he/she wishes to do so. There is no automatic appeal.

MOST IMPORTANT: Always consult with a staff judge advocate, one of the USN's Region Legal Service Offices, or a USMC Legal Services Support Section as soon as possible.

\section{OTHER CONSIDERATIONS:}

- All convictions for a sex-related offense will now result in a mandatory dismissal for officers and a dishonorable discharge for enlisted personnel. Further, if an eligible sexrelated offense goes to court-martial it must be tried in a general court-martial and may not be disposed of at any lesser court-martial forum. An eligible sex-related offense is defined as rape, sexual assault, rape and sexual assault of a child, forcible sodomy, or an attempt to commit one of these offenses. 
- Law now prohibits a commander and the SA-IDA from considering the character and military service record of the accused when making an initial disposition decision for a sex-related offense.

- CONVENING AUTHORITY LIMITATIONS AS A RESULT OF THE FY-14 NATIONAL DEFENSE AUTHORIZATION ACT:

O Action on court-martial findings (guilty/not guilty):

- The convening authority (CA) CANNOT modify court-martial findings if:

- The offence involves rape, sexual assault, a sexual offense against a child, or forcible sodomy; or

- The offense's maximum allowable punishment exceeds two years OR the sentence actually adjudged includes a punitive discharge or confinement exceeding six months.

- If a CA modifies a court-martial finding in any other case he/she needs to provide a written explanation for doing so.

o Action on a court-martial sentence:

- The CA can modify a sentence for an offense unless the actual adjudged sentence includes a punitive discharge or confinement exceeding six months.

- For such a sentence, the CA can only modify it pursuant to a written recommendation from the trial counsel indicating that the accused provided substantial assistance in another trial or if the sentence modification is pursuant to a pre-trial agreement.

- If there is a pre-trial agreement, a mandatory minimum sentence of dishonorable discharge may only be commuted to a bad conduct discharge. 
REFERENCES:

(a) MCM, MRE 301-305

(b) UCMJ, Article 31(b)

(c) MILPERSMAN 1620-010

(d) JAGMAN Appendix A-1-(b-d)

(e) JAGMAN Appendix A-1-v

(f) JAGMAN Appendix A-1-(M-n)

MAJOR CRIMINAL OFFENSES: Do not allow anyone from your command to question or interrogate a Servicemember before discussing the case with a staff judge advocate and NCIS.

ALWAYS READ ARTICLE 31(b) RIGHTS: When (1) you suspect a Servicemember of committing an offense and (2) you are going to ask the Servicemember a question relating to the offense (e.g., asking questions or making statements that are likely to evoke an incriminating response).

\section{ARTICLE 31(b) RIGHTS:}

- A Servicemember is entitled to be informed of his/her Article 31(b) rights when suspected of violating any punitive article of the Uniform Code of Military Justice and the member is going to be questioned about the offense(s).

- Use the rights warning form [see reference (e)]. Article 31(b) rights contained on the warning form should always be read as stated before any interrogation, however informal the questioning. Do not ask the Servicemember any questions unless the Servicemember has affirmatively and in writing waived the right to remain silent and the right to a lawyer.

- Waivers of Article 31(b) rights must be made freely, knowingly, voluntarily, and intelligently. It is critical to ensure the Servicemember understands his/her rights and the consequences of waiving any or all of his/her rights.

- If the Servicemember wants to remain silent or asks for a lawyer, the command MUST NOT ask any questions or ask any more questions, even if the Servicemember had previously waived his/her right to remain silent and answered questions prior to later desiring to remain silent and/or ask for a lawyer.

PRIOR QUESTIONING WITHOUT RIGHTS WARNING: Provide a "cleansing warning" if the Servicemember was previously questioned and did not receive his/her Article 31(b) rights warnings. To do this, (1) advise the Servicemember that the prior statement cannot be used against him/her and that (2) even though he/she made the earlier statement, he/she can still choose to remain silent and request a lawyer. Finally, (3) fully advise the member of his/her rights using reference (e) and record in writing whether the member waived his/her rights.

NEW OFFENSES: If during a conversation or questioning of a Servicemember, a the command begins to suspect that the Servicemember has committed a new or different offense from the one originally asked about, the questioner must stop the questioning immediately and complete a new rights warning form inclusive of the new or different offense(s) [see reference (e)].

ARTICLE 31(b) AND NON-JUDICIAL PUNISHMENT (NJP): At mast/office hours, only part of Article 31(b) is read. Sailors always have the right to remain silent but do not have a right to an attorney during NJP. However, if it is reasonably foreseeable that an accused will make an 
admission or actually does make an admission that warrants court-martial punishment, the CO should provide a full reading of all Article 31(b) rights and execute a waiver if the Servicemember agrees to waive his/her rights at mast/office hours [see reference (e)] to protect the admissibility of such confessions in court. That said, full rights warnings must be given at all other stages in the process (e.g., prior to any questioning by a supervisor, investigating officer, law enforcement officer, Chief's disciplinary review board, or executive officer inquiry).

SERVICEMEMBER UNDER THE INFLUENCE OF DRUGS OF ALCOHOL: A member must be in a physical and mental condition to knowingly, intelligently, and voluntarily waive his/her rights. Do not try to interrogate a Servicemember who is under the influence of drugs of alcohol.

FALSE PROMISES OR THREATS: A confession must be voluntary. DO NOT use threats or false promises to elicit an incriminating statement because a military judge may determine later that it is not admissible.

PROMISE OF LENIENCY: Only a General Court-Martial Convening Authority (flag and general officers) have the authority to grant immunity or leniency for testifying. Do not promise a Servicemember that what he/she says against his/her interests will not be used against them [see reference $(f)]$. 
REFERENCES:

(a) MCM, MRE 311-316

(b) MILPERSMAN 1620-010

(c) SECNAVINST 5430.107 (series)

(d) JAGMAN Appendix A-1-w

(e) JAGMAN Appendix A-1-x

THE COMMANDING OFFICER (CO) OR OFFICER IN CHARGE (OIC) AUTHORIZING A SEARCH MUST BE NEUTRAL AND DETACHED: If the CO or OIC over the suspected Servicemember was the victim of the offense in question, he/she must refer any search authorization request to a superior in the chain of command.

NON-DELEGABLE AUTHORITY: Only the CO or OIC can issue a search authorization, unless prohibited as detailed above. The $\mathrm{CO}$ or OIC must personally make the probable cause determination. No one else in the chain of command can act for the $\mathrm{CO}$ or OIC unless they are acting as the $\mathrm{CO}$ or $\mathrm{OIC}$ in the absence of the $\mathrm{CO}$ or OIC.

MAJOR CRIMINAL OFFENSES: DO NOT conduct a search before referring the case to NCIS, unless the search is necessary to protect life or property or to prevent the destruction of evidence before NCIS can become involved.

SEARCH AUTHORIZATIONS MUST BE BASED ON PROBABLE CAUSE: Probable cause is defined as [See Appendix A - Commanding Officer Search and Seizure Checklist]:

- A reasonable belief that a crime has been committed and that evidence of the crime will be located at the place to be searched. The reasonable belief must be supported by a factual bases and information must be reliable and credible.

\section{JURISDICTION:}

- PERSON (ON/OFF BASE): With probable cause, a CO or OIC can authorize the search of persons under his/her command. Per reference (b), searches shall be, whenever possible, conducted by or in the presence of a Servicemember of the same sex.

- ON-BASE PROPERTY: With probable cause, a CO or OIC can authorize the search or seizure of any property under his/her immediate control. For areas not under the CO's or OIC's immediate control contact the installation staff judge advocate as the installation commander may have jurisdiction.

- OFF-BASE PROPERTY IN U.S.: The CO or OIC may not authorize a search of offbase property in the United States. The CO or OIC must work with NCIS to obtain civilian authority to conduct an off-base search. (Note: a CO or OIC may not have jurisdiction to authorize a search in Public/Private Venture Housing; consult with the installation or Region staff judge advocate.)

- OFF-BASE PROPERTY OUTSIDE THE U.S.: The CO or OIC may authorize searches a Servicemember's property. (Note: some Status of Forces Agreements limit or prohibit such off-base search authorizations. Consult with a staff judge advocate for overseas search authorization issues.) 
QUEST FOR EVIDENCE: If looking (searching) for evidence, DO NOT order or conduct an inspection (e.g., health and comfort, wellness, readiness, etc.) in the area where the evidence may be located.

- The primary purpose of the inspection must be a valid military purpose, to include: (1) security; (2) military fitness; (3) good order and discipline; and (4) readiness.

- Courts may throw out evidence seized in a search disguised as an in section. Factors the courts will consider in evaluating whether an inspection is really an illegal search are (1) if the inspection was not previously scheduled, and it followed the report of an offense; (2) if it targeted specific individuals; or (3) if t subjected specific individuals to a greater degree of scrutiny than others.

COMMON AREAS: May be searched anytime without a search authorization. Drug dogs may be used in passageways, workspaces, or common areas at any time. A drug dog alert from within a common area may establish probable cause to order a search of private property (but the $\mathrm{CO}$ or OIC must still make the decision whether probable cause exists and whether to issue an authorization).

USE OF FORMS: Search authorization forms are found at JAGMAN A-1-w [see reference (d)]. Anyone providing information to support the request to search should be sworn and under oath.

SPECIFICITY ON THE FORMS: When authorizing a search, the $\mathrm{CO}$ or OIC must describe the place to be searched and the items to be seized. The list of items to be seized should include every item of evidence that may be expected to be found and should include the language, and "any parts, pieces, or components thereof."

ALWAYS ASK FOR CONSENT: Before actually conducting a search or authorizing one, the owner of the property should be asked for consent to search. If it is obtained, document the consent in writing [see reference (e)]. Consent must be voluntarily obtained to be valid; meaning the individual must be told they can say no. Consent can be limited or withdrawn at any time. Limitation or withdrawal of consent cannot serve as a basis for probable cause. 


\section{REFERENCES:}

(a) MCM, RCM 501-504, 704, 1003, 1107, 1301-1306

(b) UCMJ Articles 16, 22-25

(c) JAGMAN Section 0120

\section{TYPES OF COURTS-MARTIAL}

\section{SUMMARY COURT-MARTIAL (SCM):}

- Commanding officers (CO) and Officers in Charge (OIC) have authority to convene SCMs. The CO or OIC is referred to as the convening authority (CA).

- SCMs cannot try officers, only enlisted personnel.

- All enlisted personnel (sea and shore duty) have an absolute right to refuse SCM.

- The CA appoints one officer as the SCM officer who serves as the military judge (MJ), trial counsel (TC), and defense counsel (DC) all rolled into one.

- The accused has no right to military counsel, but he/she may be represented by military counsel (at no expense to the accused) if one is detailed to the case. The accused also has the right to retain civilian counsel at his/her own expense, if civilian representation will not unreasonably delay the proceedings.

- Punishments at a SCM are limited. [See Appendix 12 of the Manual for Courts Martial (MCM): Maximum Punishment Chart.]

- The CA takes final action on the findings and punishment awarded by the SCM within seven days.

- The Military Rules of Evidence apply at a SCM.

\section{SPECIAL COURT-MARTIAL (SPCM):}

- COs may convene SPCMs.

- Full criminal trial for officers and enlisted personnel.

- Consists of a MJ, at least three members (jurors), a TC, a DC (DC may include detailed military counsel, individual military counsel (IMC), and/or civilian counsel. Civilian counsel is at the expense of the accused).

- Maximum punishments available at a SPCM are listed in Appendix 12 of the MCM.

- The CA may approve pre-trial agreements.

- The CA takes action on the findings and sentence after the clemency period has expired.

GENERAL COURT-MARTIAL (GCM):

- A Uniform Code of Military Justice (UCMJ) Article 32 pre-trial investigation is required before any charges are referred to a GCM. A CA may order an Article 32 investigation.

- **UPDATE** FY-14 NDAA: Section 1702 (effective 26 Dec 2014) will change how an Article 32 hearing is conducted. A victim, whether civilian or military, may not be required to testify at the hearing. The Article 32 investigation/hearing officer must be senior in rank to the TC and DC and must be a judge advocate except in extraordinary circumstances.

- Only flag or general officers (and a very few specifically designated non-flag/general officers who are COs) may convene a GCM [see reference (c), section 0120].

- GCMs involve a MJ, at least 5 members, TC, and DC (military and/or civilian).

- GCMs have the authority to issue the maximum punishment listed for any UCMJ offense. 
- GCMCAs may approve pre-trial agreements.

- GCMCAs take action on findings and sentences after the clemency period has expired.

- OTHER CONSIDERATIONS:

o Law now requires that all convictions for a sex-related offense result in a mandatory dismissal for officers or a dishonorable discharge for enlisted personnel. Further, all sex-related offenses must be tried at a GCM, when a court-martial is warranted, and may not be disposed of at any lesser forum when charges are appropriate for referral. A sex-related offense is defined as rape, sexual assault, rape and sexual assault of a child, forcible sodomy, or an attempt to commit one of these offenses.

- Law also requires additional review if a GCMCA elects not to refer a sex-related charge to a GCM. If the GCMCA's staff judge advocate recommends referring a case to a GCM after the Article 32 investigation and the GCMCA chooses not to, this decision must be reviewed by SECNAV. However, if the SJA recommends not referring the case to a GCM and the GCMCA concurs, this decision must be reviewed by the next GCMCA in the chain of command.

MECHANICS OF CONVENING A COURT-MARTIAL: A court-martial is created anew for each individual case. A CA creates a court-martial by signing a court-martial convening order. The convening order creating the court-martial must be signed - creating the court-martial - before the CA signs the charge sheet referring the charges to the court martial. The court-martial must exist first before any charges can be referred to it. A convening order contains the following content:

- Convening order number and the date it is signed. That will be the date the court comes into existence, after which charges in a particular case can be referred to it.

- The authority to convening a court-martial.

- The type of court convened (SCM, SPCM, GCM) and the name of the members (jurors) assigned to that court-martial.

- The personal signature of the CA.

\section{SELECTION OF MEMBERS:}

- Members shall be persons who, in the opinion of the CA, are the best qualified by reason of their age, education, training, experience, length of service, and judicial temperament.

- Members must be senior to the accused, unless unavoidable.

- The accused is entitled to a fair and impartial panel. Members with personal knowledge of the charges will likely be disqualified.

- Do not attempt to "stack" or directly or indirectly influence the members.

- Enlisted members are only detailed if an enlisted accused requests enlisted members. In such a case, absent military exigency, one-third of the final members panel must be enlisted and the members must come from a unit other than the accused's unit.

Note: Make absolutely sure both a convening order and the preferral block on the charge sheet (block 11) have been signed and dated prior to referring charges to a court-martial.

[See Appendix B - Overview of the Military Justice System] 
REFERENCES:

(a) MCM, RCM 104, 504

(b) UCMJ Articles 13, 22(b), 37

(c) JAGMAN Section 0129

JUDICIOUS AND FAIR: Congress has entrusted commanding officers (COs) with the responsibility to administer discipline and justice in the Armed Forces. COs should be vigilant to ensure all actions are consistent with the Uniform Code of Military Justice (UCMJ) and those that are not are held accountable in accordance with law and regulation.

INFORMED DECISIONS: Ensure that independent investigations are convened to discover all the relevant evidence and information that bears on the reliability and credibility of that evidence in order to make an informed decision about how to proceed. Ensure that all decisions are fair and impartial and based on the known facts.

\section{ACCUSER CONCEPT:}

- For a Special Court-Martial (SPCM) or a General Court-Martial (GCM), the convening authority (CA) may not:

o Sign the accuser block on a charge sheet;

o Direct that someone else sign the accuser block on a charge sheet; or

o Have a personal interest in the case (e.g., as a victim or witness to the underlying alleged offenses reflected in the charges).

- If such a situation exists, the current CA must forward the case to a superior to disposition.

\section{UNLAWFUL COMMAND INFLUENCE - ACTIONS TO AVOID:}

- PUBLIC OPINIONS: Do not express public opinions on an accused's innocence, guilt, or appropriate punishment for crimes in general or in an individual case.

- UNLAWFUL INFLUENCE: Do not order a subordinate commander to dispose of a case in a particular way. Each commander must be allowed to exercise independent judgment totally free of interference from a superior.

- INFLEXIBLE POLICY: Do not have an inflexible policy on disposition or punishment in general across all cases. Each case and each punishment must be appropriately decided based on the particular facts.

- INFLUENCE REGARDING RESULT: Do not censure, reprimand, or admonish the court or any member, military judge, or counsel with respect to findings or sentence adjudged.

- INFLUENCE ON MEMBERS: Do not select or remove court members in order to obtain a particular result. Never directly or indirectly communicate with members regarding a preference for a desired outcome. Once convened, interactions with members of a court-martial should be avoided. The Servicemember's primary duty is to that courtmartial.

- INFLUENCE ON MILITARY JUDGE: Do not attempt or even appear to put pressure on a military judge, counsel, court members to obtain a particular result.

- INFLUENCE ON WITNESSES: Witnesses may not be intimated or discouraged or obstructed from testifying. If a witness testifies (truthfully) on behalf of an accused, no retribution shall be taken against him merely for testifying. 
PRETRIAL PUNISHMENTS: A court-martial will decide the punishment. An accused may not be punished before trial. Do not use pretrial restraint as a method to punish an accused before trial.

THE STANDARD: Would the ordinary American citizen lose faith in the military justice system or consider it unfair? Ensure that an accused Servicemember receives all the due process rights provided under law and regulation, many of which the U.S. Constitution requires.

[See Appendix C - Court-Martial Maximum Punishment Chart] 
REFERENCES:

(a) MCM, RCM 304, 305

(b) UCMJ Articles 10, 13

(c) JAGMAN Section 0127

FOUR TYPES OF PRETRIAL RESTRAINT (PTR) (from least to most severe):

- Conditions on liberty (e.g., orders to report periodically to specified officials; orders not to go to certain places or to associate with certain people such as the victim)

- Restriction in lieu of arrest

- Arrest

- Pretrial confinement (PTC)

\section{AUTHORITY TO ORDER PTR:}

- Who

o Only the CO may order PTR of an officer or a civilian

- Any commissioned officer may order PTR of an enlisted Servicemember. A CO may delegate the authority to order pretrial restraint of the CO's own enlisted

- When person el to warrant, petty, and noncommissioned officers.

o PTR is appropriate when there is a reasonable belief that:

- A court-martial offense has been committed;

- The person to be restrained committed the offense;

- The restraint ordered is required by the circumstances; and

- There is concern that the Servicemember will not appear at trial and/or will engage in serious misconduct, and less severe forms of restraint are inadequate

- $\quad$ PTR decisions must be made on a case-by-case basis. The least severe form of PTR necessary under the circumstances should be used. PTR may not be used for offenses that are intended to be handled by NJP. PTR is appropriate only when the command intends to try the accused by general or special court martial.

PUNISHMENT BEFORE TRIAL IS PROHIBITED: PTR may be used only to ensure the presence of the accused at trial and/or to prevent future serious misconduct.

PTR (EXCLUDING CONDITIONS ON LIBERTY) STARTS SPEEDY TRIAL PROVISIONS: When a Servicemember is put in PTR, the constitutional and statutory speedy trial clocks begin, necessitating swift action to ensure arraignment. Immediately notify the local USN Region Legal Service Office or USMC Legal Services Support Section when a Servicemember is placed in PTR.

SUICIDAL OR INTOXICATED PRISONERS: PTC is not appropriate and brigs will not accept such Servicemembers. Servicemembers requiring PTR who are suicidal or under the influence of drugs or alcohol should be referred to medical before commencing any type of PTR.

DOCUMENTING CO'S APPROVAL OF PTC: When PTC is imposed, the CO must be notified and approve the PTC within 24 hours. A written memorandum ("48-hour letter") explaining why PTC is warranted must be prepared and signed by the $\mathrm{CO}$ within 48 hours and forwarded to the brig. If the $\mathrm{CO}$ is not "neutral and detached (e.g., a victim of the Servicemember in PTC), an 
officer who is neutral and detached must make a probable-cause decision to continue PTC within 48 hours. If continued PTC is approved, the commander shall prepare a written memorandum that states the reasoning that continued restraint is warranted within 72 hours. This memo will then be forwarded to the seven-day independent reviewing officer (IRO), who will decide at a PTC hearing whether continued PTC is appropriate.

COMMAND REPRESENTATIVE AT PTC HEARING: Within seven days of confinement, an IRO appointed by the area coordinator will conduct a hearing to review the reasons for continued confinement. The command shall send a representative to the hearing at the brig.

COMMAND VISITS: Servicemembers in PTC should receive a weekly command visit to address any personal and professional matters that need to be handled while the Servicemember is in PTC.

RESERVE NOTE: The guidance above applies to reservists on active duty (AT or ADT). A reservist in a drilling status [inactive duty for training (IDT)] should not be subjected to PTR until the reservist is recalled to active duty to stand for a court-martial. A reservist who has been involuntarily recalled to active duty to stand for a court-martial or non-judicial punishment cannot be confined without the permission of the Secretary of the Navy (SECNAV).

Reservists on AT or ADT may be extended involuntarily beyond their normal release date as a result of apprehension, arrest, confinement, investigation, or filing of charges that may result in trial by court-martial and execution of any sentence adjudged by a court-martial.

Reservists on IDT (a normal reserve drilling period) may be retained in that status by an officer empowered to convene a court-martial for not more than two full working days past the end of the IDT period if: (a) there is probable cause to believe the accused committed an offense for which the maximum punishment authorized is confinement for more than 10 years or death; (b) approval, either oral or written, for a holdover period is obtained prior to the expiration of IDT from the officer empowered to convene a general court-martial; and (c) immediate action is taken to order the member to active duty for trial by court-martial.

An accused reservist held over may be placed in PTC as circumstances warrant. The order to active duty in such a case, however, must be approved by SECNAV, the Under Secretary of the Navy, or the Assistant Secretary of the Navy, no later than two full working days past the end of the IDT period. The request for an order to active duty must state the reasons why PTC is necessary.

If necessary, the request to order an accused to active duty may be made directly by message or telephone. 


\section{PRETRIAL AGREEMENTS}

\section{REFERENCES:}

(a) MCM, RCM 705

(b) JAGMAN Section 0137

NEED FOR PRETRIAL AGREEMENTS (PTA): PTAs, when appropriate, serve the interests of both the government and the accused. In exchange for a guilty plea and a limit on the authorized punishment that may be imposed on the accused, the government is often spared the time and expense of lengthy trials, which commands must pay for with Operation and Management funds. In addition, guilty pleas with PTAs often obviate the need for the victim and witnesses to participate in a trial, saving participants the mental and emotional toll of a courtmartial. A guilty plea supported by a PTA also may assist a command with maintaining normal operations and mission readiness and/or accomplishment.

CONVENING AUTHORITIES (CA) MUST APPROVE ALL PTAs: PTAs are not entered into without the express written consent of the CA and the accused. Trial counsel (TC) and staff judge advocates (SJA) for the CA may make recommendations but only the CA may approve a PTA.

\section{SCOPE OF A PTA:}

- The accused may agree to:

o Please guilty

o Waive an Article 32 investigation/hearing

o Waive members (e.g., agree to be tried by military judge (MJ) alone)

o Waive government funding of sentencing witnesses

o Be tried no later than a specific date

o Stipulate to facts or testimony that establish guilt

o Make restitution to the victim

o Testify against others

o Conform behavior as conditions of probation or any form of leniency

o Waive the rights to an administrative separation board after trial

o A particular form for court-martial

- The CA may agree to:

o Protect the accused from part or all of any part of the adjudged sentence

o Drop, reduce, or not to proceed with certain charges

0 Protect the accused from potential automatic sentencing provisions

PTA NEGOTIATION PROCEDURES: Negotiations may originate with the accused, the defense counsel (DC), TC, SJA, or the CA. Any proposals that do not originate with the CA must be forwarded to the CA for consideration. As part of the negotiation:

- Counteroffers are permissible

- The final agreement must be in writing

- The PTA must contain all aspects of the agreement, Under-the-table agreements, or any side agreements not contained in the PTA, may render the entire written PTA agreement invalid

- Authority to sign the PTA may be delegated by the CA to the TC. Any such delegation should be in writing to satisfy a court-martial that the TC has the authority to sign on behalf of the CA. 


\section{WITHDRAWAL FROM THE PTA:}

- The CA may withdraw:

o At any time before performance by the accused begins;

0 If the accused fails to fulfill a material term of the PTA;

0 If the MJ finds disagreement as to a material term; and/or

0 If the court-martial's findings are set aside by a court of appeals

- The accused may withdraw at any time, but after findings (guilty/not guilty) are announced by the court-martial, the accused may withdraw only with permission of the MJ. 


\section{POST-TRIAL REVIEW}

\section{REFERENCES:}

(a) MCM, RCM 1101, 1103-1107, 1113

(b) UCMJ Articles 57, 58, 58a, 58b, 60

(c) JAGMAN Sections 0151, 0152

(d) JAGINST 5814.1A

POST-TRIAL PROCEDURES: The government has the duty to ensure timely post-trial processing of military justice cases. The government must meet strict guidelines in disposing of a case after a sentence is adjudged at trial. This is important to convening authorities (CA) since a failure to adhere to proper processing of records of trial (ROT) could result in an overturned conviction [see reference (d)]. [See also Convening Authority's Action Checklist in enclosure (4) of reference (d).]

CA ACTION: Review of the court-martial by the CA after the trial is a crucial but often neglected step in the court-martial process that may cause serious legal consequences and accountability action against the CA.

EFFECTIVE DATE OF ADJUDGED PUNISHMENTS: Most punishments do not take effect until the CA takes action on the sentence adjudged at a court-martial. Exceptions to this are confinement, which starts immediately, and forfeiture of pay and reduction in pay grade, which start 14 days after trial [see reference (c)]. Other punishments (e.g., restriction, hard labor without confinement, etc.) will not go into effect until the CA acts on the adjudged sentence. Dismissal, dishonorable discharge (DD), and bad conduct discharge (BCD) will not take effect until appellate review is complete.

AUTOMATIC PUNISHMENTS: In addition to adjudged punishments, there are two types of automatic (statutory) punishments which go into effect for certain types of cases:

- AUTOMATIC REDUCTION: When an enlisted Servicemember's court-martial sentence, as approved by the CA, includes (1) a discharge or (2) more than 90 days of confinement, the Servicemember will automatically be reduced to the paygrade of E-1 upon the date of the CA's action.

- CA's OPTIONS: The CA can suspend, remit (cancel), modify (approve reduction to a lower paygrade but not all the way down to E-1), or allow automatic reduction all the way down to $\mathrm{E}-1$ to occur.

- AUTOMATIC FORFEITURE: When any member's court-martial sentence includes (1) confinement for more than 6 months or death, or (2) a BCD or DD plus any amount of confinement, the member will automatically forfeit two-thirds pay and allowances in the case of a special court-martial or all pay and allowances in the case of a general courtmartial (GCM) starting at the earlier of the CA's action on the adjudged sentence or 14 days after the sentence is adjudged. The automatic forfeiture will be taken throughout the period of confinement and parole.

o CA's OPTIONS: The CA can defer automatic forfeiture until CA's action. This means the automatic forfeiture of pay will not take effect, as it normally would, 14 days after trial. Deferment changes the effective date to the date of the CA's action. At CA's action, the CA can approve the automatic forfeiture, or the CA may waive the forfeiture for a maximum of six months and direct the amount of money to be forfeited to the accused's dependents. Usually, the accused sets up an allotment for a dependent in the amount of the automatic forfeiture. 
WHEN THE CA MAY TAKE ACTION: Before the CA's action, the ROT must be prepared by the USN Region Legal Service Office or the USMC Legal Services Support Section, authenticated by the trial counsel and military judge, and served on the accused and his/her defense counsel (DC). For all GCMs that result in a finding of guilty in any cases involving punitive discharge, a staff judge advocate or legal officer must review the ROT and prepare a memorandum to be served on the accused and his/her DC. Finally the accused must be given the opportunity to seek clemency from the CA. An accused seeks clemency by "submitting matters" (such as letters from family members, friends, command members, or even the victim and members of the court-martial) that explain to the CA why he should approve a lower sentence than the sentence adjudged at trial. CAs must also consider any victim input and victims have a right to provide information for the CA to consider.

ATTENTION TO DETAIL: CA's action letters must include specific information about the accused and must accurately reflect information about the trial. Use of the standard language and forms in the MCM and JAGMAN is crucial.

**FINDINGS OF THE COURT: The CA is not required to take any action on findings. However, the CA has the following options:

- The CA may approve or disapprove the court's findings

- The CA may disapprove a finding of guilty on an original, more serious charge but approve a finding of guilty for a lesser included offense.

- The CA may not change a finding of not guilty to a finding of guilty; however, a finding of guilty may be changed to a finding of not guilty.

- If the CA says nothing about the findings, it is presumed that the CA approves the findings of the court-martial.

**SENTENCE OF THE COURT: The CA must take action on the sentence. The CA has the following options:

- The CA may approve any punishment as adjudged by the court-martial.

- The CA may disapprove any punishment in whole or in part.

** THE DISCRETION THE CA HAS TO APPROVE OR DISAPPROVE FINDINGS AND SENTENCES IS NOW LIMITED AS A RESULT OF RECENT CONGRESSIONAL ACTION. APPENDIX D - CONVENING AUTHORITY LIMITATIONS ON FINDINGS MODIFICATIONS; AND APPENDIX E - CONVENING AUTHORITY LIMITATIONS ON SENTENCING MODIFICATIONS, DETAIL WHERE CA DISCRETION IS CONSTRAINED DEPENDING ON THE TYPE OF CASE AND/OR THE TYPE AND AMOUNT OF PUNISHMENT ADJUDGED. 


\section{VICTIM/WITNESS ISSUES}

\section{REFERENCES:}

(a) DODD 1030.01

(b) SECNAVINST 5800.11B (series)

(c) OPNAVINST 5800.7A (series)

(d) SECNAVINST 1752.4A (series)

(e) OPNAVINST 1752.1 (series)

(f) NAVADMIN 128/05

(g) MCO P5800.16A (series)

(h) MCO 5300.17 (series)

(i) MCO $1752.5 \mathrm{~A}$ (series)

(j) DODI 1342.24 (series)

(k) SECNAVINST 1752.3B (series)

(l) OPNAVINST 3100.6J (series)

(m)SECDEF Memo of 14 Aug 2013

(n) 10 U.S.C. § 1565(b)

(o) MARADMIN 583/13

\section{DEFINITIONS:}

- Victim: A person who has suffered direct physical, emotional, or pecuniary harm as a result of the commission of a crime.

- Witness: A person who has information or evidence about a crime within the investigative jurisdiction of the Department of the Navy (DON), and who provides that knowledge to an appropriate DON representative.

APPOINT A COMMAND VICTIM AND WITNESS ASSISTANCE COORDINATOR: A responsible individual should be appointed in writing to coordinate victims'/witnesses' issues and to act as a Data Collection Officer for victims and witness issues in the command.

BASIC REQUIREMENTS: Upon notification of an incident where a victim or a witness of a crime is identified, ensure that victim and/or witness advisement of rights is made using DOD Form 2701 [see reference (d), enclosure (1)].

COUNSELING AND TREATMENT: Victims of sexual assault and rape should receive immediate treatment and counseling [see reference (c)]. Contact the Family Advocacy Representative (USN) or Family Advocacy Program Manager (USMC) [see reference (k)].

PREVENT REPRISAL: Protect victims and witnesses. Remove the alleged offender from the workspace is necessary. For an alleged military offender consider the necessity of issuing a military protective order (MPO). [See FAMILY ADVOCACY/DOMEXTIC VIOLENCE and PRETRIAL RESTRAINT]. A MPO may also be issues in situations other than family violence (e.g., boyfriend/girlfriend disputes). Consider TAD transfers of an alleged offender or victim to ensure safety if necessary. If the victim is military or a military dependent refer them to a legal assistance attorney for specific victim's legal counseling, which is detailed below. If the alleged offender is a civilian, consider seeing a debarment order preventing him/her from accessing the base. In addition, it may be advisable for the victim of a civilian offender to seek a civilian no contact order from local authorities. 
PSYCHIATRIC EVALUATION: Do not refer a victim or witness for a mental health evaluation unless it is done in compliance with the Mental Health Evaluation Instruction [see Mental Health Evaluations].

FOLLOW-UP INFORMATION: Provide information and assistance to victims and witnesses at all states of investigation, trial, and post trial. Victims and witnesses should be informed regarding apprehension of the accused, changes in confinement status, investigation status, decisions not to prosecute, preferral and referral of charges, convictions, sentencing, and final resolution of the charges against the accused at trial and after any appellate processing [see references (a), (b), (c), and (g)].

\section{POTENTIAL INCIDENT REPORTING REQUIREMENTS:}

- OPREP-3 for major incidents and SITREPS formatted in accordance with OPNAVINST 6100.6J (information from NAVPERS 1752/1).

- Major criminal offenses must be referred to NCIS.

- Violent crime message.

- For incidents involving sexual assaults, immediately notify the local Sexual Assault Prevention and Response (SAPR, formerly SAVI) representative, NCIS, and the local staff judge advocate.

- Incidents involving sexual harassment [see Sexual Harassment].

- Incidents involving officers in accordance with TYCOM/Second Echelon requirements [see Officer Misconduct].

FAMILY ADVOCACY PROGRAM (FAP): FAP provides clinical assessment, treatment, and services for military members and their families involved in allegations of domestic abuse or child abuse. FAP's goals are to ensure the victim's safety and well being as well as offender accountability. These principals form the basis of the FAP clinical provider's work in responding to allegations of domestic abuse and child abuse [see reference $(k)$ and DOMESIC VIOLANCE/FAMILY ADOVCACY INCIDENTS].

TRANSITIONAL COMPENSATION: Family members who were abused by a Servicemember who is subsequently separated from the military service because of that abuse, either by courtmartial or administrative separation, are entitled to transitional compensation [see reference (j)]. Transitional compensation is not based on the financial needs of the family. The program provides monthly payments of transitional compensation and other benefits (e.g., medical, dental, etc.) to the family members as long as the family members do not reside with the abusive former Servicemember. The local USN and USMC family services centers can assist with the transitional compensation application process.

LEGAL ASSITANCE: Legal assistance attorneys at USN Region Legal Service offices and USMNC Legal Services Support Sections will provide the following services to victims:

- Information on the Victim/Witness assistance programs in the Fleet, including;

0 The rights and benefits of victims.

o The role of a victim advocate and victim privileges.

0 The difference of privileged communication with a legal assistance attorney and unprivileged communications to a victim advocate.

- The difference between restricted and unrestricted reporting.

- General information concerning military justice and the roles and responsibilities of the trial counsel, defense counsel, and investigators.

- Emotional, mental health, and medical counseling services. 
- The availability of protections provided by civilian and military protective orders.

- Transitional compensation and other state/federal program benefits for victims of crime.

- Traditional legal assistance services (e.g., estate planning, tax advice, powers of attorney, consumer affairs, family law advice, etc.).

VICTIMS LEGAL COUNSEL (VLC): Per reference (j), on 14 Aug 2013, the Secretary of Defense directed that each service immediately implement a victim legal advocacy program to provide legal advice and representations to victims of sexual assault. On 1 Jan 2014, the USN and USMC each created a Victims' Legal Counsel Organization (VLCO). The mission of the VLCO is to provide legal advice and representation to the victims of certain crimes. A VLC is a judge advocate who will be detailed to advocate on a victim's behalf by providing legal counsel throughout the investigation and court-martial process. References $(\mathrm{m})$ through (o) provide additional guidance on a victim's eligibility for VLC representation. Contact a staff judge advocate in order to determine whether a particular victim is required to meet with a VLC.

\section{OTHER CONSIDERATIONS:}

- The Secretary of the navy will provide guidance to commanders regarding their authority to take appropriate action to remove or temporarily reassign a Servicemember accused of committing a sex-related offense from a position of authority or from an assignment. This may not be used as a form of punishment but is intended to promote good order and discipline within the unit and to protect the victim if he/she is in the same unit as the accused.

- Defense counsel (DC) may not interview a victim of a sex-related offense without first requesting access to the victim through the trial counsel (TC). Further, the victim now has the right to have the TC or VLC present for the interview with the DC. 


\section{SECTION II:}

ADMINISTRATIVE CORRECTIVE MEASURES

AND

NON-JUDICIAL PUNISHMENT 


\section{REFERENCES:}

(a) RCM 306

(b) JAGMAN

(c) MILPERSMAN

(d) BUPERSINST 1610.10C

(e) MCO P1610.10C

(f) SECNAV M-5510.30

(g) BUPERSINST 1430.16F

(h) SECNAVINST 1920.6C

APPROPRIATE ACTION IN EVERY CASE: The case disposition decision is one of the most important and difficult decisions facing a commander. The discussion in reference (a) lists 10 factors that the commander should consider when deciding how to address a case of misconduct or poor performance by an officer or enlisted Servicemember (e.g., character of the accused's military service, nature of the incident, victim and witness availability, etc.) In any event, prompt action is always essential.

NO ACTION OR DISMISSAL: Upon completion of an investigation a commander may decide to take no action on an offense if appropriate under the totality of the circumstances. If charges have been preferred, they may still be dismissed.

ADMINISTRATIVE ACTION POLICY: Administrative action may be taken in addition to or instead of disciplinary action as circumstances warrant. However, administrative action should not be used as a form of punishment and should not substitute for appropriate disciplinary action.

\section{ADMINISTRATIVE OPTIONS:}

- Informal resolution at the lowest level of the chain of command. For example, informal counseling, providing an apology, etc.

- Non-punitive measures: leadership tools designed to correct unacceptable behavior or performance.

o Non-punitive censure [reference (b), section 0105]

- Oral or in writing; private action that may not be referenced in any official service documentation, but underlying conduct may be mentioned in appropriate official documentation.

o Extra Military Instruction (EMI) [reference (b), section 0103]

- Training tool designed to identify and correct a deficiency

- Training must be logically related to deficiency.

- Assigned for no longer than necessary to correct the deficiency.

- No more than two hours per day outside working hours; avoiding religious observances.

- May be completed during working hours or after hours, but only the $\mathrm{CO}$ or $\mathrm{OIC}$ may assign EMI after normal working hours.

o Denial of privileges [reference (b), section 0103

- Those with the power to grant the privilege also have the power to revoke the privilege.

- Only privileges (e.g., use of recreational facilities) and not rights (e.g., medical, dental, etc.) may be withheld. 
o Letter of Instruction (LOI) [reference (c), section 1611-1620]

- Written guidance use to correct a deficiency. Unlike non-punitive censure, a LOI may be referenced in any official service documentation, and the underlying conduct may also be mentioned in appropriate official documentation.

- Use of evaluations (EVALS) and fitness reports (FITREPS) to document unacceptable behavior [reference $(d)$, section 1610.10c; reference $(e)$ ]

- Security clearance adjustments or withdrawal [reference (f)]

- Withholding or withdrawing of an advancement or promotion recommendation [reference (g)]

- Reassignment/early transfer/delay of transfer

- Detachment for Cause [reference (c), sections 1611-1620]

- Administrative separation (enlisted personnel) or Board of Inquiry (officers) [reference (c), section 1920; reference $(h)]$

LAWFUL WAYS TO DENY NORMAL LIBERTY: Normal liberty cannot be curtailed unless as a part of a lawful punishment imposed by non-judicial or a court-martial, or under the following circumstances which are not punitive in nature.

- EMI

- Liberty risk (only applicable overseas)

- Extension of hours for mission-essential requirements

- Limited health/safety reasons

- Pretrial restraint in anticipation of courts-martial

VOLUNTARY RESTRAINT: Voluntary restraint, "house arrest," or "confinement to quarters" is never authorized unless part of a lawful punishment which requires certain procedures and provision of due process rights to the accused.

\section{REMEDIES FOR ILLEGAL NON-PUNITIVE MEASURES:}

- Request mast with the CO

- UCMJ Article 138 complaint against the CO

- U.S. Navy Regs. 1150 complaint against any superior other than the CO

- Congressional inquiry

- IG complaint

RESERVIST NOTE: Normal liberty can be denied for reservists on active duty. The guidance provided above applies to reservists on active duty. Reservists just in a drilling status do not have liberty. Accordingly, a CO may not deny liberty to a reservist in a drilling status. A CO cannot lawfully require a drilling reservist to work beyond the normal four-hour drilling period. Additionally, a CO cannot restrict a drilling reservist's liberty between drilling periods. 


\section{REFERENCES:}

(a) UCMJ, Article 15

(b) MCM, Part V

(c) JAGMAN, Sections 0106-0108, 0124

AUTHORITY: Only a commanding officer (CO) over the accused has the authority to impose non-judicial punishment (NJP). This authority is non-delegable and NJP may be impose on USN and USMC members of the command. Some flag officers may delegate their authority to impose NJP to a principal assistant. However, the general rule is COs cannot delegate their authority to conduct NJP. If the executive officer (XO) is acting $\mathrm{CO}$, then the $\mathrm{XO}$ as acting $\mathrm{CO}$ can impose NJP since the authority to impose NJP rests with the position with $\mathrm{CO}$ and not with the specific individual occupying the CO's position.

\section{OTHER CONSIDERATIONS REGARDING AUTHORITY TO IMPOSE NJP:}

- TIMING OF NJP: The authority to impose NJP rests with the CO in whose command the accused now serves; not the $\mathrm{CO}$ of the accused at the time of the offense.

- TAD PERSONNEL: The accused can be subject to NJP by either the CO of the TAD command or the accused's permanent command $\mathrm{CO}$, but not both for the same offense.

- EMBARKED UNITS: Unit commanders must defer to the prerogative of the ship CO to decide wither to conduct NJP on embarked personnel. The default is always that the ship CO has NJP authority over all embarked personnel on the ship. The ship CO may delegate his/her authority to the COs of embarked units, but absent such a delegation the ship CO retains the NJP authority. However, if a unit is only aboard a ship for transportation purposes and is not attached or an assigned unit to the ship, the CO of the unit aboard solely for transportation purposes has NJP authority over his/her personnel.

- MULTI-SERVICE COMMANDS: Personnel are subject to NJP from the multi-service commander. Often, multi-service commanders will designate the senior USN and USMC officer at the command to conduct NJPs for their respective members. Any such designation must be done in writing and a copy of the designation must be provided to the Office of the Judge Advocate General (OJAG), Criminal Law Division (Code 20) and to the Commandant of the Marine Corps (CMC).

OFFENSES PUNISHABLE: A CO has broad discretion to decide what offenses should be handled at NJP.

- GENERAL GUIDANCE: NJP is typically for "minor" offenses. Determining if an offense is minor is up to the commander's discretion. Among the many factors to be considered is whether the minor offense is an offense where a punitive discharge or more than one year's confinement is not authorized at court-martial. If such a punishment is not authorized, then the offense is generally considered minor. However, this is a guiding principal and not a hard rule for consideration of categorizing offenses.

- DOUBLE PUNISHMENT: Punishment of a minor offense at NJP will bar a subsequent court-martial for the same offense. Punishment of a serious offense at NJP will not bar a subsequent court-martial for the same offense, but the accused will receive credit for any punishment performed as a result of the NJP against any ultimate court-martial sentence. In such cases, the military judge will decide whether an offense is minor or major. 
- PRIOR CIVILIAN ACTION [reference (c), section 0124]: Prior federal court action bars NJP or court-martial. Prior state, local, or foreign court action does not necessarily bar NJP or court-martial, but the command must request permission to proceed from the General Court-Martial Convening Authority (GCMCA) over the accused, and any GCMCA decision must be reported to OJAG or the CMC if permission is granted.

o Criteria the GCMCA may consider in granting permission to conduct subsequent NJP or court-martial:

- Exceptionally light civilian sentence, impracticable probation terms, court concludes without a conviction or acquittal after a trial on the merits, unique military interest such as lack of civilian prosecution for military specific crimes.

DUAL ACTION: If both the Navy and a civilian law enforcement agency have jurisdiction over an offense, prosecution efforts should be coordinated. The Senior Officer Present Afloat and the area coordinator staff judge advocate, as well as NCIS, should be consulted if it appears that both the Navy and local authorities are contemplating prosecution.

STATUTE OF LIMITATIONS: There is a two year statute of limitations from the date of the offense; not two years from the date the command found out about the offense.

RESERVE NOTE: Reservists are subject to Uniform Code of Military Justice jurisdiction if they commit an offense defined by the UCMJ while on active duty or in a drilling status. The guidance provided above relating to a CO's authority and discretion applies to reserve COs and reservists.

- NJP can be imposed during active duty or inactive duty training (IDT) when the misconduct occurred or at a subsequent period of active duty or inactive duty training so long as this is within two years of the date of the offense. The accused can waive his/her right to be present at NJP, and the CO or officer in charge may impose NJP and require any punishment to take effect during a subsequent period of active duty or IDT.

- Reservists can be awarded restriction and extra duty at NJP. However, the restriction or extra duty may not extend beyond the normal termination of the duty period. Awarded but unserved restriction or extra duty can be carried over to a later period of active duty or IDT. Extra duties and arrest in quarters may not be imposed on reservists if they are IDT.

- Reservists cannot be awarded confinement on bread and water without approval of the Secretary of the Navy.

- Fines on reservists permanently assigned to inactive duty shall be based on the total amount subject to forfeiture at the time adjudged.

- A CO can request that the GCMCA involuntarily recall the accused to active duty or IDT for the purpose of imposing NJP. 


\section{REFERENCES:}

(a) UCMJ, Article 15

(b) MCM, Part V

(c) JAGMAN, Sections 0109-0115

(d) MCO P5800.16A (series)

DISCIPLINARY REVIEW BOARD (DRB) AND EXECUTIVE OFFICER INQUIRY (XOI): These are investigative tools conducted by the senior enlisted leadership of an enlisted accused member, which makes disciplinary recommendations to the Executive Officer (XO), who then conducts $\mathrm{XOI}$ and either dismisses the charges or forwards them to the Commanding Officer (CO) with a recommendation about whether or not to proceed with non-judicial punishment (NJP). Accused Servicemembers cannot refuse to attend a DRB or an XO Inquiry (XOI). Neither mechanism is authorized to make guilty findings or impose punishments nor is either required to take place before NJP. [See Appendix K - Executive Officer Inquiry Guide]

\section{RIGHT TO REFUSE NJP:}

- All Servicemembers can refuse NJP unless they are attached to or embarked on a vessel. The operational status of the vessel is irrelevant to whether a member can refuse NJP.

- The right to refuse NJP ends when the CO imposes punishment at NJP. Anytime before, even at NJP until the punishment is announced, the Servicemember can refuse NJP and terminate the NJP proceedings.

- If a member refuses NJP, the CO retains all administrative and other disciplinary options, including taking the charges to court-martial. It will be up to the $\mathrm{CO}$ to decide how to proceed in the event a Servicemember refuses NJP. Servicemembers cannot "demand court-martial" in lieu of NJP. The CO is under no obligation to grant the request for court-martial. The decision whether or not to take a Servicemember to courtmartial after refusing NJP is entirely and absolutely at the CO's discretion.

\section{RIGHT TO CONSULT WITH COUNSEL:}

- There is no right to legal counsel at NJP. The only right to legal counseling related to NJP is the right to consult with a lawyer about whether or not to accept NJP. The right applies only to members who have the right to refuse NJP (e.g., those not attached to or embarked on a vessel).

- If a member has the right to refuse NJP, asks to consult with counsel, and is denied this opportunity, the command may still hold NJP (presuming the Servicemember did not actually assert his/her right to refuse NJP). The only consequence to the command is that this NJP will not be admissible in aggravation at any later court-martial that might occur for the same or unrelated conduct. (Booker rights.)

RIGHTS AT THE NJP HEARING:

- To be present. The CO may not hold NJP absent the Servicemember unless the Servicemember has waived the right to a personal appearance.

- To remain silent.

- To have a personal representative assist with preparation and be present (this is not a right to counsel).

- To examine all evidence used against him/her.

- To present matters in defense or extenuation and mitigation. 
- To call "reasonably available" witnesses (there is no subpoena power over civilian witnesses).

- To a public hearing. A member may request a closed NJP but he/she has no right to one.

MILITARY RULES OF EVIDENCE (MRE): Except for privileges and the right against selfincrimination, the MREs do not apply at NJP.

STANDARD OF PROOF: The CO must be convinced by a preponderance of the evidence that an accused committed every element of each charged offense in order to be found guilty. A preponderance of the evidence means that it is simply more likely than not that a fact is true. It is the least stringent standard of proof and requires less certainty than clear and convincing evidence and substantially less than belief beyond a reasonable doubt.

CO's SCRIPT/GUIDE FOR NJP: See reference (e), Appendix A-1-f. This guide helps the CO conduct a legally sufficient NJP and ensures that required due process is afforded to the accused. It is not recommended that COs conduct NJP without this script.

\section{CO's OPTIONS AT NJP:}

- Find the accused guilty of one or more of the charges and impose an appropriate punishment

- The CO may impose the statutory maximum punishment for any offense for which an accused is found guilty at NJP. [See Appendix F-NJP Punishment Limitations Chart]

- Dismissal, which equates to an acquittal on one or all of the charges.

- Dismissal with imposition of administrative/non-punitive measures.

0 It is recommended that the discussion and imposition of any administrative/nonpunitive measures take place after the conclusion of the NJP hearing.

- Terminate the NJP before making a finding and imposing punishment and refer the matter to court-martial or a superior authority for disposition.

\section{PUBLICATION OF NJP RESULTS:}

- The results of a NJP hearing may be published within one month of the hearing, or if the NJP is appealed, within one month of the disposition of the appeal.

- Generally, if only military members have access to the publication of NJP results, then full publication, including the name of the accused, is allowed. If there is the potential for civilian access to the information, the Servicemember's full name must be removed. There are exceptions to restricting full publication based on the rank and/or position of the disciplined Servicemember and/or the nature of the misconduct or if there is compelling public and/or media interest. See JAGMAN, Chapter I, section 0105(b) for factors to consider with regard to disclosure. 
REFERENCES:

(a) UCMJ, Article 15(d)

(b) MCM, Part V

(c) MILPERSMAN 5812-010

(d) JAGMAN Section 0118

(e) MCO P5800.16 (series)

THOSE WITH AUTHORITY TO GRANT CLEMENCY OR TAKE CORRECTIVE ACTION:

- The officer imposing NJP;

- The successor in command to the officer imposing NJP; or

- The appellate authority (the General Court-Martial Convening Authority (GCMCA) over the officer imposing NJP)

\section{TYPES OF CORRECTIVE ACTION:}

- SET ASIDE: Terminating any or all of the punishment (executed or unexecuted) and restoring all property, privileges, and rights affected by that portion of the punishment set aside. Set asides are used to correct clear injustice. Clear injustice is defined as an unwaived factual or legal error which affirmatively injured the rights of the member. Clear injustice does not include the fact that the member's performance has been exemplary subsequent to the punishment or that the punishment may have a future adverse effect on retention or promotion potential of the member. Absent unusual circumstances, the power to set aside punishment will be exercised within four months of the imposition of punishment. Set asides exceeding the four-month timeframe must include a detailed justification of the unusual circumstances which resulted in the delay. An NJP authority may only set aside punishments that he/she has the power to impose. Setting aside an NJP has the effect of voiding the punishment and restoring the Servicemember to the position he/she would have been in had the NJP not been imposed, including repayment of back pay for any awarded reduction in rate or forfeitures and fines [see reference (c)].

- REMISSION: Canceling unexecuted portions of a punishment. The end of a current enlistment or discharge automatically remits any remaining unexecuted punishment. Servicemembers may not be retained beyond their End of Active Obligated Service to serve NJP punishment.

- MITIGATION: A reduction in the quantity or type of an unexecuted punishment. The new mitigated punishment may not be for a period greater than the original punishment.

- SUSPENSION: Holding the punishment in abeyance for up to six months.

o CONDTIONS OF SUSPENSION: The member cannot commit further violations of the Uniform Code of Military Justice. Any additional terms should be in writing and must be lawful orders capable of performance. (Examples of conditions: making restitution to the victim, to not enter certain establishments, to submit to searches, to conduct training, to successfully complete a course of treatment or rehabilitation, etc.)

o VACATING OF SUSPENSION: If a Servicemember violates the terms of a suspended NJP punishment, the suspension may be vacated by any authority authorized to impose the punishment that was suspended. The Servicemember should be notified and, although a hearing is not required, unless impracticable, 
the Servicemember should be given an opportunity to be heard. The decision to vacate a suspension cannot be appealed.

\section{TIME LIMITS:}

- Per reference (c), the power to set aside a NJP must be exercised within a reasonable amount of time after the punishment has been executed. Absent unusual circumstances, within four months is considered a reasonable amount of time. The request for any set aside must be sent via the first flag or general officer in the chain of command to Navy Personnel Command for approval. 


\section{REFERENCES:}

(a) UCMJ, Article 15

(b) MCM, Part V

(c) JAGMAN, Sections 0116 and 0117

(d) MCO P5800.16A (series)

\section{REVIEWINGIAPPELLATE AUTHORITY:}

- USN: The designated area coordinator or the General Court-Martial Authority in the chain of command of the officer imposing NJP.

- USMC: The immediate superior in the operational chain of command to the officer imposing NJP.

\section{GROUNDS FOR APPEAL:}

- UNJUST: The evidence does not support the guilty finding or there was a substantial procedural error or illegal aspect of the NJP.

- DISPORPORTIONATE: the punishment is disproportionate to the offense, too harsh, or unfair under the specific circumstances of the case.

\section{TIME LIMITATIONS:}

- The Servicemember has five working days (excluding weekends and holidays) from the date of the NJP to file an appeal.

- Extensions may be requested for good cause.

- Late appeals may be denied only by the appellate review authority. Therefore, all appeals, no matter how late, must be forwarded to the appellate authority regardless of the date submitted.

\section{PROCEDURE:}

- Appeals must be in writing.

- They must be routed by the Servicemember via the officer who imposed NJP.

- Any endorsement by the chain of command should include a statement of facts, copies of evidence relied upon at the NJP, including any investigative documentation, witness statements, etc.

- A copy of the Servicemember's record book must also be routed with the appeal.

REQUEST FOR STAY OF RESTRAINT: Applies only to punishments of restraint and extra duties. A Servicemember punished at NJP may request in writing that any unexecuted restraint and extra duties be stayed if the appellate authority fails to act on the appeal in five calendar days. If requested and the appellate authority has failed to act on the appeal in five days, the unexecuted restraint and extra duties are stayed until the appellate authority acts.

REVIEWINGIAPPELLATE AUTHORITIES SCOPE: The review/appellate authority can only review the appeal to determine if the officer imposing NJP abused his/her discretion. The review authority cannot make guilty findings, impose greater or different punishments, or substitute charges. The appellate authority can only take the corrective actions detailed above or let stand the findings and punishment imposed by the officer imposing NJP.

REFERRAL TO A JUDGE ADVOCATE: A NJP appeal must be referred to a judge advocate for review if the punishment awarded at NJP included: 
- Arrest in quarters for more than 7 days;

- Forfeiture of more than 7 days pay;

- Reduction of paygrade of an E-4 or higher;

- Extra duties for more than 14 days; and/or

- Restriction for more than 14 days

REHEARING: Only the reviewing/appellate authority may direct a rehearing, which is akin to a new NJP within the parameters set forth by the review/appellate authority. At any rehearing, the maximum punishment is limited to the punishment imposed at the original NJP. 


\section{SECTION III:}

ADMINISTRATIVE INVESTIGATIONS 
REFERENCES:

(a) JAGMAN, Chapter II

(b) MILPERSMAN 1770-010

(c) MCO P5800.16A

(d) JAGINST 5830.1A (series)

(e) JAGMAN Investigations Handbook

\section{TYPES OF JAGMAN INVESTIGATIONS:}

- Preliminary Inquiry

- Courts of Inquiry

- Board of Inquiry

- Command Investigation

- Litigation-Report Investigation

- Dual-purpose investigations

PRELIMINARY INVESTIGATION (PI): The JAGMAN provides the commanding officer (CO) the authority to convene an appropriate investigation. When the $\mathrm{CO}$ does this, he/she becomes the convening authority (CA) for that investigation. The JAGMAN allows CAs to initiate a basic, three-day PI to determine whether further investigation is required. Based upon the result of the $\mathrm{PI}$, the CA may decide to take no further action or to convene another type of JAGMAN investigation. Furthermore, if the incident may involve potential litigation claims, then the PI must be conducted under the supervision of a judge advocate.

COURT OF INQUIRY (COI): The most formal of all JAGMAN investigations is the COI. It is used for the most serious types of incidents, known as "major incidents," involving multiple deaths, significant national or international public or press interest, significant environmental damage, etc. [see reference (a), Appendix A-2-a, paragraph 9]. A COI can only be convened by a General Court-Martial Convening Authority (GCMCA) or another person designated by the Secretary of the Navy. COls have the power to subpoena witnesses.

BOARD OF INQUIRY (BOI): [Not to be confused with officer separation boards of inquiry.] BOls are less formal than a COI, but also used for "major incidents." BOls must also be convened by a GCMCA. Unlike COls, BOls have no subpoena power but then can order naval personnel to appear, testify, and produce evidence.

COMMAND INVESTIGATION (Cl): Most frequently used investigation of all JAGMAN investigations. However, a Cl would not be used for any incident considered a "major incident" unless a GCMCA determines otherwise. Unless the standard operating procedure in a particular command structure dictates otherwise, all Cls are to be reviewed and finalized not by the CA, but by the GCMCA for the CA who ordered the investigation.

- Usually just one person will be assigned as a command investigating officer (IO), and this person is usually senior to the accused and usually senior to most known relevant witnesses.

- Any testimony obtained for a $\mathrm{Cl}$ can be taken sworn or unsworn.

- A Cl must include the findings of fact, the opinions of the IO, and the IO's recommendations for disciplinary, corrective, or other appropriate administrative actions. 
LITIGATION-REPORT INVESTIGATION (LR): This form of JAGMAN investigation is utilized when the primary purpose of the investigation is to defend or protect the legal interests of the Department of the Navy and the United States. If conducted properly, the LR is designated as "attorney work product" and protected from disclosure. Due to the high sensitivity of a LR, it should not be conducted without consulting a judge advocate and may only be released by the Office of the Judge Advocate General (OJAG) (Code 15 - Tort Claims Unit).

- The CA must consult with the "cognizant judge advocate" before convening a LR.

- LRs require a special type of convening order [see reference (a)].

- The investigation is conducted under the direction and supervision of a judge advocate.

- There are special rules for taking witness statements.

- Opinions and recommendations in the LR can only be ordered under the authority of the cognizant judge advocate.

- Every page of the report will be labeled "FOR OFFICIAL USE ONLY/LITIGATION ATTORNEY WORK PRODUCT" [see reference (a), section 0210e].

- $\quad$ LRs may not be used to investigate major incidents or where an active-duty death has occurred.

ENDORSEMENTS: CAs should address any and all deficiencies identified in the investigation, and detail corrective actions taken or planned. Special rules apply that may limit any reference to certain administrative and disciplinary actions taken in response to an investigated incident

- Cls: Per reference (a), all command investigations should be forwarded to the GCMCA in the chain of command. However, the GCMCA may set local policy on which types of Cls should be forwarded. Refer to reference (a) for proper routing of a JAGMAN investigation.

- LRs: All LRs must be forwarded to the OJAG (Code 15), Investigations Branch, 9620 Maryland Avenue, Suite 100, Norfolk, Virginia 23511-2989.

RETENTION: Cls must be retained for at least two years and then forward to OJAG (Code 15), Investigations Branch for retention. Any contemplated disposal of a LR shall be coordinated with OJAG Code 15 (DSN 325-4600 or (202) 685-4609) before destruction.

FREEDOM OF INFORMATION ACT RELEASE AUTHORITY: At a minimum, the lowest level release authority for Cls is the cognizant GCMCA. For LRs, only OJAG (Code 15) is authorized to release a report.

LINE OF DUTY INVESTIGATION (LODI)/MISCONDUCT DETERMINATIONS: Whenever a Servicemember is injured or ill and such injury or illness may result in permanent disability or if it may result in the Servicemember missing duty for a period of more than 24 hours, the Servicemember's command must conduct a LODI. The results of the LODI must be forwarded for final action to the GCMCA. Usually a LODI will be a component of a $\mathrm{Cl}$ and not a separately documented investigation [see reference (b)].

DUAL PURPOSE INVESTIGATIONS: Some major incidents will produce the need for multiple forms of other JAGMAN investigations. Contact a staff judge advocate or OJAG for assistance determining what type of investigation is most appropriate and whether a dual investigation may be required [see reference (a), sections 0204, 0210, 1105(d)].

RESERVE NOTES: Refer to section 0224 in reference (a). 
NOTE: Law now requires commanders to immediately report sex-related offenses to the pertinent military criminal investigative organization (e.g., NCIS, etc.) Therefore, a command must not conduct its own $\mathrm{PI}$ or $\mathrm{Cl}$ into an allegation of a sex-related offense until after the cognizant military criminal investigative organization decides not to pursue the matter. 


\section{DEATH INVESTIGATIONS}

\section{REFERENCES:}

(a) JAGMAN, Sections 0209, 0215, 0225-0232

(b) MILPERSMAN $1770-010$ to 260

(c) MCO P5800.16A (series)

(d) MCO P3040.4 (series)

PERSONNEL CASUALTY REPORT: This report is required in the event of a death of a Servicemember [see reference (b)].

NCIS NOTIFICATION: NCIS must be notified if there is a Servicemember or civilian death occurring on a naval vessel or a USN or USMC aircraft or installation, except when the cause of death is medically attributable to disease or natural causes.

\section{JAGMAN INVESTIGATION:}

- If a death occurred CONUS, off-base, while the Servicemember was off duty, and there is no connection between the naval service and the circumstances of the death, the command may conduct a limited investigation and simply obtain the investigation completed by civilian authorities and maintain the record as an internal report. The command shall document, in writing, the reasons a limited investigation was conducted, attached the enumerated reasons to the internal report.

- At a minimum, a preliminary inquiry shall be conducted into the death of a member of the naval service or into the death of a civilian aboard a place under naval control.

- If a death is the result of a previously known medical condition and the quality of medical care is not an issue or if the death was caused by enemy action, no investigation is required.

- Under all other circumstances, a full JAGMAN investigation (typically a command investigation) is required.

STATUS OF INVESTIGATION REPORTS: Status reports are required at reasonable intervals until the JAGMAN investigation is forwarded to the next reviewing authority [see reference (b)], who is usually the immediate superior over the officer who ordered the investigation into the circumstances of the death in question.

LINE OF DUTY (LOD) DETERMINATIONS: These are required of all active-duty death cases. If the deceased's conduct is called into question as a contributing factor in his/her death, the commanding officer may appoint an individual not associated with the case (outside the chain of command) to review the investigation to ensure thoroughness and accuracy of the findings [see reference (a), section 0215, 0231].

FORWARDING: Do not delay in forwarding the investigation or finalized documents that are part of the investigation up the chain of command while awaiting final autopsy reports, death certificates, etc. Such documentation can be forwarded under separate cover and added to the investigation [see reference (a), section 0228(b)].

\section{RESERVE NOTES:}

- Section 0224 of reference (a) pertains specifically to procedures for LOD determinations that involve reservists. Accordingly, this reference addresses issues that arise during reservist death investigations. 
- Reference (b) addresses casualties and survivor benefits pertaining to reservists and deals specifically with reporting the death of non-active-duty sailors.

- Reference (c) states that a LOD determination should be conducted whenever an activeduty Servicemember of the naval service dies. Reference (c), however, does not specifically address the need for a LOD determination in the case of a reservist who dies while performing military duty. Nevertheless, reference (a) and reference (d) states that the term "active duty" for purposes of LOD determinations in death cases includes reserve components serving on active duty, active duty for training (ADT), and inactive duty for training (IDT) (drilling status).

- The USMC Casualty Procedures Manual states that the term "active duty" includes applicants of the Reserve Officer Training Corps and members of the Reserve Component serving on active duty, ADT, and IDT. 


\section{REFERE CES:}

(a) SECNAVINST M-5510-36 (Chapter 12)

(b) JAGMAN, Chapters I and II

POLICY: A loss of classified material occurs when it cannot be accounted for or be physically located. A compromise is also the unauthorized disclosure if classified information to a person who does not have a valid clearance, authorized access, or a need to know. A possible compromise occurs when classified information is not properly controlled.

REPORTING REQUIREMENTS: Per reference (a), an individual who becomes aware of a loss or compromise must immediately notify their commanding officer (CO) or security manager (SM). The CO or SM shall immediately initiate a preliminary inquiry (PI). If during the course of the $\mathrm{PI}$ it is determined that a loss or compromise of classified information did occur the local $\mathrm{NCIS}$ office must be notified. The references listed above establish additional reporting requirements. The format for appointing orders for JAGMAN investigations should comply with reference $(a)$, exhibits $12 A-D$.

\section{PRELIMINARY INQUIRY IN LOSS OR COMPROMISE [see reference (a)]:}

- The CO will appoint a command official (not the SM or any person involved in the incident) to conduct the PI.

- The PI shall be initiated and completed within 72 hours.

- A PI message report or letter must be sent to the immediate superior in command (ISIC) over the CO ordering the PI as well as OPNAV (N09N2), the originator and original classification authority of the classified information in question, the local NCIS office, the National Security Case Disposition Authority (NSCDA), the Office of the Judge Advocate General (Code 30), and others listed in reference (a).

- The PI shall completely and accurately identify the information lost or compromised.

- If the PI determines that no loss or compromise or that the possibility of compromise than the message report is not required.

- Results of the PI may indicate that a more detailed JAGMAN command or higher-level investigation is required.

\section{JAGMAN INVESTIGATION (USUALLY A COMMAND INVESTIGATION):}

- A JAGMAN investigation, usually a command investigation $(\mathrm{Cl})$ may be used or needed to identify and recommend any appropriate corrective or disciplinary action.

- The CO will appoint a command official with a proper-level security clearance to deal with the classification level of the lost of compromised information.

- The SM will not be appointed to conduct the CI.

- Reference (b) provides guidance on conducting a Cl into lost or compromised classified information, including how to properly mark and classify the report and enclosures to the $\mathrm{Cl}$.

- Forward the Cl to OPNAV (N09N2) via the administrative chain of command and provide informational copies to NCIS, the original classification authority, and the originator of the information in question.

\section{NATIONAL SECURITY CASE REPORTING [see reference (b)]:}

- Results of the PI or NCIS investigation need to be assessed to determine if the loss or compromise of classified information meet the criteria for a national security case 
- A national security case is one which, to any serious degree, involves the compromise of a military or defense advantage over any foreign national or terrorist group; involves the willful compromise of classified information; affects our capability to resist hostile or destructive action; or involves any act of terrorism.

- If any of these categories come into play, a more detailed JAGMAN investigation is required.

- A JAGMAN investigation for a national security case must be overseen by a senior line commander who is designated as a NSCDA.

- If designated as a national security case, the NSCDA must make periodic message report (every 15 days) to the Chief of Naval Operations until resolution or until the case is determined to not be a national security case.

JUDGE ADVOCATE GENERAL REPORTING: Report all cases to OJAG Code 30 that involve classified information, whether or not designated a national security case:

- When criminal prosecution is contemplated;

- Whenever a major development in the case or investigation occurs; or

- At least every 30 days.

ISIC MAJOR CASE/HIGH-VISIBILITY CASE REPORTING REQUIREMENTS: Some ISICS require periodic reporting on certain types of cases considered "major" or "high visibility." The report sent to OJAG noted above can also be used to satisfy any ISIC requirement to report on major or high-visibility cases. 
SECTION IV:

CLAIMS 


\section{CLAIMS OVERVIEW}

\section{REFERENCES:}

(a) JAGMAN, Chapters II, VIII, and XI

(b) JAGINST 5890.1A (series)

INVESTIGATION REQUIREMENT: If an incident occurs which gives rise to the possibility that a claim may be submitted either for or against the government, some form of administrative investigation will be required in order to adjudicate or defend the government against the claim. Typically, a JAGMAN investigation will be required.

- A litigation-report investigation is appropriate whenever an incident may potentially result in a claim or litigation against the Navy.

- Consult the cognizant staff judge advocate before convening a litigation-report investigation.

NOTIFICATION: The Office of the Judge Advocate General (OJAG), Tort Claims Unit (Code 15) should be notified of any incident which might result in a claim. The Tort Claims Unit in Code 15, located in Norfolk, Virginia, may be contacted at (757) 341-5483 or DSN 341-4583.

CLAIM RECEIPT: Should the command receive an actual claim, it must be date stamped and the original claim submission must be immediately forwarded to Code 15 , along with any accompanying material and the original envelope with postmark sent by the individual making the claim.

ADVANCE COPY OF INVESTIGATION: Provide Code 15 with an advance copy of any type of investigation conducted into the claim received at the command.

NOTIFICATION OF LAWSUIT: If a lawsuit has been filed against an individual within the command, the command of the Department of the Navy, immediately notify OJAG Code 15 at (202) 685-4600 or DSN 325-4600.

ADMIRALTY INCIDENTS: Any claim that may arise from the operation of a vessel upon navigable waters is considered an admiralty incident. Every admiralty incident must be reported immediately to the OJAG Admiralty Division (Code 11) at (202) 685-5040 or DSN 325-5040.

FOREIGN CLAIMS: [see FOREIN CLAIMS section] 


\section{SECTION V:}

ADMINISTRATIVE SEPARATIONS

AND

OFFICER MISCONDUCT 


\section{ENLISTED ADMINISTRATIVE SEPARATION BASICS}

\section{REFERENCES:}

(a) DODD 1332.14

(b) MILPERSMAN

(c) MCO P1900.16 (MARCORSEPMAN)

(d) NAVADMIN 131/10

(e) MCO P1070.12K (series)

(f) 10 U.S.C. $\S 1177$

(g) MARADMIN 328.10

PURPOSE: Enlisted administrative separations (ADSEP) are intended to promote readiness by maintaining high standards of performance, conduct, discipline, achieve and maintain authorized force levels, and provide for the separation of enlisted personnel under various circumstances.

BASIS FOR SEPARATION: The basis for separation is the reason for separating a Servicemember. A list of all bases can be found in reference (b), section 1910-100 and reference (c), Chapter 6 . All bases are divided into two broad categories:

- VOLUNTARY: The Servicemember requests separation. Reasons may include personal family hardship, pregnancy, conscientious objector, etc. All voluntary separations are initiated and considered "At the Convenience of the Government."

- INVOLUNTARY: The military service initiates the ADSEP process, usually because the Servicemember has committed misconduct or demonstrated poor performance.

MANDATORY BASES FOR SEPARATION: A commander is required to initiate the ADSEP process when a Servicemember has engaged in the following:

- USN

o Sexual misconduct

o Sexual harassment

o Misconduct that could have lead to death or serious bodily injury

o Drug abuse

o Illicit use of prescription/over the counter medications

o Supremacist or extremist conduct

o Alcohol treatment rehabilitation failure

o Failing to pass three physical fitness assessments in a four year period (this includes body composition assessment failures).

- Family Advocacy Program failure

- USMC

Second substantiated DUI (date-dependent)

o Sexual misconduct

o Sexual harassment

o Drug abuse

o Illicit use of prescription/over the counter medications

o Supremacist or extremist conduct

o Failure to pass the combat fitness test or the physical fitness test

o Failure to meet certain performance standards

o Second substantiated DUI 
ADDITIONAL MADATORY ADSEP BASIS: Mandatory ADSEP processing for inappropriate conduct by a Servicemember exercising authority over a person in entry-level processing or training, such as with a recruit or a trainee. The offender shall be subject to mandatory ADSEP processing if the Servicemember is not punitively discharged at a court-martial. Examples of the types of relationships subject to this provision are:

- Medical Entry Processing staff and recruits

- Recruiter and recruits

- Instructors and students

CONVENING AUTHORITY (CA): The CA is the official authorized to initiate and convene the ADSEP process. Normally, the Servicemember's commanding officer is the CA for enlisted ADSEP processing.

ADSEP NOTIFICATION AND BOARD PROCEDURES: These terms refer to the two different methods for initiating and processing a Servicemember for ADSEP. The decision regarding which method to use depends on the seniority of the Servicemember and the least favorable characterization of service to which they may be subject [e.g., honorable, general, or other than honorable (OTH)].

- NOTIFICATION PROCEDURE: Appropriate for all Convenience of the Government cases and for misconduct cases where the CA believes that either an honorable or a general discharge is warranted. In order to use the notification procedure under these circumstances. If the Servicemember has six years of service or more, he/she is still entitled to elect to have an ADSEP board, even if he/she is may only be subject to an honorable or general discharge.

- BOARD PROCEDURE: Must be used, or at least offered to the Servicemember subject to ADSEP, if he/she could receive an OTH discharge or has six or more years of active and/or reserve service. Almost all mandatory ADSEP processing cases will require the board procedure. The Servicemember can waive the right to an ADSEP board, but that is at the discretion of the Servicemember in question.

\section{CHARACTERIZATION OF SERVICE:}

- HONORABLE: Met the standard of acceptable conduct and performance; or is otherwise so meritorious that any other characterization is clearly inappropriate. For USN personnel, the Servicemember must have an evaluation trait average of 2.50 or above at the time of his/her end of active obligated service (EAOS). For USMC, the Servicemember must have Pro/Con marks of 3.0/4.0 at his/her end of active service (EAS).

- GENERAL (UNDER HONORABLE CONDITIONS): The Servicemember provided honest and faithful service, but negative aspects of his/her service outweighed the Servicemember's positive service. (of losing significant Department of Defense (DOD) and Veterans Administration (VA) benefits.)

- OTH: The Servicemember demonstrated one or more aspects or a pattern of misconduct that constituted a significant departure from the conduct expected from Servicemembers. (A collateral consequence to this characterization is that the Servicemember is at risk of losing almost all DOD and VA benefits.) 


\section{SEPARATION AUTHORITIES (SA):}

- USN

- SPECIAL COURT-MARTIAL CONVENING AUTHORITY (SPCMCA): A SPCMCA can initiate the ADSEP process when the process will involve the notification procedure and there is no possibility the Servicemember subject to ADSEP processing will receive an OTH. In all cases where a SPCMCA initiates ADSEP processing normally the SPCMCA will also be the SA. However, the Servicemember can request review of his/her case by the General Court-Martial Convening Authority (GCMCA) and that the GCMCA act as the SA rather than the SPCMCA.

- GCMCA: A GCMCA will act as the SA when the ADSEP board procedure is used and the board recommends that the Servicemember receive an OTH.

- BUPERS/SECRETARY OF THE NAVY (SECNAV): BUPERS or SECNAV will act as the SA when active duty or reserve personnel are recommended for involuntary separation within two years of retirement. BUPERS or SECNAV will also be the SA when the basis for separation is "Best Interests of the Service" (BIOTS).

- USMC

- GCMCA: The cognizant GCMCA will act as the SA in most cases.

- DEPUTY COMMANDANT FOR THE MARINE CORPS (MANPOWER AND RESERVE AFFAIRS) [DC/M\&RA]: DC/M\&RA will serve as the SA when a Servicemember is being processed for involuntary separation and has 18 or more years of total active military service.

- SECNAV: SECNAV will serve as the SA for all reserve cases where the Servicemember is within two years of retirement and for all cases where the basis of separation is BIOTS.

LEGAL REVIEW: In cases where an OTH is recommended, or when a letter of deficiency is submitted by the Servicemember/defense counsel, the record of the ADSEP proceeding must be reviewed by a judge advocate before the SA can take final action.

CONDITIONAL WAIVERS: A Servicemember entitled to an ADSEP board may request a conditional waiver of his right to a board, contingent upon receiving a general or honorable discharge. Such requests can only be approved by the cognizant GCMCA and if favorably endorsed by the CA for the ADSEP processing in question. Conditional waivers may not be available for some mandatory bases of separation.

ENDORSING ADSEP BOARD CASES: If an ADSEP board recommends retaining the Servicemember, the CO may still recommend discharge to the SA in his/her endorsement of the board's recommendation. With respect to characterization of service, a CO cannot recommend a less favorable characterization than the one recommended by the ADSEP board. The CO can always recommend a more favorable recommendation, but it will be the SA who makes the final decision regarding separation and characterization of service.

DOCUMENTING CONDUCT AS A PREREQUISUTE TO INITIATING ADSEP PROCESSING: Under references (a) and (b), prior documentation memorializing a Servicemember's previous misconduct or performance problems may be a firm prerequisite to initiating ADSEP processing. Clear guidance on who may issue a Page 13 or Page 11 should be issued by the $\mathrm{CO}$, and documentation of Servicemember's conduct should always adhere to the ADSEP documentation requirements so that CO's will have the ability to initiate ADSEP processing in the future if necessary. When in doubt, document issues formally with a Page 13 or Page 11 or 
with an informal memorandum for the record if the $\mathrm{CO}$ does not wish to include the formal documentation in the member's service record. However, usually a MFR will not substitute for the Page 13 or Page 11 requirement in when called for by references (a) and (b). For the USMC, the CO must sign any adverse Page 11 entries. Formal counseling memorialized in writing is normally required as a prerequisite for initiating ADSEP for the following bases:

- Parenthood

- Personality disorder

- Entry-level performance

- Physical fitness failure (including weight control)

- Unsatisfactory performance

- Refusing medical treatment

- Pattern of misconduct

- Minor disciplinary infractions

- Physical or mental conditions not amounting to a disability

- If required by reference (b), sections 1004 and 6105

ADSEP AFTER EAOS/EAS: A Servicemember may not be adversely administratively discharged after the end of his/her enlistment except for a separation in lieu of trial by courtmartial (SILT). If a Servicemember is extended beyond his/her EAOS/EAS for purposes of court-martial, and the command decides not to pursue a court-martial, the member must be separated with a characterization of service warranted by the service record, unless the command's action is based on a member-submitted SILT request. Commands should consult with a staff judge advocate before taking action on such a case. Under no circumstances may a command extend a Servicemember past his/her EAOS/EAS solely to ADSEP them.

ADMINISTRATIVE LEAVE: Separation leave shall not be granted for members who are being administratively discharged.

POST-TRAUMATIC STRESS SYNDROME (PTSD)/TRAUMATIC BRAIN INJURY (TBI): Screenings or medical evaluations for PTSD/TBI are required in some cases before a command can initiate ADSEP processing against a Servicemember. This may be required to determine whether either or both conditions exist and whether one or both contributed to the conduct subjecting the Servicemember to ADSEP.

- USN: Reference (g) provides that if a Sailor, in the two-year period prior to ADSEP processing, served in an imminent danger-pay area, then an evaluation must be made to determine whether he/she has been diagnosed with PTSD/TBI. If diagnosed with either condition, then an additional medical evaluation will be required to determine whether PTST/TBI was a contributing factor to one or more of the bases of ADSEP processing. If so, then the Chief of Navy Personnel serves as the SA in those circumstances.

- USMC: References (c) and (h) provide that all Marines with over 180 days of activeduty service will undergo a medical evaluation before involuntary ADSEP processing is initiated. If $\mathrm{PTSD} / \mathrm{TBI}$ is present, then a medical evaluation by a clinical psychologist or psychiatrist will be required to determine whether PTSD/TBI was a contributing factor to one or more of the bases of separation. If so, and the Marine is recommended for separation with either a general or OTH, then the GCMCA's (as the SA) final action endorsement shall explain the reasons for the Marine's separation and characterization of service, taking into account the diagnosis as a contributing factor. 
RESERVE NOTES: A reservist who is not on active duty or who is serving under a call or order to active duty for 180 days or less begins entry-level status upon enlistment. Entry-level status for such a reservist terminates as follows:

- 180 days after beginning training if the member is ordered to active duty for training for one continuous period of 180 days or more; or

- 90 days after the beginning of the second period of active-duty training under a program that splits the training into two or more separate periods of active duty.

HARDSHIP SEPARATIONS [see reference (b)]: A USN reservist, serving on inactive duty, may be transferred to the Individual Ready Reserve (IRR) or Standby Reserve when the hardship prevents participation in the Selected Reserve (SELRES) but not mobilization of the reservist, or may be discharged when the hardship would prevent the reservist's mobilization. ADSEP cases for reservists on inactive duty shall be approved by the appropriate SPCMCA and upon completion of the ADSEP forwarded to Navy Personnel Command (NPC).

ERRONEOUS OF DEFECTIVE ENLISTMENT [see reference (b)]: For SELRES personnel, the SA is NPC.

UNSATISFACTORY PARTICIPATION IN THE READY RESERVE [see reference (b)]: The notification ADSEP procedure detailed above should be used for these cases. If the CO determines that discharge is not warranted, he/she may recommend that the Servicemember be transferred to the IRR or the Standby Reserve (Inactive). This recommendation should be included in the CO's letter of transmittal (LOT) of the ADSEP package and recommendation to NPC. The characterization of service should be honorable or general.

SEPARATION BY REASON OF PHYSICAL DISABILITY [reference (b)]: Reservists on inactive duty may be separated by reason of physical disability upon a determination that they are not physically qualified to perform the duties of their rating on active duty in the reserves in a reasonable manner due to disease or disability.

FORWARDING ADSEP PACKAGES [see reference (b)]: All ADSEP packages for reservists, even for those members discharged locally, must be forwarded to NPC under a LOT. The CO or acting CO must sign the LOT; LOT's may not be signed "by direction." If discharged locally, the LOT must include the effective date of discharge and a copy of the service record entry. See reference (b) for a LOT template.

TRANSFER TO NON-PAY BILLETS: Naval Operational Support Center (NOSC) COs have the authority to assign unsatisfactory participants to non-pay billets if the member is being processed for ADSEP. COs should consider if the reservist is a mobilization asset prior to transferring personnel to a non-pay billet. Assignment to a non-pay billet may be made as soon as a NAVPERS Form 1910/31 or a NAVPERS 1910/32 is signed by the NOSC CO. NOSC $\mathrm{COs}$, at their discretion, may retain all reservists being processed for ADSEP in their unit until processing is complete.

MINIMUM NOTICE OF PROCESSING [reference (b)]: Drilling reservists (inactive duty reservists) must have a minimum of 30 days from the date of notice of ADSEP processing is delivered personally or received by mail at the reservists designated mailing address to respond to the notice. If mailed, the notice of processing should be mailed in such a way that the command receives notice of delivery of the correspondence. 
OTHER CONSIDERATIONS: SECNAV will be establishing policy for the enhanced protections of prospective members and new members of the armed forces during entry-level processing and training. A punitive policy for inappropriate and prohibited relationships, communication, conduct, or contact between a member and a prospective member of the armed forces is in effect. 


\section{REFERENCES:}

(a) MILPERSMAN

(b) MCO P1900.16F (MARCORSEPMAN)

\section{WHEN ADMINISTRATIVE SEPARATION (ADSEP) BOARDS ARE REQUIRED:}

- If the Servicemember has six or more years of military service; and/or

- If the Servicemember is being processed for ADSEP and the least favorable characterization of service that could be assigned is an other than honorable (OTH) discharge.

\section{ADSEP BOARD COMPOSITION:}

- Three or more commissioned, warrant, or noncommissioned officers (E-7 and above).

- A majority of the board members must be commissioned officers and/or warrant officers.

- The senior member must be an O-4 or above (line or staff corps).

- $\quad$ The E-7 or above member must be senior to the Servicemember subject to ADSEP processing.

- If the Servicemember subject to ADSEP is a reservist, there must be at least one commissioned officer reservist on the board.

WITNESS REQUESTS: Any requests for witnesses by the Servicemember subject to ADSEP processing must be timely. Boards do not have subpoena power for civilian witnesses. The commanding officer ( $\mathrm{CO}$ ) or other official acting as the convening authority $(\mathrm{CA})$ may expend funds to bring a witness (military or civilian) to the board if life testimony is both necessary and the witness is reasonably available based on operational commitments, etc. The CA should consider factors such as cost, delay, and interference with mission accomplishment when deciding whether to spend funds to bring a witness to a board. Testimony via telephone and video-teleconference is permitted.

FUNDING FOR THE PRODUCTION OF WITNESSES: The CA may authorize funding for the production of witnesses only if the senior member of the board (after consultation with a judge advocate appointed as the board's legal advisor) determines that:

- The testimony of the witness is not redundant with that of another witness or other forms of evidence;

- The personal appearance of the witness is essential to a fair determination on the issues;

- Written or recorded testimony will not accomplish adequately the same objective as live testimony;

- The need for live testimony is substantial, material, and necessary for proper disposition of the case; and

- The significance of the personal appearance of the witness, when balanced against the practical difficulties of producing the witness, favors production of the witness

- Factors to be considered in relation to the balancing test include, but are not limited to

o The cost of producing the witness.

0 The timing of the request for production of the witness.

o The potential delay to the board that may be caused by waiting to produce the witness.

o The likelihood of significant interference with military operations by either delaying the board and/or producing the witness. 
CONTINUANCE REQUESTS: The Servicemember subject to ADSEP processing should be given reasonable time in order to prepare for an ADSEP board.

- The senior member of the board rules on all requests for a continuance.

- Ensure that a request for continuance does not place the Servicemember subject to separation past his/her end of active obligated service (EAOS)/end of active service (EAS), in which case the member cannot be administratively separated [see above: ADSEP after EAOS/EAS].

- If the Servicemember subject to ADSEP goes on unauthorized absence while an ADSEP board is pending, the board may proceed without the presence of the member.

o For the USMC, the ADSEP board cannot proceed without permission from the Commandant of the Marine Corps unless the Marine subject to separation meets the requirements of reference $(b)$, paragraph 6312.

CHALLENGES FOR CAUSE: Either the recorder, who represents the government, the counsel for the Servicemember subject to ADSEP, or the Servicemember him/herself can challenge a member of the board and request the member's excusal if there is evidence that the member cannot make a fair and impartial decision. The CA rules on all challenges for cause, unless the CA has authorized the legal advisor for the board to do so.

\section{ISSUES TO BE DECIDED AND RECOMMENDED BY THE ADSEP BOARD:}

- If the basis for separation (e.g., misconduct, poor performance, etc.) is supported by a preponderance of the evidence ("more likely than not" standard);

- If the basis is supported, should the Servicemember be separated or retained; and

- If separated, what should be the characterization of service upon discharge (honorable, general, or other than honorable).

ADSEP BOARD EVIDENCE: The Military Rules of Evidence do not apply, except for privileges and the right against self-incrimination.

- Pre-service/prior enlistment adverse matters may only be considered on the issue of retention or separation if the evidence is not too remote, isolated, or irrelevant. Such information cannot be used on the issue of characterization of service. Only current enlistment matters may be considered for the characterization of the current enlistment.

- Findings of a court-martial or civilian courts are binding upon ADSEP boards on the question of whether the basis for separation is supported by the evidence.

RESERVE NOTE: Letters of transmittal conveying a case involving reservists processed for ADSEP for unsatisfactory performance in the Ready Reserve to the Separation Authority must include a copy of the reservist's drill muster record, NAVPERS Form 1570/2, Satisfactory Participation Requirements/Record of Unexcused Absences, notices to report for physical examinations, and letters trying to locate the reservist. 
REFERENCES:

(a) MILPERSMAN 1611

(b) BUPERSINST 1610.10 (series)

(c) U.S. Navy Regulations, Article 1122(b)

(d) MILPERSMAN 1070-020(c)

(e) SECNAVINST 1920.6C (series)

(f) MCO P5800.16A (series)

NOTE: In all cases of officer misconduct, whether or not required, it is best practice to contact BUPERS (PERS-834) at (901) 874-2090/4424 or DSN 882-2090/4424 for assistance with USN cases, or Headquarters, USMC (JAM) at (703) 614-4250 or DSN 224-4250 for assistance with USMC cases.

NOTIFICATIONS REQUIREMENTS: The following cases require notification and follow on reports for instances of officer misconduct to the offices noted above:

- AN INTENT TO TAKE AN OFFICER TO NON-JUDICIAL PUNISHMENT (NJP)

- COMPLETION OF NJP: Notify PERS or JAM by letter as soon as the results are final, including any appellate action. NJP results must be sent via the first flag officer in the administrative chain of command [see references (a) and (f) for appropriate format and informational requirements]. The officer imposing NJP must also recommend whether the officer should be removed from any promotion list, detached for cause, and whether he/she should be required to show cause for retention ("show cause" means to initiate administrative separation (ADSEP) processing in officer cases)

- INTENT TO TAKE AN OFFICER TO COURT-MARTIAL: At a minimum no later than when charges are preferred against the officer.

- THE FINAL RESULTS OF ANY COURT-MARTIAL OR CIVILIAN COURT ACTION

- ARREST BY CIVILIAN AUTHORITIES: The commanding officer (CO) shall report initial pertinent information to PERS or JAM by e-mail. This includes the nature of the civil charges. Subsequent status reports shall be submitted as appropriate, but not less than every 30 days or when there is a significant development in the case. When the results of the civilian action are final, the $\mathrm{CO}$ shall submit a Final Civil Action Report to PERS or JAM by letter.

- UA: COs shall report all facts and circumstances immediately to PERS or JAM by message. Next of kin letters must be sent after 10 days of UA status and a DD Form 553 notification must be sent after 30 days when the UA turns into deserter status. If the officer who is UA had access to classified information and there is any indication the UA status may be related to the classified material then NCIS must be notified.

o COs located in CONUS shall contact the primary next of kin by telephone to notify them of the officers UA status and request assistance in returning the officer to military authorities. All other CO's will do the same when the absentee officer's next of kin reside in the local area.

NON-PUNITIVE LETTERS OF CAUTION (NPLOC): These are a common administrative counseling tool to address an officer's poor performance and/or minor disciplinary issues. NPLOCs may not be referred to in fitness reports (FITREPS) or forwarded to BUPERS. The underlying facts necessitating the NPLOC may be referred to in FITREPS or another official record. However, if any adverse matters are going to be included in a FITREP or in the officer's 
service record, he/she must be given the opportunity to make a statement in connection with the adverse entry.

LETTERS OF INSTRUCTION (LOI): LOIs serve the same purpose as NPLOCs, but LOIs can be referred to in FITREPS and in other official documents in the officer's service record.

Whether they are referred to or included in service record documents is at the discretion of the officer's $\mathrm{CO}$. As an adverse matter for entry into the record, the officer who received the LOI has a right to comment on the matters addressed in the letter. COs should be aware that the inclusion of an LOI in a service record or if referred to in a FITREP may have significant adverse impact on the officer's chances for promotion, assignment, and overall career progression.

ADSEP CATEGORIES: Officers may be administratively separated from the service for the following reasons:

- VOLUNTARY:

o Resignation

0 Release from active duty (RAD)

o Retirement

o Inter-service transfers

o Convenience of the Government (e.g., parenthood, hardship, separation to accept public office, etc.)

- INVOLUNTARY:

o Involuntary RAD

o Failure to promote

o Separation in lieu of court-martial

o Substandard performance of duty

- Misconduct or moral or professional dereliction

o Force shaping to maintain authorized personnel levels

SEPARATION PROCESS: An officer may be separated using the notification procedure or the board procedure. These processes are similar to the two types of procedures used for enlisted ADSEPs. ADSEP boards for officers are called "Boards of Inquiry" (BOI). The notification procedure may be used for probationary officers (those with six or less years of service) and who are not subject to possibly receiving an other than honorable (OTH) characterization of service upon discharge. All other officers are entitled to a $\mathrm{BOI}$, though they may waive the right to a board.

SHOW CAUSE AUTHORITY (SCA): Only the SCA, as designated and appointed by SECNAV, may convene a BOI. For USN, PERS has been designated as the SCA. For USMC, the Commandant of the Marine Corps (CMC) has been delegated SCA. CMC has further delegated this authority down to the Deputy CMC (Manpower and Reserve Affairs). The Secretary of the Navy has authorized generals and lieutenant generals in command to be designated as alternate show cause authorities. 


\section{DETACHMENT FOR CAUSE}

\section{REFERENCES:}

(a) MILPERSMAN 1611-020

(b) MILPERSMAN 1616-010

AUTHORITIES FOR OFFICER AND ENLISTED DETACHMENT FOR CAUSE (DFC): DFCs for chief petty officers and selected petty officers are conducted in accordance with reference (b). DFC for officers must be conducted in accordance with reference (a). In all cases, Commander, Navy Personnel Command (CNPC) is the approval authority.

GROUNDS: There are four reasons for requesting an officer DFC:

- Misconduct;

- Substandard performance involving one or more significant events (gross negligence or complete disregard);

- Substandard performance over an extended period of time after counseling or a letter of instruction (LOI); or

- Loss of confidence of an officer in command.

TIMING: Normally, DFC should be the option of last resort unless alternative measures are inadequate due to the nature of the circumstances. DFC will generally not be an option when:

- Reassignment of the officer within the command is possible;

- It is clearly being improperly used as a disciplinary action or in lieu of appropriate disciplinary action;

- The officer is in receipt of PCS orders and his/her relief is already on board; or

- Other available and reasonably effective alternatives exist within the command to resolve the situation.

DOCUMENTATION: Unsatisfactory performance over an extended period of time must be properly documented (e.g., LOIs). All allegations must be adequately supported by appropriate inquiry and documentation.

DISCIPLINARY ACTION: If disciplinary action and a DFC request are contemplated by the commanding officer, disciplinary action must occur first and then the $\mathrm{CO}$ may request a DFC of the officer in question. The CO may still request a DFC without disciplinary action if the CO believes that disciplinary action is not warranted or feasible at the time and it is imperative to remove the officer from the command. In cases where disciplinary action is not or cannot be taken first, the $\mathrm{CO}$ must provide an explanation of the circumstances in the DFC request sent to CNPC.

DETACHMENT PAPERWORK: The officer subject to DFC must be notified in writing that the $\mathrm{CO}$ is initiating a request and that it will appear in his official record. The officer must be given time (usually 15 days) to provide an written response to be included in the DFC request as it routes to CNPC. The officer may waive providing a response, but that waiver should me documented in writing.

NOTIFICATION: A commanding officer contemplating submitting a DFC request should notify $P E R S$ in advance that a DFC request is or may be forthcoming. 
SECTION VI:

COMMAND URINALYSIS PROGRAMS 


\section{REFERENCES:}

(a) OPNAVINST 5350.4D (series)

(b) SECNAVINST 5300.28E (series)

(c) MCO 5300.17

(d) Navy and Marine Corps Specimen Submissions for Steroid Testing

(e) Navy Alcohol and Drug Abuse Prevention Program Synthetic Drug Urinalysis Operating Guide (Apr 2012)

(f) MARADMIN 681/12

(g) NAVADMIN 082/12

POLICY: In accordance with references (a) through (g), wrongful use of drugs is inconsistent with USN and USMC policy. Commanders must be vigilant in ensuring a properly administered urinalysis program prevents and screens for the wrongful use of drugs.

COORDINATORS AND OBSERVERS: Command urinalysis program coordinators (UPC) must be designated as such in writing by their commanding officers (CO). Whenever possible, COs should assign officers of noncommissioned officers to be UPCs. Observers must also be used to ensure that tested Servicemembers provide actual specimens from their own body.

ATTENTION TO DETAIL AND SECURITY: The entire specimen collection process will be scrutinized in any court-martial or administrative separation board. For test results to be admissible there must have been a tight chain of custody and protection of samples after collection.

TESTING GOAL FOR USN: All USN personnel shall be tested at least once per fiscal year. The most effective means of accomplishing this goal is through unit sweep testing. There are three categories of unit sweeps:

- UNIT SWEEP: A unit sweep is the testing of an entire command or unit at once. Unit sweeps are (although no longer mandated), an effective detection and deterrence tool and are recommended for use by all commands. Commands may be subjected to up to five unit sweeps per fiscal year.

- SUB-UNIT SWEEP: Selection, random or otherwise, of an entire sub-unit or identifiable segment of a command. Examples of a sub-unit include an entire department, division, or watch section; all newly reported personnel; pay grade, or all personnel who surrender or are apprehended after an unauthorized absence. As a matter of policy, all newly reporting personnel shall be tested within 72 hours.

- END OF FISCAL YEAR TESTING: To ensure all USN personnel are tested annually, commands shall review all personnel onboard who were not tested during the course of the year and conduct an end of fiscal year unit sweep for all untested personnel.

TESTING GOAL FOR USMC: Every unit shall have an aggressive compulsory Urinalysis Testing Program, which ensures systematic screening of all Marines annually, regardless of rank, for the presence of drugs. Unites will test at least ten percent of their population monthly under the "IR" (random-selection) premise. All Marines reporting in from PCS and leave will be tested within 72 hours of their arrival or return.

24-HOUR UNAUTHORIZED ABSENCE (UA) AND SUB-UNIT TESTING: Commands may establish policies to test all Servicemembers returning from UAs longer than 24 hours as a sub- 
unit sweep. The policy should be in writing and enforced equally and consistently to all Servicemembers returning from UAs in excess of 24 hours.

\section{"FAILURE TO GO":}

- USN: If a Servicemember claims to be unable to provide a sample during the command's prescribed collection period, the Servicemember shall be turned over to the Master-at-Arms and remain under observation at all times until a sample is provided. If, after a period of 24 hours, the Servicemember still cannot provide a urine sample, the Servicemember shall be examined by a military medical authority to investigate the possibility of physiological or psychological problems. The examination should be completed the same day of the collection and documented in the Servicemember's medical record. If a failure to provide a sample is a chronic problem, the Servicemember shall be sent to a Branch Medical Clinic or Medical Treatment Facility for further observation.

- USMC: Should a Marine be unable to provide a specimen during the prescribed collection period or arrive after the collection period ends, the sample collection process will not be postponed. The coordinator will inform the Marine's commanding officer, who will determine a collection time for that individual. If a Marine submits less than 30 millimeters (one-third full), it is permissible to require the Marine to remain in a controlled area under observation, and to drink fluids normally consumed in the course of daily activity until such time as the Marine is able to provide a specimen or the balance of an incomplete specimen. In the case of an incomplete specimen, the unit coordinator will maintain custody of the incomplete specimen and designate an observer to witness that the bottle remains on the collection table until the given collection time has ended. If the Marine cannot provide the balance of the specimen in the same bottle at the end of the collection period, the bottle will be labeled, sealed by the individual and sent to the Department of Defense (DoD) certified laboratory with the collection. The urinalysis ledger will be annotated in the remarks that the specimen had, "minimum volume." No Marine Corps specimens will be discarded from a collection due to insufficient volume.

REFUSAL TO PROVIDE: A commissioned officer (but not the $\mathrm{CO}, \mathrm{XO}$, or legal officer) should give a direct order to provide a specimen. If the member continues to refuse to provide a sample, then appropriate administrative and/or disciplinary action may be taken.

POSITIVE RESULTS: A message report from the Navy Drug Screening Laboratory (NDSL) is official notification of lab test results and constitutes authority to take administrative and/or disciplinary action. Use of the results may be limited depending on the basis for testing. For example, command-directed fitness-for-duty urinalyses may not be used to punish a member nor used to give a Servicemember an other than honorable characterization of service (although the Servicemember may be processed for administrative separation.) Using all information available (including self-confession, urinalysis results, Substance Abuse Rehabilitation Program screening results, service records, and chain of command recommendations), the CO must make an initial decision on [ (See Appendix G - Use of Positive Urinalysis Results]:

- DETERMINE THAT THE SERVICEMEMBER IS A DRUG ABUSER. Determine that the Servicemember's positive urinalysis was the result of knowing drug use (e.g., the Servicemember was not prescribed medication that led to the positive urinalysis) and initiate mandatory administrative separation processing. Servicemembers diagnosed as drug dependent will be offered treatment prior to separation. 
- DETERMINE THAT THE SERVICEMEMBER IS NOT A DRUG ABUSER. Determine that the Servicemember's positive urinalysis was the result of unknowing drug use or a break in the chain of custody of the urine sample. In such cases, the positive urinalysis should not be considered a drug-abuse incident and no documentation is required. If the positive urinalysis is determined not to be a drug abuse incident, the command shall notify OPNAV (N135 and the command's immediate superior in command, echelon 2 or 3 via official correspondence of the circumstances that warranted such a determination.

NOTE: Only samples tested at a DoD certified lab or one of the three Navy drug labs can be used as evidence for punitive action or administrative discharge [see reference (a)].

STEROIDS: All USN and USMC units should forward specimens for steroid testing to the NDSL, San Diego at:

Navy Drug Screening Laboratory

34425 Farenholt Avenue, Suite 40

San Diego, CA 92134-7040

- Navy commands must request an authorization for steroid testing from BUPERS.

Requests must be on command letterhead and should be included with the submitted specimen(s). Specimens submitted for steroid testing analysis will not be tested for the standard DoD drug test panel unless specifically requested by the submitting unit. $A$ minimum of $60 \mathrm{ml}$ must be submitted for steroid testing. A minimum of $75 \mathrm{ml}$ must be submitted if the command also requests the standard DoD test panel. The NDSL, San Diego, will forward specimens to the University of California, Los Angeles (UCLA) Olympic Analytical Laboratory for steroid testing. Upon completion of testing, the UCLA laboratory will send the steroid drug test results to the NDSL, San Diego. NDSL, San Diego will transmit the steroid drug test results, via encrypted email (PKI), to the services' points of contact (POC) below. The service POC will transmit the steroid test results to the submitting unit.

\author{
USN POC: \\ Mr. Danny Lara \\ MPT\&E/N1351 \\ Navy Alcohol and Drug Abuse Program \\ Urinalysis Program Specialist \\ Email: danilo.lara@navy.mil \\ Phone: (901) 874-4240, DSN 882 \\ Fax: (901) 874-4228, DSN 882
}

\title{
USMC POC:
}

Mr. Eric Hollins

Headquarters, Marine Corps

Email: eric.c.hollins@usmc.mil

Phone: (703) 784-9526, DSN 278

Fax: (703) 784-9825, DSN 278

SYNTHETIC DRUGS: Limited testing may be available for certain chemical compounds of designer drugs. [See references (a), (f), and (g).] Commanders shall obtain authorization for testing for synthetic drug compounds from OPNAV N135F per reference (a). The command 
request letter (see reference (e) for a sample) must be forwarded to OPNAV N135F via email or fax:

Synthetic Drug Testing

Email: mill sdtestreq@navy.mil

Phone: (901) 874-4232, DSN 882

Fax: (901) 874-4228, DSN 882

- Reference (e) addresses the procedures for collecting, shipping, notifying, and reporting results from these urinalysis tests.

- For each positive sample: (1) NCIS and the command will be notified; (2) NCIS may open an investigation; (3) the command may take appropriate actions related to health, safety, and security based on a positive result; and (4) commanders may conduct further inquiry if misconduct is suspected [see references $(f)$ and $(g)$ ]. 
SECTION VII:

PHYSICAL

AND

MEANTAL HEALTH ISSUES 


\section{HIV ISSUES}

\section{REFERENCES:}

(a) SECNAVINST 5300.30E (series)

(b) SEVNAVINST 1850.4 (series)

(c) NAVMC 2904

(d) DODINST 6485.01 (series)

NOTIFICATION OF POSITIVE SCREENING: Results of a positive HIV screening must be provided to the Servicemember as well as all medical/dental record holders.

ASSESSMENT INTERVIEW: This health assessment of a Servicemember testing positive for HIV must be completed by a cognizant medical health authority, and include counseling on risk factors, transmission factors, and blood donation.

LIMITATIONS ON THE USE OF HIV INFORMATION: Information gained during initial medical assessments and interviews cannot be used against the Servicemember in a court-martial, nonjudicial punishment, involuntary administrative separation proceedings (for other than medical reasons), as a bar to re-enlistment, or as a basis for an adverse evaluation or fitness report.

CONFIDENTIALITY IS THE RULE: Any official with knowledge of a Servicemember's HIV status must handle this information with the highest degree of confidentiality. A Servicemember's health information shall not be released to anyone unless there is a demonstrated need to know. The Privacy Act and the Health Insurance Accountability and Portability Act also apply strict limitations on the release of any medical information, including information about a Servicemember's HIV status and overall health.

TRANSMISSION CONTROL: A Servicemember with laboratory evidence of HIV infection will receive training on the prevention of further transmission of HIV infection to others and the legal consequences of knowingly exposing others to HIV infection. Failure to comply with a "safesex" order may result in a violation of Articles 90 or 92 under the Uniform Code of Military Justice. Additionally, some courts-martial have upheld a violation of UCMJ Article 134 for conduct "to the prejudice of good order and discipline in the Armed Forces," and under UCMJ Article 128 for knowingly exposing or infecting others.

ASSIGNMENT OF MEMBER: Military personnel who are HIV positive and retained under reference (a) shall be assigned on a case-by-case basis in consultation with the treating medical provider and the respective personnel bureau (PERS-82 for USN and the Commandant for the Marine Corp (Manpower and Reserve Affairs) for USMC).

VOLUNTARY SEPARATION: Servicemembers may request voluntary administrative separation that within 90 days after official documentation of a diagnosis of HIV infection (e.g., when the Servicemember signs a medical board report confirming the HIV infection). The characterization of service for voluntary separation for this purpose will be either honorable or general (under honorable conditions) depending on the quality of the Servicemember's overall service. Administrative separations under this provision may be delayed for up to 180 days after the initial medical evaluation of HIV positive status to minimize staffing shortfalls.

INVOLUNTARY SEPARATION: Servicemembers who are HIV positive and who demonstrate medical conditions of immunologic deficiency, neurologic deficiency, progressive clinical or laboratory abnormalities associated with HIV, or and AIDS-defining condition will be assessed 
and potentially administratively processed involuntarily through the Disability Evaluation System in accordance with reference (b).

RESERVE NOTE: Reservists with HIV are not eligible for periods of active duty beyond 30 days except under the conditions of mobilization and pursuant a service decision by the Secretary of the Navy. Reservists who are HIV positive and not on extended active duty are not eligible for medical evaluation in military treatment facilities. 


\section{REFERENCES:}

(a) DODINST 6490.04

(b) DODINST 6490.08

POLICY: The Department of Defense (DoD) fosters a culture of support in the provision of mental health care and requires commands to do anything they can to dispel the stigma often associated with seeking mental health care.

MENTAL HEALTH REFERALS: Commanders and appropriate supervisors who in good faith believe that a subordinate Servicemember may require a mental health evaluation (MHE) are authorized to direct the Servicemember to a medical treatment facility for a MHE. A commanddirected MHE has the same status as any other lawful military order and failure to comply with the order can result in administrative or disciplinary action. Servicemembers may only be referred to a mental health provider (MHP) for a MHE for legitimate mental health reasons and never as reprisal. Under no circumstances may a commander or supervisor refer a Servicemember for a MHE as a reprisal for making or preparing a lawful communication to the chain of command, any inspector general, a member of Congress, or other appropriate person.

RULES: Reference (a) provides guidance about referring a member for a MHE. Commands should contact their local staff judge advocate (SJA) to ensure they are following up-to-date procedures for making a referral for a MHE. Reserve commands should seek guidance from the respective SJA supporting the reserve command. Reference (b) states that healthcare providers will not notify a Servicemember's commander when mental health care is obtained unless, under specific circumstances, that presumption is overcome; normally due to concern the Servicemember may harm him/herself, others, or the mission.

\section{COMMANDER'S RESPONSIBILITIES PRIOR TO MAKING A MHE REFERAL:}

- NON-EMERGENCY SITUATIONS: Advise the Servicemember that there is no stigma associated with obtaining mental health care. Direct the Servicemember to the MHP, providing the Servicemember with correct contact and location information for the medical treatment facility, and the date, time, and name of the MHP. If time permits, commands should consult a MHP before directing the referral to ensure that a referral is appropriate under the known circumstances. The order and logistical information directing a member to get a MHE evaluation should always be put in writing.

- EMERGENCY SITUATIONS: Focus on the immediate safety of the Servicemember and any others who may be at risk as necessary. Immediately direct and/or transport the Servicemember to a medical treatment facility. If time permits, alert the medical treatment facility that a Servicemember requires an emergency MHE. Document any actions associated with an emergency MHE referral to memorialize why the command directed a Servicemember for an emergency MHE.

SERVICEMEMBER'S RIGHTS IF ADMITTED TO THE HOSPITAL AS A RESULT OF A MHE: If involuntarily admitted to the hospital as a result of a MHE, the Servicemember has a right under appropriate hospital supervision - to contact a relative, friend, chaplain, attorney, an inspector general, or anyone else the member chooses.

WRONGFUL REFERALS: All allegations of improper MHE referrals are investigated by the Navy Inspector General and reported to the DoD Inspector General. 


\section{SECTION VIII:}

SEXUAL HARASSMENT,

FRATERNIZATION,

AND

HAZING 


\section{SEXUAL HARASSMENT RESPONSE}

\section{REFERENCES:}

(a) SECNAVINST 5300.26D (series)

(b) OPNAVINST 5354.1F (series)

(c) U.S. Navy Regulations

(d) NAVPERS 5454/2 Formal Complaint Form

(e) NAVPERS 15620 Informal Resolution Documentation

(f) MCO P5354.1D (series)

(g) MILPERSMAN 1910-233

(h) MCO P1900.16F (MARCORSEPMAN) 6210 (series)

\section{POTENTIAL REPORTING REQUIREMENTS}

- OPREP-3 NAVY BLUE for major incidents

- OPREP-3 UNIT SITREP for minor incidents

- Major criminal offenses, such as sexual assaults, shall be reported to NCIS (see NCIS Incident Reporting)

- Violent Crimes Message (see Violent Crime Reporting)

- Officer misconduct reporting requirements

SEXUAL HARASSMENT DEFINED: Sexual harassment is unwelcome sexual advances, requests for sexual favors, or other verbal or physical conduct of a sexual nature when: (1) made a term or condition of a person's employment status, pay, or career; (2) used as a basis for any job decision affecting that person; or (3) it interferes with an individual's work performance or creates a hostile or offensive work environment. Sexual harassment is a gender-neutral and sexual-orientation neutral concept.

INFORMAL RESOLUTION: Commanders should encourage the command and command members to use the Informal Resolution System prior to filing a formal sexual harassment complaint. [See reference (e).]

FORMAL COMPLAINT: Individuals who believe they have been the victim of sexual harassment should use reference (d), the Formal Complaint Form.

INVESTIGATION REQUIREMENTS: All formal complaints of sexual harassment will be processed according to the following procedures:

- WITHIN 24 HOURS: After receipt of a complaint and within 24 hours, the complaint must be presented to the commanding officer (CO). The alleged victim, alleged offender, and any witnesses must be offered services and informed of the complaint process in accordance with reference (d). Advocates shall be assigned to any involved parties unless a particular party to the complaint waives the services of an advocate. Any waiver of an advocate or any associated services under reference (d) shall be made in writing and/or annotated on the NAVPERS $5354 / 2$ form or by a memorandum for the record.

\section{- WITHIN 72 HOURS:}

o USN: The command shall initiate an investigation after receipt of the complaint. A naval message describing the situation, using the format found in OPNAVINST 3100.6J and as amended by enclosure (6) of reference (b), must be sent to the cognizant general court-martial convening authority (GCMCA), the command's 
echelon II immediate superior in the chain of command, CNO, and the USN Equal Opportunity Office.

o USMC: USMC commands shall notify the GCMCA that a complaint has been received and make every effort to initiate an investigation within 72 hours.

- WITHIN 14 DAYS: Complete the investigation or file a progress report within 20 days of commencement of the investigation and every 14 days thereafter until the investigation is complete. File a final command report with the GCMCA, including the results of the investigation and whether or not any administrative or disciplinary action was taken. If disciplinary action was taken, the actual punishment awarded should not be placed in the message. [See references (b), (d), and (h).]

PREVENT REPRISALS: Commands are urged to remove the alleged offender from the workspace if there is a reasonable possibility of further sexual harassment or reprisal by the alleged offender.

PRIVACY ACT CONSIDERATIONS: Commanders shall maintain the confidentiality of the personal information of all parties involved.

MENTAL HEALTH EVALUATION: Commands shall not order the alleged offender, the alleged victim, or any other related party for a Mental Health Evaluation unless the requirements of the Department of Defense mental health instruction have been met. [See Mental Health Evaluations.]

LEVEL OF INVESTIGATION: The CO determines the level of investigation required to adequately address a sexual harassment complaint based on the seriousness of the harassment alleged, the validity of the parties involved, and the magnitude of the incident on the parties involved and/or the command in general. COs shall ensure that the investigating officer appointed to inquire into the allegation is neutral and qualified. The investigating officer should be senior to the complainant and the alleged offender. It is advisable to consider an outside investigator if the command investigation would have the appearance of being partial to either the complainant or the alleged offender. All efforts should be coordinated by the command legal advisor. If the complainant and the alleged offender are from different commands, the $\mathrm{CO}$ of the alleged offender has the responsibility to conduct the investigation. [See Appendix FHandling Sexual Harassment Allegations]

DISCIPLINARY OR ADMINISTRATIVE ACTION: COs should take timely and tailored action when appropriate.

MANDATORY ADMINISTRATIVE SEPARATION PROCESSING: Per references $(\mathrm{g})$ and $(\mathrm{h})$, COs must process a Servicemember for separation if the substantiated sexual harassment involves:

- Actions, threats, or attempts to influence another's career or job in exchange for sexual favors; or physical contact of a sexual nature which, if charged as a violation of the Uniform Code of Military Justice, could result in a punitive discharge. 


\section{REFERENCES:}

(a) OPNAVINST 5370.2C (series)

(b) Marine Corps Manual 1100.4

(c) U.S. Navy Regulations

(d) UCMJ, Article 134

BACKGROUND: Unduly familiar relationships between seniors and subordinates are contrary to naval custom as they undermine respect for authority and erode the good order and discipline that is essential to the naval service's ability to accomplish its mission. Fraternization is prohibited and punishable under the Uniform Code of Military Justice. Being in a direct seniorsubordinate supervisory relationship or in the same chain of command is not a prerequisite for fraternization.

UNDULY FAMILIAR RELATIONSHIP DEFINED: There is no single definition of what constitutes an unduly familiar relationship. Except when a relationship is per se prohibited, such as in the case of officers and enlisted personnel for example, each relationship must be evaluated on a case-by-case basis. Examples of unduly familiar relationships should they occur for prescribed paygrades or positional relationships, include, but are not limited to: dating, shared living accommodations, intimate or sexual relations, commercial solicitations, private business partnerships, gambling, and borrowing money when such activities are prejudicial to good order and discipline or are of a nature to bring discredit on the naval service.

PREJUDICIAL TO GOOD ORDER AND DISCIPLINE: A relationship is prejudicial to good order and discipline when it results in circumstances which: call into question the senior Servicemember's objectivity; result in actual or apparent preferential treatment; undermine the authority of the senior member; or compromise the chain of command and/or the mission.

PROHIBITED RELATIONSHIPS (presumed to be prejudicial to good order and discipline):

- OFFICER/ENLISTED: Unduly familiar relationships between officers and enlisted Servicemembers and that do not respect differences in grade or rank.

- CHIEF PETTY OFFICER/JUNIOR ENLISTED: Personal relationships between chief petty officers and junior personnel (E-1 to E-6), who are assigned to the same command, that are unduly familiar and that do not respect differences in grade or rank.

E-1 to E-6 ENLISTED SERVICEMEMBERS OF DIFFERENT PAYGRADES: Personal relationships between two enlisted Servicemembers, both of which are in paygrade E-1 to E-6, are prohibited if:

- They are unduly familiar to the extent they do not respect differences in paygrade; and

- Are prejudicial to good order and discipline.

OFFICER RELATIONSHIPS: The same rule that applies to E-1 to E-6 enlisted Servicemembers of different paygrades applies to all officer paygrades.

STAFF AND INSTRUCTOR/STUDENT PERSONNEL: Personal relationships between staff or instructor Servicemembers and student personnel within training commands that do not respect differences in grade, rank, and/or the staff/student professional relationship are prohibited. 
RECRUITER/RECRUIT AND APPLICANT: Personal relationships between recruiters and recruits or applicants that do not respect the special professional relationship between them are prohibited. Such relationships by their very nature are prejudicial to good order and discipline.

RELATIONSHIPS WITH SERVICEMEMBERS OF OTHER ARMED SERVICES: The fraternization policy applies to all prohibited relationships between Navy members and other members, regardless of service. Multi-service commands must create clear policies because of differences in service regulations and customs.

GENDERL NUETRAL: The focus of the fraternization policy is on the detriment to good order and discipline and not on the gender of the parties involved.

SUBSEQUENT MARRIAGE: Parties that were in a relationship that constituted fraternization cannot cure the fraternization by marrying. Marriage does not excuse Servicemembers who were in a fraternizing relationship before they married, and they can still be held fully accountable with administrative or disciplinary means.

MARRIED MEMBERS: Will not be assigned to the same chain of command (consistent with the needs of the USN/USMC).

RESPONSIBILITY FOR PREVENTING FRATERNIZATION: The responsibility for avoiding fraternization rests primarily with the senior Servicemember in the relationship. However, both Servicemembers are accountable for their own conduct and both may be dealt with administratively or with disciplinary means.

ALLEGATIONS: All allegations of fraternization must be promptly investigated, and commanders should take appropriate administrative and disciplinary action. [See Appendix IHandling Fraternization Allegations] 


\section{HAZING PREVENTION}

\section{REFERENCES:}

(a) SECNAVINST 1610.2A (series)

(b) OPNAVINST 3100.6J (series)

(c) MCO 1700.28B (series)

(d) OPNAVINST 3120.32J

(e) ALMAR 045/03

(f) SECNAVINST 5800.11B

(g) MCO 3504.2

POLICY: Commands must regularly emphasize the wrongfulness of hazing, take steps to proactively train Servicemembers to avoid hazing incidents, and immediately investigate allegations of hazing.

PREVENTION: Requires continues education and awareness from command leadership. Use the definition and examples below in that regard. The listing below is not all inclusive and other known examples should be included and discussed within commands as a preventative measure. Hazing may be indicative of larger command climate concerns and, therefore, must be taken seriously and dealt with promptly. At the command level all hazing incidents shall be tracked by the assigned Command Managed Equal Opportunity program manager(s), Equal Opportunity Advisors, and Equal Opportunity Program Managers.

HAZING DEFINITION: Hazing is defined as any conduct whereby a military member or members, regardless of service or rank, without proper authority causes another military member or members, regardless of service or rank, to suffer or be exposed to any activity which is cruel, abusive, humiliating, oppressive, demeaning, or harmful. Soliciting or coercing another to perpetrate any such activity is also considered hazing. Hazing need not involve physical contact among or between military members; it can be verbal or psychological in nature. Actual or implied consent to acts of hazing does not eliminate the culpability of the perpetrator(s). Whether an individual consents or volunteers is totally immaterial; no Servicemember may consent to acts of hazing being committed upon them.

SPECIFIC EXAMPLES THAT ARE CLEARLY PROHIBITED: "Tacking On" promotions or warfare insignia; initiations that have not been approved and are unsupervised by the chain of command; handcuffing or physically securing Servicemembers to fixed or movable objects; taping or tying a Servicemember's arms or legs; forced/non-consensual cutting or shaving of hair; forced or non-consensual removal of clothing; "red bellies"; placing or pouring liquid or foreign substances on a person or their property; requiring a person to consume substances or food, especially food not normally prepared or suitable for consumption; sabotaging personal property of another to cause even minor injury or damage; any horseplay or minor assault upon the person of another; or any other act that could even remotely subject a person to injury, ridicule, or degradation.

HAZING DOES NOT INCLUDE: Command-authorized or operational activities, the requisite training to prepare for missions or operations; administrative corrective measures employed lawfully, extra-military instruction employed lawfully; athletic events; command-authorized physical training; lawful contests or competitions; and other similar activities that are lawful and authorized by the chain of command. 
INITIATIONS AND SPECIAL CEREMONIES: Must be approved by the chain of command. Specific guidance is contained in reference (d). At a minimum, such events must contain the following:

- The $\mathrm{CO}$ or his/her direct representative shall be personally involved in the planning and execution of the event;

- Glamorization of alcohol or alcohol abuse by event participants and guests shall not be tolerated;

- Sexually suggestive activities, props, costumes, skits, gags, or gifts are prohibited;

- Personal, ethnic, and religious beliefs of those in attendance shall be respected;

- There will be no coercion of Servicemembers to participate. Any participation by principals or guests shall be strictly voluntary; and

- Proper medical screening of participants (when appropriate to the activity or individual involved) and compliance with health, safety, and environmental regulations shall be a part of the event planning.

INVESTIGATIONS: When an allegation of hazing is made, commanders must initiate an investigation within 24 hours. It is highly recommended that commanders document the investigation as well as any remedial actions taken, including a command climate survey.

SUPPORTING THE ALLEGED VICTIM: Alleged hazing victims and witnesses shall immediately be advised of their rights and offered legal assistance, medical assistance, and counseling, as necessary. Commanders shall ensure that alleged victims/witnesses are advised and given access to victim/witness advocacy services in accordance with reference (f).

REPORTING REQUIREMENTS: Substantiated incidents of hazing must be reported via OPREP-3 NAVY BLUE to CNO or CMC. An update via SITREP must be sent every 30 days until final command administrative and/or disciplinary action is taken. [See references (a) through (c).] 
SECTION IX:

\section{FREEDOM OF EXPRESSION}


REFERENCES:

(a) First Amendment, U.S. Constitution

(b) DODINST 1325.06

(c) SECNAVINST $5720 \mathrm{C}$ (series)

(d) DODINST 1300.17

(e) SECNAVISNT 1730.7 (series)

(f) DODINST 4105.70

(g) OPNAVINST 1620.2A

(h) MCO 1620.2D

(i) DOD Directive 1344.10

(j) NAVADMIN 110/06(i)

(k) MARADMIN 029/10

(l) MARADMIN 207/13

COMMANDERS' BALANCING TEST: Constitutional rights involving freedom of expression should be preserved to the maximum extent possible, consistent with mission accomplishment, security, and good order and discipline. [See reference (b).]

NO CONTEMPTUOUS WORDS OR PHRASES: Article 88 of the Uniform Code of Military Justice prohibits officers from being disrespectful to senior government leaders (e.g., the President of the United States, the Vice President, members of Congress, the Secretary of Defense, the Secretary of the Army, etc.)

PORNOGRAPHY: The presence of pornography on a military installation can be strictly limited.

- Private possession can be prohibited overseas on a military installation.

- Private possession in CONUS is generally permissible (except for child pornography).

- No sexually explicit material may be offered for sale or rental on property under Department of Defense control, and no member of the Armed Forces or DoD civilian officer or employee, acting in his/her official capacity, shall offer for sale or rental any sexually explicit material. [See reference (e).]

HANDBILLS, POSTERS, LEAFLETS, NEWSLETTERS, PAPERS, NOTICES, ETC.: The commanding officer $(\mathrm{CO})$ of a unit can and should require prior approval before distribution. The balancing test detailed above should be applied in a content-neutral manner, which means assessing whether the content of the communication is inconsistent with mission accomplishment, security, and good order and discipline, and taking consistent action with respect to other similar communications. A commander cannot allow or prohibit certain content or communications based solely on whether he/she personally agrees or disagrees with the substance of the message.

MANDATORY PUBLIC AFFAIRS OFFICER/SECURITY REVIEW: A review is required for any publication written by a military Servicemember that pertains to military matters. A commander should coordinate such a review with the local public affairs officer and security personnel if necessary. [See reference (b).]

ON-BASE GATHERINGS: A commander shall prohibit on-base gatherings if the gathering presents a clear danger to loyalty, morale, good order and discipline, or interference with mission accomplishment. This requirement shall be applied evenly and fairly with respect to any gathering that presents such a threat. 
OFF-BASE GATHERINGS: The attendance of a Servicemember at an off-base gathering may be prohibited if:

- The Servicemember is on duty;

- The event is in a foreign country, and the gathering is illegal or if violence is likely to occur; and

- The Servicemember may be prohibited from wearing a military uniform at the gathering if he/she is allowed to attend.

OFF LIMITS: A CO may declare places temporarily off limits to Servicemembers in emergencies until the Armed Forces Disciplinary Control Board (AFDCB) or Area Coordinator can act. Reasons for declaring places off limits include, but are not limited to: when there is a clear danger to loyalty; morale; good order and discipline; interference with mission accomplishment; adverse effect upon the health, safety, welfare, and morale of Servicemembers or their family members; or when the place put off limits has engaged in discriminatory practices.

- OVERSEAS: An overseas CO has much greater discretion and authority to place areas off limits on a longer-term basis. Overseas COs are advised to consult with their immediate superiors in command regarding the existence of an area off-limits policy or if the $\mathrm{CO}$ intends to place an area off limits on a long-term basis.

UNIONS AND UNION-LIKE ACTIVITY: Military Servicemembers are not permitted to form unions, engage in strikes or slowdowns, or picket military authorities.

MEMBERSHIP IN SUPREMACIST OR EXTREMIST GROUPS: Active participation in such organizations or conduct in furtherance of their stated goals is prohibited. Active participation includes, but is not limited to: publicly demonstrating or rallying with the group or on its behalf; fundraising; recruiting and training new members; organizing or leading such organizations; or otherwise engaging in activities in furtherance of such organizations that are viewed by the Servicemember's command to be detrimental to good order, discipline, morale, or mission accomplishment. Essentially, any activity greater than mere membership in the organization possibly constitutes active participation and commanders may take appropriate administrative and/or disciplinary action. It is recommended to consult with a staff judge advocate should this issue arise.

- ADMINISTRATIVE SEPARATION: A Servicemember shall be processed for administrative separation if his/her active participation in a supremacist or extremist organization is substantiated by his/her $\mathrm{CO}$ or higher authority.

RELIGIOUS ACCOMODATION: It is DoD policy to accommodate religious practices to the greatest extent possible consistent with mission accomplishment, security, and good order and discipline. Commanders must consider a request for religious accommodation and either grant or recommend denial of it based on the totality of the circumstances. A request for religious accommodation may only be denied if there is a compelling governmental reason, such as security, health, good order and discipline, mission accomplishment, and there are no lesser means of restricting the practice in question. Requests must be considered in the context in which they are asked. A request that is granted based on the current assignment and duty station of the requestor does not grant blanket and indefinite approval for the religious accommodation. When the requestor changes assignments or duty stations he/she must rerequest the accommodation if so desired. Likewise, if any circumstances change during a current assignment for which a request for religious accommodation has been granted, then the $\mathrm{CO}$ may recommend terminating the accommodation or re-considering its appropriateness 
under the circumstances. Recommendations to deny requests for religious accommodation will be elevated to the Chief of Navy Personnel for USN and the Commandant for the Marine Corps (Manpower and Reserve Affairs) for USMC. [See references (d) and (i).] In addition, accommodation requests that would require a waiver of service regulations require the same level of approval authority.

\section{TATTOO POLICY:}

- USN:

o No tattoos on the face, neck, scalp, or anywhere on the head.

o Tattoos on the body shall not be visible through white uniform clothing.

0 Any tattoo otherwise permitted must not be prejudicial to good order and discipline or service discrediting; contain sexually explicit depictions or words; exhibit discrimination due to ethnicity, race, national origin, gender, or religion; and/or contain supremacist or extremist content.

o If a tattoo is exposed in a short-sleeve uniform shirt, it shall not be any larger than the hand with fingers extended with the thumb touching the base of the index finger.

- USMC:

o No tattoos on the head or neck.

o No "sleeve tattoos" (ones that cover or almost cover the entire arm or leg).

o No "half-sleeve" or "quarter-sleeve" tattoos (ones that cover or almost cover above or below the elbow or knee) visible to the eye when wearing standard physical training gear.

o No service discrediting tattoos or tattoos that contain sexist, racist, vulgar, antiAmerican, anti-social, gang-related, or extremist content.

- Members may be "grandfathered" in if an otherwise objectionable tattoo existed prior to promulgation of the current tattoo policies. Commanders should ensure that a page 11 or page 13 entry is made memorializing the grandfathering. [See references $(g)$ and $(h)$ for more guidance.] 
SECTION X:

GRIEVANCE PROCEDURES 


\section{REFERENCES:}

(a) U.S. Navy Regulations, Articles 1150 and 1156

(b) UCMJ, Article 138

(c) JAGMAN, Chapter III

(d) MCO 1700.23F (series)

(e) NAVMC Directive 1700.23F (series)

REQUEST MAST: Members of the naval services have the right to communicate directly with their commanding officer ( $\mathrm{CO}$ ) at a proper time and place as determined by the $\mathrm{CO}$. No one may force the Servicemember to reveal the matter that he/she wishes to discuss with the CO.

- COs should encourage individuals to request mast in order to resolve matters at the lowest level in the chain of command. Once a request for mast is submitted, all levels of the chain of command should work to resolve the issue. Only the individual who requested mast may withdraw the request. If the Servicemember withdraws the request, the fact he/she withdrew it and the reason for it should be documented and preserved.

- Requesting mast is an individual right; however, reference (a) prohibits members from joining together to protest or complain. In the Navy, the Sailor may request mast up to his/her CO. In the USMC, a Marine may request mast with any officer in his chain up to the commanding general.

U.S. NAVY REGULATIONS, ARTICLE 1150 COMPLAINTS: An "Article 1150" complaint is a formal complaint that may be submitted against any superior, inside or outside the chain of command. However, a Servicemember may not file an Article $1150 \mathrm{complaint}$ against his/her CO. Complaints against a Servicemember's CO will be submitted as Uniform Code of Military Justice, Article 138 complaints.

\section{- PROCEDURE:}

o SAME CHAIN OF COMMAND: If the superior against whom the complaint is filed is in the same chain of command as the complaint, then their common $\mathrm{CO}$ will handle the complaint. If the matter is satisfactorily resolved, there is no need for the $\mathrm{CO}$ to report the matter to higher authority. However, if the complainant is not satisfied with the outcome, he/she may submit an Article 138 complaint against the $\mathrm{CO}$.

o SEPARATE CHAINS OF COMMAND: If the superior is not in the same chain of command as the complainant, the complaint shall be forwarded via the complainant's $\mathrm{CO}$, the respondent, and the respondent's $\mathrm{CO}$, to the officer exercising general court-martial convening authority (GCMCA) over the respondent. The GCMCA is required to look into the matter and make appropriate determinations and actions to resolve it.

ARTICLE 138 COMPLAINTS: These complaints can be submitted only by a complainant against his/her current $\mathrm{CO}$. Before submitting an Article 138 complaint, the complainant must first seek redress from the $\mathrm{CO}$ to resolve the matter. If the $\mathrm{CO}$ fails to take action on the request for redress or does not redress the matter to the satisfaction of the complainant, the complainant may then submit an Article 138 complaint against the CO.

\section{- PROCEDURE:}

o The complainant must submit the complaint within 90 days of discovering the alleged wrong. Failure to do so may result in the complaint being returned and 
not considered for timeliness. However, the GCMCA that considers the complaint may still act on it and waive the timeliness defect.

o The complaint must be routed through the $\mathrm{CO}$ against whom the complaint is made. The $\mathrm{CO}$ has 30 days to respond to the complaint and forward it to his/her GCMCA.

o The GCMCA may conduct any further investigation required to determine whether or not some or all of the complaint has merit and whether or not to grant some or all of the requested relief. Immediately upon receipt of the complaint, the GCMCA must notify the Office of the Judge Advocate General (OJAG) Code 13 (Administrative Law Division) for tracking purposes.

o Once the GCMCA acts on the complaint, the determination and actions of the GCMCA will be reviewed by Code 13. If some or all of the complaint is found lacking merit or some or all of the requested redress is denied, the complaint will be forwarded to the Secretary of the Navy (SECNAV) for final determination. SECNAV has delegated authority for acting on Article 138 complaints to the Assistant SECNAV (Manpower and Reserve Affairs).

o A complaint may be withdrawn in writing by the complainant at any time.

o All complaints, whether acted upon or withdrawn, must be maintained for two years.

[See Appendix J - Complaints of Wrong Commanding Officer Checklist]

RETALIATION PROHIBITED: Federal law prohibits anyone from taking any retaliatory action against a Servicemember for communicating to a court-martial, participating in an investigation (including those associated with Article 1150 and Article 138 complaints), or for any communication regarding sexual assault in any context. 


\section{REFERENCES:}

(a) SECNAVINST 5370.5B (series)

(b) SECNAVINST 5370.7D (series)

(c) DOD Directive 7050.06

(d) MCO 5370.8

DoD Fraud, Waste, and Abuse Hotline: 1-800-424-9098

Navy Inspector General (NAVIG): 1-800-522-3451; NAVIG is the "eyes and ears" of the Secretary of the Navy, the Chief of Naval Operations, and the Commandant of the Marine Corps.

- Echelon II commanders are responsible for written internal procedures for processing hotline referrals at appropriate levels within the chain of command.

- There is a mandatory requirement to post information on DoD/USN/USMC Hotline programs on command bulletin boards and other public spaces viewable to command members.

- Commanders are directed to encourage and support reporting of fraud, waste, and abuse throughout all levels of command; military and civilian.

INVESTIGATION PROCEDURES: If a command is tasked with conducting an investigation into a complaint, the commanding officer (CO) must ensure standards of independence, completeness, timeliness, and accountability are met. At a minimum, the $\mathrm{CO}$ must implement the following procedures:

- Assign an impartial investigator, outside and independent of the operation or individual specified in the complaint.

- Ensure all questions or issues raised in the complaint are satisfactorily answered;

- Adhere to any due dates from the IG for completing the report and routing it through the chain of command.

- Take appropriate remedial measures in the form of disciplinary and/or administrative action and training if needed to correct the issue(s) raised in the complaint.

- Retain the investigative materials and documentation of remedial action for two years.

- Use the NAVIG Investigations Manual or the USMC IG Assistance and Investigations Manual as a guide for the investigation.

- The confidentiality of the informant is a must.

- NO REPRISAL can ever be taken against a known or suspected informant.

WHISTLEBLOWER PROTECTION ACT (10 U.S.C. § 1034): This act prohibits reprisal or taking or threatening to take any unfavorable personnel action or withholding or threatening to withhold any favorable personnel action, because an employee makes or prepares to make a lawful communication to a Member of Congress, an IG, or any other person designated by regulations or established administrative procedures for such communications. Violations of this act are punishable under the Uniform Code of Military Justice and a basis for disciplinary action against civilian employees. The contents of this act and implementing regulations (reference (b)) must be published on the command bulletin board. 


\section{CONGRESSIONAL INQUIRIES}

\section{REFERENCES:}

(a) MILPERSMAN 5216-010

(b) SECNAVINST 5215.5 (series)

(c) U.S. Navy Regulation 1155

(d) SECNAVINST $5730.5 \mathrm{~J}$ (series)

(e) JAGMAN

RIGHT TO COMMUNICATE: No person may restrict any Servicemember from communicating with Congress in the Servicemember's personal or private capacity. Absolutely no reprisal actions may be taken for such a communication.

PRIVACY ACT CONCERNS: In responding to a Member of Congress, the responder must ensure that any personal information about the Servicemember included in the response is releasable information. Privacy Act waivers may need to be obtained by the command prior to sending a response.

CORRESPONDENCE: Each Congressional inquiry should receive a prompt, courteous, and complete reply. The reply should be accurate even though the nature of the reply may be unfavorable to the command or service. A final or interim reply MUST be sent to the Congressional office initiating the inquiry within five working days of receipt, which may also include routing the response through the chain of command and through the Office of Legislative Affairs. Time must be allocated to account for desired internal Department of the Navy (DON) review of the inquiry and any response sent in reply.

USN: DON activities contacted directly by Members of Congress are responsible for replying directly on routine and non-policy matters. Copies of both incoming and outgoing correspondence resulting from direct contact with Members of Congress shall be provided to the Chief of Legislative Affairs or Navy Appropriations Matters Office as appropriate.

USMC: All Congressional inquiries should be immediately forwarded by fax to the Office of Legislative Affairs at (703) 614-4172/4768 or DSN 224-4172.

INFORMING CHAIN OF COMMAND: Check local instructions from senior commanders for reporting requirements and processing of Congressional inquiries. 
SECTION XI:

INFORMATION ACCESS 
REFERENCES:

(a) SECNAVINST $5720.42 \mathrm{~F}$ (series)

(b) SECNAVINST 5820.8A (series)

(c) 32 CFR Part 701

(d) 5 U.S.C. $§ 552$

RESOURCES: USN FOIA online: www.foia.navy.mil; USMC http://hqinet001.hqmc.usmc.mil/FOIA/index.htm

ACCESS TO RECORDS: FOIA gives all persons (including foreign citizens and governments) a right to access government "agency records" unless such records are specifically exempted from disclosure. Records include information maintained in an electronic format. Requestors of information must indicate that they are seeking information pursuant to FOIA.

EXEMPTIONS: If there is any question about whether a record must be released, the record must be forwarded with the FOIA request seeking it to the Initial Denial Authority (IDA). The IDA will determine whether the record must be released or whether it should/must be withheld from the requestor. Some of the specific exemptions under FOIA include:

- Classified information;

- Purely internal rules and procedures;

- Memos containing internal advice and recommendations (pre-decisional);

- Records which contain personal and private information (e.g., personal medical and service records; mailing lists containing names and/or addresses of military personnel or civilian employees, regardless of their duties, of the Department of Defense, etc.); or

- Law enforcement records or records of ongoing investigations.

IDAs: Generally, only an IDA may deny release of a properly requested record. IDAs are typically Flag/General Officers or officers exercising general court-martial convening authority.

FEES: Requestors may be charged fees for production of requested records. Details as to fees and fee waivers are set out in reference (b), enclosure (3). Note that typically a total fee of $\$ 15.00$ or less is waived.

TIME LIMITS: The proper recipient of a FOIA request must respond within 20 working days. A command may obtain an informal extension from the requestor or a formal request for an extension from the IDA.

SPECIAL RECORDS: Certain FOIA requests require special handling. Requests for the following must be forwarded to the appropriate custodian of the record:

- Naval Criminal Investigative Service reports;

- Inspector General reports;

- Court-martial records;

- Mishap or safety reports;

- Nuclear information; and

- Medical quality assurance reports.

ANNUAL REPORTING AND TRACKING: FOIA action officers must track all FOIA cases and all reimbursable fees. Use DD Form 2086 for all FOIA requests [see reference (b)]. Such 
records will also help in submitting annual FOIA reports. Echelon II IDAs are required to collect annual FOIA reports no later than 25 October of each year.

REQUESTS FOR INFORMATION RELATED TO LITIGATION: If the FOIA request (or any other request for information) is believed to be related to litigation in which the government is or might become a party, notify the local USN Region Legal Service Office, USMC Legal Services Support Section, and the Office of the Judge Advocate General (Code 15 - General Litigation) at (202) 685-5450 or DSN 325-5450. 
REFERENCES:

(a) JAGMAN

(b) SECNAVINST 5211.5E (series)

(c) DONCIO MSG $171952 Z$ APR 07

(d) DONCIO MSG 30154Z NOV 06

(e) MARADMIN 162/10

(f) DODI 1000.30

RESOURCES: USN Privacy Act online website: http://privacy.navy.mil; USMC guidance is contained in reference $(e)$.

PURPOSE: The Privacy Act limits the government in collecting personal information that will be stored in a "system of records," and permits individuals access to information in such systems that contain personal information about them, unless specifically exempted from disclosure.

DENIAL AUTHORITIES: Only a proper "denial authority" may deny release of a properly requested record. Denial authorities are typically Flag/General Officers or officers exercising general court-martial convening authority.

PRIVACY ACT WARNINGS: These warnings are required when someone from the command is requesting personal information (e.g., social security numbers, phone numbers, addresses, etc.), which will then be stored in a system of records (e.g., personal or medical files, training records, JAGMAN investigations, etc.) [See reference (a) for sample Privacy Act warning forms.]

INDIVIDUAL ACCESS TO FILES: In most cases, an individual may access any record that contains personal information about them. However, there are exceptions to this rule and the personal information about others that may be contained in the same record will need to be protected.

THIRD PARTY ACCESS TO FILES: In most cases, a third party may not access any record that contains personal information about someone else. There are some exceptions, including, but not limited to:

- Internal release within an agency ("need to know");

- Routine uses as defined in the system of records notice (located at http://privacy.navy.mil);

- Statistical research;

- Law enforcement activity; and

- Congressional inquiries (where made on behalf the individual about whom the information is sought).

PRIVACY ACT REQUESTS: Privacy Act requests are to be acknowledged within 10 working days by the system manager and acted upon within 30 working days. Requestors can appeal denials of release of information within 60 calendar days to the appropriate denial authority [see reference (b)].

TRACKING: For each record disclosed to a party outside the Department of Defense (DoD) in response to a Privacy Act request, document such release with a "Disclosure Accounting Form" 
- OPNAV Form 5211/9, which is contained in reference (b) and available on the Navy Privacy Act website.

REDUCTION OF SOCIAL SECURITY NUMBER (SSN) USE: Reference (f) mandates that DoD personnel shall reduce or eliminate use of SSNs wherever possible. The use of partial SSNs (e.g., "last four") is included in this mandate. [See enclosure (2) of reference (f) for acceptable uses of the SSN.]

PII BREACHES: Actual or possible loss of control, unauthorized disclosure, unauthorized access, and wrongful release of PII must be reported within one hour to the Department of the Navy Chief Information Officer (DONCIO) or to the USMC Public Affairs Officer. Within 24 hours, DONCIO will instruct on whether to notify the affected individuals. If DONCIO directs notification, the affected individuals must be notified within 10 days. See http://www.doncio.navy.mil for additional guidance. 


\section{REFERENCES:}

(a) DoD 6025-18R

(b) DOD 8580.02R

(c) 45 CFR, Part 160

RESOURCES: The Department of Defense (DoD) provides information regarding HIPAA and implementing regulations within the department on the following website:

http://www.tricare.mil/tma/privacy/hipaa.aspx.

PURPOSE: HIPAA, among other things, is intended to strictly protect personal health information and to prohibit its release unless specifically authorized by the Servicemember or pursuant to law or regulation. Unlike with the Freedom of Information Act, where the presumption is information is freely accessible, under HIPAA, the presumption is that medical information is NOT accessible. A specific authorization must exist for medical information to be released to anyone but the Servicemember in question.

APPLICABILITY: HIPAA applies to health care providers who generate protected health information about patients. Health care providers cannot release protected health information unless authorized. Even when there is an exception which authorizes release, only the minimum necessary information may be released for the specific, appropriate purpose for which it is sought.

NOTE: Even if HIPAA is not applicable to specific health information or other personal information about a Servicemember, the Privacy Act may still apply and prohibit release absent a compelling reason and an authorized exception permitting limited release. Once protected health information has been released to a command, HIPAA no longer applies; however, the Privacy Act may apply and act to prohibit commands from further releasing protected health information without consent or a legal authorization. Never release protected health or other personal information without consulting with a judge advocate.

APPROPRIATE RELEASES OF PROTECTED HEALTH INFORMATION: Protected health information may be released to the following persons and for the following reasons:

- To the individual Servicemember;

- For routine uses within an agency; for example, to facilitate medical treatment, payment, record keeping, and other necessary health care purposes pursuant to law and regulation; or

- To the Commanding Officer (CO) of a Servicemember only to the extent necessary to determine fitness for duty or to carry out any other activity necessary to the proper execution of the mission.

o HIPAA and service regulation provide the $\mathrm{CO}$ or his/her written designee with the ability to obtain medical information on Servicemembers within his/her command. 
SECTION XII:

RELATIONS WITH CIVILIAN AUTHORITIES 


\section{CIVILIAN JURY DUTY}

\section{REFERENCES:}

(a) SECNAVINST 5822.2 (series)

(b) 28 U.S.C. $\S 1863$

(c) 10 U.S.C. $\S 982$

AUTOMATIC FEDERAL COURT EXEMPTIONS FOR JURY DUTY: Reference (b) exempts all active-duty members from serving on federal juries.

AUTOMATIC STATE COURT EXEMPTIONS FOR JURY DUTY: Flag officers, general officers, commanding officers (CO), Servicemembers assigned to operating forces, those in a training status, and those outside the continental United States are exempt from serving on state juries [see reference (a)].

DISCRETIONARY STATE COURT EXEMPTIONS FOR JURY DUTY: Officers with authority to convene special courts-martial (SPCM) may exempt members from state/local juries if jury duty would:

- Unreasonably interfere with performance of their duties; and/or

- Adversely affect readiness of the command as a whole

PROCESS FOR OBTAINING A DISCRETIONARY JURY DUTY EXEMPTION: The CO should sign a written letter to the appropriate state official (e.g., the clerk of the court) notifying the official that the $\mathrm{CO}$ is exempting the Servicemember from jury duty for one of the aforementioned reasons.

OIC OR CO WITHOUT AUTHORITY TO CONVENE SPCM: An OIC or CO without the authority to convene a SPCM who wishes to exempt a Servicemember from jury duty should forward a request for the exemption with a justification as soon as possible to an officer in the chain of command who has the authority to convene a SPCM.

MEMBERS WHO ARE AVAILABLE FOR JURY DUTY: Such members may fulfill their jury duty obligations and shall not be charged leave or lose any other entitlements during their period of jury duty service.

FEES AND REIMBURSEMENTS: All fees accrued to Servicemembers for jury duty are payable to the U.S. Treasury and may not be retained by the Servicemember. Servicemembers are entitled to, and may retain, any reimbursement from the state or local jury authority for actual expenses incurred in the performance of jury duty. 
REFERENCES:

(a) 10 U.S.C. $\S 814$

(b) OPNAVINST 5100.12 (series)

(c) 10 U.S.C. $\S 1382$

(d) U.S. Navy Regulations, Article 0822

\section{JURISDICTION OVER CRIMES BETWEEN MILITARY AND CIVILIAN AUTHORITIES (military installations may have different types of jurisdiction arrangements):}

- EXCLUSIVE: The federal government has exclusive authority to make and enforce local laws. Civilian misconduct may be prosecuted in federal court. The local USN or USMC legal office will have a Special Assistant U.S. Attorney to prosecute civilian offenses on federal installations. Minor driving infractions are usually handled in an installation traffic court [see reference (d)].

- CONCURRENT: State and federal governments have equal authority to make and enforce local civilian laws. The Department of the Navy or civilian law enforcement may respond to an incident, and either may pursue prosecution over the alleged military or civilian offender. Each base or installation must have a memorandum of understanding with local civilian law enforcement agencies regarding issues pertaining to roles, responsibilities, jurisdiction, and criminal prosecution.

- PROPRIETARY: The federal government is merely a tenant on the land and retains no power to make or enforce local laws. State law controls, and state law enforcement normally makes all arrests. Prosecutions will occur in state courts. Active-duty Servicemembers may also be prosecuted in state court for traffic violations and other crimes. Civilian prosecution will not necessarily preclude disciplinary action and punishment under the Uniform Code of Military Justice (UCMJ) for the same offense.

THE TYPE OF JURISDICTION DOES NOT AFFECT ENFORCEMENT OF THE UCMJ OVER MILITARY PERSONNEL: The UCMJ applies in all places and at all times to all active-duty personnel. On installations with concurrent or proprietary jurisdiction, a violation of the UCMJ might also be a violation of local law, which means military personnel could be prosecuted in state court. Again, state court prosecution is not necessarily a bar against military punishment under the UCMJ.

\section{MILITARY DETENTION OF CIVILIANS FOR DELIVERY TO CIVILIAN AUTHORITIES:}

Regardless of the type of jurisdiction, commanding officers may not confine civilians but may detain them for a reasonable time until civilian law enforcement assumes physical custody of the individual. In the event that a $\mathrm{CO}$ is asked to detail a civilian, immediately notify the Naval Criminal Investigative Service.

DELIVERY OF MILITARY PERSONNEL TO CIVILIAN AUTHORITIES: Pursuant to reference (a) and under such regulations the Secretary of the Navy may prescribe, a Servicemember accused of an offense against civilian authority may be physically detained and delivered, upon request, to civil authorities for trial. [See Appendix $M$ - Delivery of Personnel]

BARRING OF CIVILIANS: Civilians who commit misconduct or who present a threat to good order and discipline on the base may be barred by the base $\mathrm{CO}$ from entering the installation. The installation $\mathrm{CO}$ must issue a written order barring the individual from entering the installation. Those who violate the order may be tried in federal court, fined, and imprisoned. [See reference $(c)$ ]. 
REFERENCES:

(a) 18 U.S.C. $\S 1385$

(b) SECNAVINST 5820.7 (series)

(c) JAGMAN, Chapter VI

REPORTING AND REIMBURSEMENT REQUIREMENT: If Department of the Navy (DON) assets are requested by civilian law enforcement agencies, permission to use those assets must come from the Secretary of the Navy (SECNAV) or SECNAV's designee. If approved, the DON will recover the cost of the DON assets used by civilian law enforcement.

POSSE COMITATUS ACT (PCA): The PCA is a federal law that makes it unlawful for the Army or Air Force to willfully execute and enforce civilian domestic laws without authorization from Congress. DOD/DON policy applies the PCA to USN and USMC. The PCA is not applicable to the Coast Guard. Willful violations of the PCA are criminal offenses.

EXAMPLES OF PROHIBITED ACTIVITIES: DON personnel may not assist civilian law enforcement agencies or personnel by participating in:

- The interdiction of a vehicle, vessel, or aircraft;

- A search and seizure;

- An arrest, apprehension, stop and frisk, or similar activity;

- Surveillance or pursuit of individuals; and

- Investigations, interrogations, or undercover operations.

\section{EXAMPLES OF PERMITTED ACTIVITIES:}

- Investigations of violations under the Uniform Code of Military Justice;

- Protection of classified information or equipment;

- Use of equipment/facilities with appropriate approval;

- Suppression of insurrection and U.S. domestic violence/disturbances;

- Protection of the President, Vice President, and other dignitaries;

- Maintenance of loaned equipment;

- Training and expert advice on operation of equipment; and

- Support necessary during chemical/biological emergencies.

APPLICATION: The PCA only applies to active duty personnel while in a duty status or when acting in an official capacity.

\section{DETENTION OF A SERVICEMEMBER FOR DELIVERY TO CIVILIAN AUTHORITIES:}

Military authorities may detain a Servicemember, even in confinement if necessary, only for a reasonable time to facilitate the prompt turnover of the Servicemember to civilian authorities.

Civilian authorities must have a warrant or reasonable belief that the Servicemember committed a civilian offense.

ARREST WARRANTS FOR ACTIVE-DUTY SERVICEMEMBERS: See reference (c) for detailed guidance and samples of necessary documentation.

- FEDERAL WARRANT FOR ARREST: Federal law enforcement authorities may arrest a Servicemember upon display of official law enforcement credentials and an arrest warrant. 
- IN-STATE WARRANT FOR ARREST: Law enforcement authorities exercising jurisdiction within the same state as a military installation or command may arrest a Servicemember upon display of official law enforcement credentials and arrest warrant. The command turning over the Servicemember must have the local law enforcement agency complete a written execution of delivery agreement.

- OUT-OF-STATE WARRANT FOR ARREST: Law enforcement authorities from a jurisdiction outside the state of the military installation or command may arrest a Servicemember upon display of official law enforcement credentials and a fugitive arrest warrant. The Servicemember may refuse to be delivered to the out-of-state law enforcement agency. If the Servicemember waives extradition and voluntarily submits to arrest, the command must ensure the local law enforcement agency completes a written execution of delivery agreement. Servicemembers have the right to consult with an attorney before agreeing to waive extradition to another state.

- FOREIGN ARREST WARRANT: Immediately notify the immediate superior in the chain of command and the cognizant staff judge advocate to determine requirements in accordance with the local status of forces agreement and any other agreements on delivery of personnel in foreign countries. Under no circumstances shall commanding officers release personnel to foreign authorities without approval from higher authority.

NOTE: In any circumstance where a commanding officer or a Servicemember refuses arrest, inform the Office of the Judge Advocate General (Code 14 - General Litigation) immediately at (202) 685-5450 or DSN 325-5450. 
REFERENCES:

(a) JAGMAN, Chapter VI, Section 0618

DISCRETION OF THE INSTALLATION COMMANDING OFFICER (CO): Repossession of personal property belonging to military personnel or their dependents located on a naval installation may be permitted at the discretion of the installation CO. The repossession agent must obtain permission from the installation $\mathrm{CO}$ in advance. In the event a repossession agent attempts to execute repossession, the installation's cognizant staff judge advocate should review the repossession documentation before the $\mathrm{CO}$ makes a decision to allow the repossession.

LOCAL INSTRUCTION OR DIRECTIVES: Should be implemented to ensure standard procedures are followed.

INFORMAL INQUIRY BEFORE REPOSSESSION IS ALLOWED: The Servicemember whose property is subject to an attempted repossession should be contacted to determine if he/she is aware of the problem and whether there is a way to resolve it.

IF REPOSSESSION IS TO BE ALLOWED: The owner of the property should be afforded the opportunity to voluntarily relinquish the property. The Servicemember should be referred to a legal assistance office as soon as possible to explore legal options to address the repossession.

NO BREACH OF THE PEACE: COs must ensure that repossessions are carried out in a peaceful manner and prohibit or stop repossession agents and Servicemembers from engaging in any type of altercation at the scene of an attempted repossession. 


\section{SERVICE OF PROCESS/SUBPOENAS}

REFERENCES:

(a) JAGMAN, Chapter VI

(b) SECNAVINST 5820 (series)

(c) MCO P5800.16 (LEGADMINMAN) Chapter 9

(d) MILPERSMAN 1050

COMMANDING OFFICER'S (CO) CONSENT/PRESENCE: Service of process (a summons to appear in court as a party) will not be permitted within a command without the CO's consent. Where practicable, the member should be served within the CO's presence or that of another designated officer. IMMEDIATELY ADVISE THE MEMBER TO SEEK LEGAL COUNSEL. [See Appendix M - Service of Process]

LOCAL, STATE, OR FEDERAL COURT SERVICE OF PROCESS: COs should permit service upon Servicemembers, civilian employees, or dependents except in unusual cases when compliance would be prejudicial to the public interest, good order and discipline, or mission accomplishment. Vessels in territorial waters of a state should be considered to be within the jurisdiction of that state for purposes of service of process.

COURTS LOCATED OUT OF STATE: Service of process shall normally be permitted under the same conditions as in-state service, but the $\mathrm{CO}$ shall ensure that the member is advised that he/she need not accept service.

SERVICE BY OUT-OF-STATE MAIL: If a Servicemember refuses to accept service of process by out-of-state mail, the refusal should be noted and the documents returned to the sender.

FOREIGN COURT/OVERSEAS SERVICE OF PROCESS: This type of service of process is normally addressed by the applicable status of forces agreement between the United States and the host nation. Before effecting service, COs should contact the area coordinator for foreign criminal jurisdiction matters as well as the cognizant staff judge advocate immediately.

RELATION TO OFFICIAL DUTIES: When service of process upon a Servicemember or a civilian employee arises from the performance of his/her official duties, COs must ensure that the Servicemember is notified of his/her applicable rights in accordance with section 0616 of reference (a) and that copies of the process and pleadings along with a description of the pertinent facts are provided to the staff judge advocate for the general court-martial convening authority. In addition, the Office of the Judge Advocate General (Code 14 - General Litigation) must also be immediately notified at (202) 685-5450 or DSN 325-5450.

NORMALLY GRANT LEAVE OR LIBERTY: Personnel who accept or are served with process should normally be granted leave or liberty to appear in court unless their absence would be prejudicial to the naval service. Servicemembers may delay civil court proceedings under the Servicemembers Civil Relief Act (SCRA) if their military duties materially affect their ability to appear in a civil court action pursuant to a summons. Servicemembers should seek counsel from a legal assistance attorney about exercising their rights under the SCRA.

SERVICE OF SUBPOENAS: Subpoenas are court orders requiring a person to testify as a witness. Subpoenas shall be handled in the same manner as service of process with the following exceptions: 
- If a Servicemember is subpoenaed as a witness representing the federal government, the member will be issued orders for temporary additional duty.

- If the Servicemember is subpoenaed as a witness on behalf of the accused in federal court, no-cost permissive orders should be issued unless the member's absence would be prejudicial to the command.

- If the Servicemember is subpoenaed as a witness on behalf of a party to a civil or state criminal action with no federal government interest, leave or liberty should be granted if not prejudicial to the command. (No-cost permissive orders shall be issued if the witness is subpoenaed because of performance of official duties.)

\section{REQUESTS FOR STATEMENTS ANDIOR INTERVIEWS WITH SERVICEMEMBERS BY}

PARTIES TO PRIVATE LITIGATION: If such a request or an attempt is made, immediately notify the cognizant staff judge advocate for the general court-martial convening authority in the chain of command. 


\section{CUSTOMS RESPONSIBILITIES}

\section{REFERENCES:}

(m)DoD Directive 4500.09E

(n) DTR 4500.9-R Part V

(o) Navy Regulations, Article 0860

PRIOR TO DEPLOYMENT: Commands must ensure that an adequate number of personnel are trained to act as military customs inspectors and that an adequate supply of customs forms are available.

\section{COMMANDING OFFICER'S RESPONSIBILITIES FOR SHIP ARRIVAL:}

- The commanding officer (CO) must notify the Customs District Director before the ship's return from a port outside U.S. customs territory to a port within U.S. customs territory.

- The CO must facilitate customs and immigration inspections and ensure proper immigration clearances for military and civilian passengers.

- The CO must ensure that custom declaration forms are distributed to all passengers and crew.

- The CO must file a cargo declaration within 48 hours, if the ship is carrying anything other than U.S. property and passengers on official business.

\section{AIRCRAFT COMMANDER'S RESPONSIBILITIES FOR AIRCRAFT ARRIVAL:}

- The Aircraft Commander must notify the Customs District Director before landing within U.S. customs territory.

- The Aircraft Commander may notify the Customs District Director by radio, telephone, or other direct means or, indirectly, through the Federal Aviation Administration's flight notification procedures.

- The Aircraft Commander must distribute custom declaration forms to the passengers and crew and facilitate the customs inspection. 


\section{FOREIGN CLAIMS}

\section{REFERENCES:}

(a) JAGMAN, Chapter VIII

PURPOSE AND SCOPE: The purpose of the foreign claims process is to promote friendly relations with foreign countries by promptly paying meritorious claims for death, injury, property damage, and other losses caused by Servicemembers or military operations. The claim must arise outside the U.S., its territories, possessions, or commonwealths.

VALID CLAIMANT: Valid claimants include citizens and inhabitants of foreign countries, corporations, and other government and business entities as well as U.S. citizens living abroad. Valid claimants do not include U.S. tourists or U.S. Servicemembers or their dependents.

CLAIMS NOT COVERED: Combatant claims, admiralty incidents, patent infringement, claims made by insurers, purely contractual claims, and paternity claims are not covered under the foreign claims process.

ESTABLISHMENT OF CLAIMS COMMISSION: Commanding Officers shall appoint responsible officers to adjudicate foreign claims. Foreign claims officers must diligently follow the requirements of reference (a) when investigating, documenting, adjudicating, and reporting claims. Type commanders frequently limit the authority of commands to settle claims or require the approval of a judge advocate. Understanding the specific foreign claims processing procedure within a command and its area of operations is essential before processing any foreign claims.

PRIVATE SETTLEMENT: When a claim results because of conduct outside the scope a Servicemember's duty a private settlement and voluntary restitution should be considered. Private settlements and restitution must be entirely voluntary on behalf of the Servicemember. The foreign claims officer should thoroughly document the incident in the same manner as a foreign claim and ensure that a final settlement agreement and release is signed by both the Servicemember and the claimant to prevent additional supplementary claims for the same incident against the United States.

FUNDING FOREIGN CLAIMS: See reference (a) for appropriate sources for funding foreign claims. 
REFERENCES:

(a) JAGMAN, §0609 and $\S 1010$

(b) Navy Regulations, Article 0828

(c) MCO P1900.16

APPREHENSION OF SERVICEMEMBERS BY FOREIGN AUTHORITIES: Commanding Officers (COs) shall report via naval message when foreign authorities apprehend a Servicemember under their command. It is the policy of the United States that all efforts should be made by the command to secure the foreign release of the Servicemember pending the final resolution of judicial process. Servicemembers that remain in the custody of foreign authorities should be encouraged to contact their family members or authorize the command to contact their family members on their behalf. When a Servicemember is released from the custody of foreign authorities, the Servicemember should be given a complete medical examination and provide a sworn statement pertaining to the conditions of the confinement. [See reference (a)].

IMPORTANT CONTACTS: The following entities should be contacted and may be able to assist in obtaining the release of or information about the foreign confinement of the Servicemember: the local region staff judge advocate, Naval Criminal Investigative Service, U.S. consulate or embassy, U.S. Defense Attaché Office, and husbanding agents. As a matter of best practice, commanders should also immediately notify their immediate superiors in the command.

STATUS OF FORCES AGREEMENT COMPLIANCE: In countries where the U.S. has a Status of Forces Agreement (SOFA), the terms of that agreement will determine whether the Servicemember may be removed from the jurisdiction and whether the United States or the host nation will prosecute the case. In many countries, disciplinary action, including non-judicial punishment, may not be conducted until the issue of jurisdiction has been resolved with the host country. Commands should consult with the cognizant judge advocate immediately.

WHEN THERE IS NO SOFA: If there is not a SOFA with the host nation, COs are not authorized to deliver Servicemembers, their dependents, or Department of the Navy civilian employees to foreign authorities. COs should contact the cognizant judge advocate immediately if requests are made by foreign authorities to deliver Servicemembers into their custody.

WARSHIP SOVEREIGNTY: Warships are immune from any other nation's jurisdiction. COs will not permit their ships to be searched or allow Servicemembers to be removed from their ship by foreign authorities. If foreign authorizes use force to compel submission, COs shall use all available means to resist. [See reference (b)].

SERVICEMEMBERS RETAINED IN FOREIGN CUSTODY: COs must ensure that Servicemembers who are retained in foreign custody are visited by a command representative on a regular basis and may not be separated from the service until they complete their sentence and are returned to the United States. [See reference (c).] 
SECTION XIV:

FOREIGN RELATIONS

AND

MARRIAGES TO FOREIGN NATIONALS 


\section{LIBERTY RISK}

REFERENCES:

(a) JAGMAN, § 0104

\section{***TO BE USED IN FOREIGN COUNTRIES ONLY***}

(Major overseas commands and numbered fleets frequently have their own liberty risk instructions with more specific guidance. Commanders must be aware of additional liberty risk policies beyond the basic departmental policies governing limiting liberty pursuant to regulations.)

APPLICABILITY: Liberty risk policies may only be implemented to limit Servicemembers' personal liberty while they are in foreign countries, whether permanently stationed in a foreign country or temporarily present pursuant to a port visit or temporary additional duty assignment. The sole purpose of liberty risk is the protection of U.S. foreign relations with host nations and, therefore, is not authorized within the United States or any of its overseas territories.

LIBERTY RISK IS SEPARATE FROM DISCIPLINARY ACTION: Liberty risk may not be used as punishment and cannot be awarded at non-judicial punishment or court-martial. Liberty risk shall not be used as a subterfuge for pretrial restraint. A Servicemember may be assigned liberty risk based on past behavior that indicates likely future conduct in a foreign country that could embarrass, discredit, or harm U.S. foreign relations with the host nation. Past behavior that could indicate likely future conduct that could harm the foreign relations of the U.S. includes, but is not limited to: alcohol related incidents, chronic intoxication, fights, theft, failures to pay bar or restaurant bills, lewd personal behavior or inflammatory, racist, or extremist behavior or statements. A commander may not place someone on liberty risk based on a mere hunch that the Servicemember may engage in inappropriate conduct. There needs to be a history of past adverse behavior that serves as the basis for the imposition of liberty risk.

\section{GENERAL GUIDANCE:}

- Only the commanding officer (CO) may assign liberty risk. The CO may consider the recommendations of a liberty risk review board.

- Placement on liberty risk cannot be automatic and must be based on actual past conduct.

- Lesser limitation on liberty or tailored liberty risk restrictions should be considered. (e.g., limited hours on shore, alcohol use prohibitions, use of liberty buddies, checking-in, etc.)

- Each individual's status must be regularly reviewed; liberty risk cannot be imposed for an indefinite period of time without justification based on specific evidence.

- Commands shall not confiscate a Servicemember's Armed Forces Identification Card (CAC) as a means of limiting liberty or freedom of movement.

\section{RIGHTS OF SERVICEMEMBERS PLACED ON LIBERTY RISK:}

- Servicemembers placed on liberty risk may request mast with the $\mathrm{CO}$ about whether the impositions or terms of liberty risk are appropriate;

- If placed on liberty risk, the Servicemember is entitled to specific notification in writing of the reason(s) for being placed on liberty risk; and

- Servicemembers on liberty risk may not be required to muster or participate in special working parties with Servicemembers serving punishment awarded at non-judicial punishment or court-martial. 


\section{MARRIAGES OVERSEAS AND MARRIAGES TO FOREIGN NATIONALS}

\section{REFERENCES:}

(a) MILPERSMAN 5352-030

REQUEST AND APPLICATION: Any Navy Servicemember planning to marry a foreign national overseas must submit an application to the area coordinator before the marriage takes place. Applications should be sent to the nearest area coordinator. Contact Commander, Naval Instillations Command (N911A) for areas not listed in reference (a).

COUNSELLING: Servicemembers and perspective spouses must be counseled regarding the legal and financial responsibilities incurred by marriage. Servicemembers should also be advised that approval is often a lengthy process and their marriage to a foreign national may or may not adversely impact their eligibility for a security clearance.

VALIDITY OF FOREIGN MARRIAGES: Generally, a marriage lawfully performed in a foreign country is considered a valid marriage under United States domestic laws.

\section{BEFORE MARRIAGE, THE PROSPECTIVE SPOUSE MUST:}

- Receive a medical screening; and

- A background check, conducted by the local U.S. embassy or consulate, which includes a criminal and subversive history investigation.

VISAS: Foreign spouses do not automatically receive visas to enter the U.S. Foreign spouses must apply for an immigrant visa with the local U.S. embassy, consulate, or the U.S. Citizenship and Immigration Service. As a result, Servicemembers who transfer back to the United States or to another country may not be able to immediately bring back their spouses or foreign-born children.

MARINES: Marines contemplating marriage to a foreign national should immediately notify the S-1 and security manager in the Marine's chain of command. 


\section{SECTION XV:}

LEGAL READINESS 


\section{LEGAL ASSISTANCE PROGRAM}

\section{REFERENCES:}

(a) JAGMAN

(b) MCO P5800.16A Chapter 14 (series) (LEGADMINMAN)

(c) JAGINST 5801.2B (series) (Legal Assistance Manual)

(d) 10 U.S.C.

AGGRESSIVE LEGAL ASSISTANCE (LA) REQUIRED: Commands are the FIRST LINE OF DEFENSE in identifying Servicemembers with legal problems and should immediately urge Servicemembers to visit LA providers to address any legal issues at the earliest opportunity before the legal issue becomes worse or unmanageable. Legal problems do not go away and only become worse with the passage of time. In order to best assist Servicemembers, legal problems must be identified and referred to a LA provider as soon as possible.

LEGAL ASSISTANCE PROGRAM: The Department of the Navy's (LA) program provides free attorney assistance to Servicemembers, their dependents and other eligible clients regarding personal legal matters not involving military disciplinary proceedings. LA is provided at all USN Region Legal Services Offices (RLSO) and USMC Legal Support Services Sections (LSSS) and is military legal offices of other services. [See reference (a), §0710.]

\section{PERSON ELIGIBLE FOR LEGAL ASSISTANCE:}

- Servicemembers on active duty for 30 days or more. LA is intended primarily for activeduty personnel, including reservists and members of the National Guard who receive orders for active duty for 30 days or more. For reservists on active duty for less than 30 days see reference (a), § 0706(b)(4) and (5).

- Dependents of Servicemembers on active duty for 30 days or more and dependents of Servicemembers who died while on active duty. (Dependents include same-sex spouses who are lawfully married and who can prove their martial status with a Department of Defense dependent identification card.)

- Retired Servicemembers and the dependents of retired Servicemembers.

- For the purpose of enhancing the readiness of reserve Servicemembers for mobilization, pre-mobilization legal counseling and assistance may be provided to active or inactive reserve personnel consistent with mobilization readiness needs. Pre-mobilization assistance normally will consist of unit briefs and drafting or updating wills, advance medical directives, and powers of attorney. Others assistance may be provided if it relates to recall or mobilizations such as: rights under the Servicemember's Civil Relief Act (SCRA) or the Uniformed Services Employment and Reemployment Rights Act (USERRA). Pre-mobilization LA is not authorized for dependents of reserve Servicemembers.

- Reserve Servicemembers and the dependents of reserve Servicemembers following release from active duty under a call to active duty for more than 30 days, issued under a mobilization authority as determined by the Secretary of Defense, for a period of time that begins on the date of the release and is not less than twice the length of the period served on active duty.

- Civilian employees who are U.S. citizens, other than foreign local hire employees, employed by, serving with, or accompanying U.S. Armed Forces, when they are assigned to a foreign country or to a vessel or unit deployed in excess of 30 days. Their dependents are also eligible for LA services. 
- Foreign Servicemembers and their dependents serving in the U.S. with U.S. Armed Forces.

- Certain former spouse of military Servicemembers, as defined in reference (d), §1072.

- Spouses, former spouses, and children who are victims of abuse by Servicemembers who lose their right to retired pay under reference (d), §1408(h).

- Dependents of Servicemembers separated for dependent abuse consistent with the transitional compensation provisions of reference (d), §1059.

CONFIDENTIALITY: Information disclosed to a LA attorney is confidential and may not be disclosed to third parties without the client's informed, voluntary, and written consent. LA offices are prohibited from disclosing information concerning a client to the client's command, including whether the Servicemember is even a client or received services. Commands should not contact LA officers to determine whether a Servicemember reported to a LA office for LA services. The LA office will not disclose whether any Servicemember visited a LA office or received services of any kind.

SERVICES: Although the availability of services may vary from office to office, services that are generally provided include: advice concerning divorce, child and spousal support, adoptions and name changes, custody, estate planning, landlord/tenant disputes, contracts, consumer fraud, identity theft, immigration issues, and the preparation of legal documents such wills, living wills, powers of attorney, and notarizations. The assistance provided does not include in-court representation, although some offices are permitted to prepare court documents for pro se litigants. Eligible persons seeking assistance should be advised to contact the nearest legal assistance office to determine whether a particular service is provided and, if not, where the nearest legal assistance provider who can provide that service is located.

LEGAL ASSISTANCE PROVIDERS: A helpful tool for locating the closest LA provider can be found at http://legalassistance.law.af.mil/content/locator.php.

CONFLICTS: Occasionally, a LA office will be prohibited from providing service to an otherwise eligible person due to an ethical conflict of interest. This usually arises when an attorney has previously provided assistance to an opposing party. Servicemembers conflicted from receiving assistance at the office will normally be referred to an alternate LA service provider. Due to regulations and professional responsibility rules governing client confidentiality, the LA office is prohibited from telling the conflicted client why he or she cannot be seen. Conflicted clients and command should not challenge a LA provider or LA office about whether or not it can/should disclose such information. LA offices have no discretion to disclose such information.

PREVENTIVE LAW: Most LA offices have a preventive law program through which attorneys and other legal professionals provide informational briefings on a variety of topics including deployment readiness, consumer law, identity theft, automobile purchases, wills, powers of attorney, and family support. Contact your local RLSO or LSSS for more information or to schedule a briefing for your command. The more notice that a requesting command can give to the local LA office the more time and services the local LA office can provide to members of that command before deployment.

PRE-DEPLOYMENT AND PRE-MOBILIZATION SERVICES: The main focus of the LA program is Fleet readiness. LA offices have been charged with maintaining legal readiness programs designed to ensure legal awareness and mission readiness. Such programs often 
include command visits and pre-deployment legal readiness check-ups. Contact your local LA provider to arrange pre-deployment or pre-mobilization LA services as soon as possible.

ROLE OF LEGAL OFFICERS (LOs): For LA matters, LOs scope of responsibilities are to create OJAG Code 16 specific powers of attorney that are issued only to officially designated command LOs, to notarize documents, to request and organize LA briefs, and to assist command members with getting appointments with LA providers. Especially as the law is constantly changing, LOs (as well as other command members) are prohibited from advising command members on how to handle LA issues and from representing the command member in front of civilian entities (e.g., going to a car dealership with the command member to try to persuade the dealership to cancel a car purchase contract). Command leadership should periodically inspect LOs to ensure that LOs are maintaining notary logbooks, LA briefs are being organized, and information protected by the Privacy Act is being properly secured. 
REFERENCES:

(a) DoDD 1350.4

READINESS: Poor legal readiness can significantly impair Servicemembers' ability to focus on mission accomplishment. Unfortunately, Servicemembers often fail to address their legal issues in a timely fashion, creating larger legal problems for themselves and their families.

Servicemembers should be encouraged and provided an opportunity to have their individual legal readiness assessed by a legal assistance attorney at least annually and well in advance of deployment.

LEGAL ISSUES: At a minimum the following legal readiness issues should be addressed before deployment:

- POWERS OF ATTORNEY (POA): A POA allows another person to act as an agent on behalf of the Servicemember. Special POAs authorize an agent to act in a specificallyauthorized capacity, such as: registering a vehicle, filing taxes, accepting or releasing government quarters, purchasing a home, executing a PCS move, etc. General POAs authorize an agent to act on the Servicemember's behalf in virtually any legal or financial capacity. Due to the risk of abuse, Servicemembers are encouraged to carefully consider the importance of choosing a trustworthy, capable agent and the actions that the Servicemember will need the agent to take on their behalf. Special POAs are the most appropriate means of authorizing an agent to act on behalf of the Servicemember. As a matter of policy within USN, LA providers will only draft a general POA in limited circumstances when absolutely warranted. Over time, third parties have become much more reluctant to honor general POAs, and often third parties have their own preauthorization procedures. General POAs can be unreliable and result in an agent unable to perform critical tasks on behalf of the Servicemember. ONLY ATTORNEYS CAN DRAFT GENERAL POAs.

- LAST WILL AND TESTAMENT: Wills ensure that a Servicemember's wishes regarding the disposition of property are carried out in the event of the Servicemember's death. They also create trusts for the protection of financial assets for minors and name guardians to raise minors upon the Servicemembers death. Servicemembers should have a current will. Servicemembers should put the location of their will on their page 2 and should notify named executors and other authorized agents should know where to locate the original will. Servicemembers should update their wills whenever they experience a significant change in financial or dependency status. As a matter of best practice, Servicemembers should review their wills at least once a year. The only way to change a will is to draft and execute an entirely new will. Any attempt to alter or amend an existing will may render it invalid. Servicemembers cannot be ordered to get a will or any other legal document from a LA office.

- LIVING WILLS AND HEALTH CARE POAs: A Living Will (also known as an Advance Medical Directive) is a document that expresses the Servicemember's wishes regarding the withdrawal of artificial life-sustaining measures when the member is terminally ill or in a persistent vegetative state. The living will provides legal directions to family members and attending physicians to withhold or withdraw artificial life support and relieves family members from having to make such a difficult decision. A Health Care POA is a legal document that designates and authorizes a person to make health care decisions for the Servicemember if the Servicemember becomes incapacitated. Such decisions may 
include whether to perform a medical procedure or whether to withhold or withdraw artificial life support in the event the Servicemember has not already directed such action through a valid living will/advanced medical directive. The Servicemember should put copies of these documents in their medical record and provide to any treating physician(s).

- SERVICEMEMBER GROUP LIFE INSURANCE (SGLI): Servicemembers should ensure that their SGLI designation forms are up to date. SGLI distributions are controlled exclusively by the SGLI designation form, which can be updated through service-specific personnel units or the command's personnel office. Servicemembers wishing to designate children under 21 years of age as beneficiaries of SGLI should seek assistance from a LA attorney concerning whether it is in the best interest of the children to establish a testamentary trust or custodianship in order to avoid significant delay and expense in event of the Servicemember's death. The only way to change the beneficiary of SGLI is to execute a new SGLI designation form. Wills and other legal instruments will NOT alter SGLI beneficiary designations. In order to avoid SGLI payouts to unintended beneficiaries, Servicemembers must complete and file new SGLI designations with service personnel units or the command's personnel office. Spouses are not automatically removed from SGLI upon divorce.

o The most frequently encountered problem with the SGLI beneficiary forms is that the Servicemember forgot to sign the form, which makes the form unenforceable.

- DD-93, RECORD OF DEPENDENCY: In the event of a Servicemember's death or incapacity, the Department of Defense and the Department of the Navy will review the Servicemember's DD-93 to determine next of kin and designations regarding whom to pay unpaid pay and allowances and death benefits (other than SGLI), as well as who is authorized to receive and dispose of the Servicemember's remains. If a Servicemember's DD-93 does not accurately reflect the Servicemember's intent, it can cause problems and confusion in contacting dependents and could result in intended dependents being denied military benefits, including a sizeable death gratuity.

Servicemembers wishing to designate children under 21 years of age as beneficiaries of their DD-93 should also seek assistance from a LA attorney concerning whether it is in the children's best interest to establish a testamentary trust or custodianship in order to avoid significant delay and expense in the event of the Servicemember's death. Like SGLI, the only way to ensure proper dispensation of unpaid pay and allowances and death benefits is to ensure the DD-93 is up to date and designates the Servicemember's intended beneficiaries. Wills and other legal documents have no bearing on DD-93 authorizations and benefits.

- FAMILY MATTERS: Family care plans and issues regarding divorce, support, custody, visitation, and military ID cards should all be resolved prior to deployment. Family care plans are not binding on state courts. Servicemembers should see a LA provider to get proper legal documentation to cover children during deployment. Poor planning in this area can result in significant distraction for the Servicemember, especially for singleparent Servicemembers, while on deployment and prevent eligible dependents from accessing military installations, medical facilities, commissaries, exchanges, and other support services. Servicemembers who are remarried and have primary custody of their children also need to complete a family care plan. 
- PENDING COURT CASES: Servicemembers should take prompt action to address or postpone pending court actions before deployment. Failing to appear in court or request a delay of proceedings due to military necessity may result in a default judgment against the Servicemember in civil or administrative cases or issuance of a bench warrant. Federal law permits stays of proceedings in civil cases (not criminal cases) when required by military necessity; however, Servicemembers and their COs must take affirmative action to contact the cognizant court to request the delay. When a CO assesses that their command member cannot attend a court hearing due to mission requirements, staff judge advocates and LA attorneys can provide COs with a form letter to submit to courts on behalf of the command member. The servicemember will generally also need to submit a request to the court asking for a stay, which can be written by the LA provider.

- CREDIT REPORTS AND PREVENTING IDENTITY THEFT: Deployed and TAD Servicemembers are highly susceptible to identity theft. In order to minimize the potential for identity theft, Servicemembers who fear that their credit may be abused while on deployment should consider filing an Active Duty Alert with ALL of the three Consumer Reporting Agencies (CRAs): Trans Union (1-800-680-7289), Equifax (1-888766-0008), or Experian (1-888-397-3742). Once an Active Duty Alert is placed a Servicemember's credit report, potential creditors are required to contact the Servicemember at the phone number provided by the Servicemember or otherwise affirmatively confirm the Servicemember's consent before extending new credit, issuing new or additional credit cards, or extending credit limits. Filing an Active Duty Alert also takes the Servicemember's name off of "prescreened" lists provided by CRAs to creditors and insurance companies that are seeking to solicit new business. Servicemembers should also be encouraged to monitor their credit reports from the major CRAs. Visit www.annualcreditreport.com for more information on obtaining a free credit report from each of the three CRAs once a year. As a matter of best practice, Servicemembers should review all three of their credit reports at least one per year or whenever they have reason to suspect questionable financial activity which they did not authorize. 


\section{SERVICEMEMBER'S CIVIL RELIEF ACT (SCRA)}

\section{REFERENCES:}

(a) 50 U.S.C. $\$ 501-596$

BACKGROUND: The SCRA is a federal law that provides Servicemembers--and in some cases their dependents--with a variety of protection in civil matters. These laws were passed in an effort to address some of the disadvantages faced by Servicemembers in dealing with their personal civil affairs due to the transient and unpredictable nature of military life. As the law is constantly changing, commands should encourage Servicemembers to get an appointment with a legal assistance (LA) attorney in lieu of the command attempting to assist the Servicemember. For purposes of identifying potential SCRA violations, several of the more important provisions of the SCRA are discussed below.

LEASE TERMINATION ("MILITARY CLAUSE"): The SCRA provides Servicemembers the right to terminate a lease for real property that is occupied or is intended to be occupied by the Servicemember or his dependents if after signing the lease:

- The Servicemember enters into the military, either as an original enlistment/commission or as an activate reservist;

- The Servicemember receives orders to deploy with a military unit for 90 days or more; or

- The Servicemember receives PCS orders.

To terminate a lease under the SCRA, the tenant must deliver written notice of the intent to terminate the lease under the SCRA and provide a copy of the orders. When deploying with a ship, the command should issue a letter verifying the approximate dates and duration that the Servicemember will be deployed. Once the Servicemember provides the required notice and documents, the lease is terminated effective 30 days from the date on which the next payment would be due. For example, if the rent is due on the $1^{\text {st }}$ day of the month and the Servicemember provides notice on the $15^{\text {th }}$ of March, the lease would be terminated effective the $1^{\text {st }}$ of May (30 days from the $1^{\text {st }}$ of April). Although landlords are prohibited by the SCRA from charging an early termination fee, the landlord can still assess fees for late payments if the tenant is behind on rent and for damage to the property.

WAIVERS: In some states, the right to terminate a lease without penalty could be waived by the Servicemember in the lease. Servicemembers are strongly encouraged to have prospective leases reviewed by a LA provider prior to signing the lease.

OTHER LEASE TERMINATION PROTECTIONS: The SCRA also provides Servicemembers the right to terminate some leases for motor vehicles if after signing the lease:

- The Servicemember receives orders to PCS from CONUS to OCONUS or OCONUS to CONUS; or in the case of Alaska or Hawaii, a PCS move to any location outside that state; pr

- The Servicemember receives orders to deploy for at least 180 days.

The same notification procedures for terminating a residential lease should be used to terminate a vehicle lease; however, the lease of the vehicle (or their attorney-in-fact) must return the vehicle within 15 days of notifying the company in writing.

STAY OF LEGAL PROCEEDINGS: The SCRA provides Servicemembers the right to stay (delay) civil and administrative proceedings if the Servicemember's ability to appear is materially 
affected by the Servicemember's military service. This protection applies only to civil and administrative proceedings, not criminal proceedings (including misdemeanor traffic citations). To request a stay, the Servicemember must submit to the court:

- A letter stating how the Servicemember's military service materially affects the Servicemember's ability to appear and when the Servicemember will be able to appear; and

- A letter from the Servicemember's commanding officer stating that the Servicemember's current duties prevent their appearance and that leave is not authorized.

Every effort should be made to allow the Servicemember to attend court proceedings. As such, COs should only issue the aforementioned letter if the operational mission requires the Servicemember to be with the command on the designated court hearing dates. If the Servicemember qualifies for the stay, the court MUST grant the stay for at least 90 days, but may grant it for much longer. The court also has the option of denying the request for a stay longer than 90 days and proceeding without the Servicemember. The SCRA does not make any legal issue "go away." The Servicemember will eventually have to resolve the matter.

DEFAULT JUDGMENTS: Servicemembers have a right under the SCRA to reopen default judgments issued in civil cases in which the Servicemember's military service materially affected his ability to appear in the case and the Servicemember has a meritorious defense. Default judgments are issued by a court when a party fails to appear in court and contest the matter. Additionally, before a court issues a default judgment, the SCRA requires that the opposing party file an affidavit with the court stating either that the person is in the military, is not in the military or that the opposing party does not know if the person is in the military. The SCRA provides penalties for filing a false affidavit but does not provide a penalty for failing to file an affidavit.

6\% INTEREST CAP: An obligation or liability bearing interest that is incurred by a Servicemember, or the Servicemember and the Servicemember's spouse jointly, BEFORE the Servicemember enters the military service may not bear interest in excess of $6 \%$ per year:

- During the period of military service and one year thereafter, in the case of an obligation or liability consisting of a mortgage, trust deed or any other security in the nature of a mortgage; or

- During the period of military service in the case of any other obligation or liability.

DOMICILE PROTECTION: The SCRA permits Servicemembers to maintain their legal domicile and residency in a state even though they relocate out of state. A Servicemember establishes domicile in a state by being physically present in that state and having the intent to permanently return to that state. Contrary to popular belief, Servicemembers do not establish domicile by simply updating their home of record at the personnel office. Once a Servicemember has established domicile in an intended state, the Servicemember should refrain from taking action contrary to that intent, such as registering to vote or obtaining a driver's license in another state.

TAXATION: The SCRA has numerous provisions designed to prevent Servicemembers from being taxed in multiple jurisdictions:

- INCOME TAX: Military pay is deemed to have been earned in the Servicemember's state of domicile and only that jurisdiction may tax military pay. This does not apply to non-military pay, which may be taxed in the jurisdiction in which the pay was earned, in the state which the Servicemember is currently living and the Servicemember's state of domicile. Military pay of Native American Servicemembers who maintain residency on a 
Federally-recognized tribal reservation is not subject to state income tax. Such Native American Servicemembers should be advised immediately to file a DD-2058-2 with DFAS to claim this exemption.

- PERSONAL PROPERTY TAX: A jurisdiction is prohibited from charging a personal property tax on a Servicemember's property if that property is located within the jurisdiction only because of the Servicemember's presence in the state due to military assignment. This protection does not apply to sales or use taxes, and the Servicemember's state of domicile always remains able to charge a personal property tax.

EVICTION PROTECTION: Landlords are prohibited from evicting Servicemembers and their dependents without first obtaining a court order. If the Servicemember can demonstrate that the military service materially affects his ability to pay the rent, the court may fashion an equitable remedy, including reducing the amount of rent. This protection applies for leases with a rent of $\$ 3,217.81$ (2014 value) per month or less.

FORECLOSURE PROTECTION: No company or individual can foreclose on a Servicemember on active duty without a valid court order if that property was obtained before entering active service. The court issuing the order has the discretion to stay the foreclosure proceedings up to one year after the end of the Servicemembers period of active service.

REPOSSESSION PROTECTION: Lenders may not repossess personal property owned by a Servicemember without first obtaining a court order. This protection applies only to obligations incurred before the Servicemember was ordered to active duty.

MILITARY SPOUSES: The domicile of the spouse of a Servicemember may also be protected by the Military Spouses Residency Relief Act (MSRRA). Under MSRRA, a Servicemember's spouse may retain his/her domicile as long as the spouse's absence from the state of domicile is a result of the Servicemember's orders. The spouse will also be able to pay state taxes in the state of domicile, even for work performed in the state of residence. Servicemembers and their spouses should contact a legal assistance attorney to determine how the MSRRA may apply to them. Such spouses should be advised to consult with a LA attorney to obtain guidance on the forms required by each respective state to obtain the protections of this provision.

OFF LIMITS: A CO may declare places or businesses temporarily "off limits" in emergencies until the Armed Forces Disciplinary Control Board (AFDCB) or Area Coordinator can act. Reasons for declaring places off limits: clear danger to loyalty, morale, good order and discipline; interference with mission accomplishment; adverse effect upon health, safety, welfare, or morals; or engages in discriminatory practices. An overseas $\mathrm{CO}$ has much greater discretion to place areas off limits, checking with the immediate superior in command (ISIC) if their intent is to place something or someplace permanently off limits. The command and ISIC staff judge advocate should report problematic off-base location $s$ and businesses to the AFDCB for consideration in placement in longer-term off limits status, which would apply to all Servicemembers in the area of area of operations. COs should also encourage Servicemembers to report to a LA office when they have been victimized by off-base businesses. The LA office can help ensure the business is reported to the AFDCB. In order to avoid being placed permanently off limits, the offending business can change business practices to the benefit of servicemembers. 


\section{DEPENDENT SUPPORT}

\section{REFERENCES:}

(a) 32 C.F.R. $\S 733$ and $\S 734$

(b) MILPERSMAN 1754-030

(c) MCO P5800.16A (LEGADMINMAN)

(d) UCMJ, Article 134

(e) MILPERSMAN 1910-140

(f) UCMJ, Article 92

(g) DOD 7000.14-R (7A, Ch. 26, Sec. 260406(B)

POLICY: Servicemembers are expected to provide continuous and adequate support for all lawful dependents. Each of the armed services has issued support guidelines. References (b) and (c) are the guidelines for the Navy and Marine Corps, respectively. Servicemembers who are the subject of nonsupport complaints should be encouraged to consult with a legal assistance (LA) attorney.

COURT ORDERS AND WRITTEN AGREEMENTS: Servicemembers are obligated to comply with valid court orders and written agreements that established support requirements. Servicemembers who fail to comply with such orders and agreements may be disciplined under reference (d) for failure to pay just debts. Servicemembers desiring to contest such orders must do so in the jurisdiction issuing the order.

MILITARY SUPPORT OBLIGATIONS: In the absence of a court order or written agreement, the service specific support obligation applies.

PERSONS ENTITLED TO SUPPORT: In the absence of a court order or written agreement, Servicemembers are obligated to support their lawful dependents including spouses, natural and adopted children, but NOT stepchildren.

NAVY GUIDELINES: Reference (b) provides the guidelines and recommended levels of support for Sailors. Commands must counsel Sailors concerning their support obligation, but may not order the Sailor to provide support.

- WAIVER OF SPOUSAL SUPPORT: Sailors may seek a waiver of the spousal support obligation when the spouse seeking support abused or abandoned the Sailor or the spouse engaged in infidelity. Waivers are processed through the Defense Finance Accounting Service (DFAS) in accordance with reference (b).

- COMMAND ACTION UNDER COMPLAINT: Commands shall counsel Sailors concerning their obligations to support their lawful dependents in accordance with reference (b) and advise Sailors of the possible consequences of failure to comply with reference (b). Commands should also encourage Sailors to seek advice from a legal assistance attorney.

- FAILURE TO PROVIDE SUPPORT: Sailors failing to provide continuous and adequate support may lose their entitlement to Basic Allowance for Housing (BAH) at the with dependents rate, receive adverse evaluations or fitness reports, receive written counseling and ultimately be administratively separated in accordance with reference (e). Commands are required under reference $(\mathrm{g})$ to recoup $\mathrm{BAH}$ for periods of inadequate support. 
MARINE CORPS FORMULA: Reference (c) provides the formula for calculating support amounts and empowers commanders to issue a lawful order to provide support in accordance with the formula. Reference (c) is punitive in nature.

- WAIVER OF SPOUSAL SUPPORT: Commanders may waive the spousal support obligation only when the spouse seeking support abused the Marine, the spouse's income exceeds that of the Marine, the spouse and the Marine are both Servicemembers or the Marine has been providing continuous support for 12 months. Commanders may also reduce the amount of support otherwise owed if the Marine is paying regular and recurring obligations for the spouse.

- COMMAND ACTION UNDER COMPLAINT: Commands shall counsel Marines concerning their obligations to support their lawful dependents in accordance with reference (c) and if necessary issue a written order to provide support. Commands should also encourage Marines to seek advice from a legal assistance attorney.

- FAILURE TO PROVIDE SUPPORT: Marines failing to provide continuous and adequate support may lose their entitlement to a housing allowance at the with dependents rate and be subject administrative and disciplinary action, including punishment under reference (f).

PATERNITY: In the case of a child born to parents who are not married, where paternity has not been established by affidavit, judicial decree or DNA testing, the member cannot be required to provide support. Any such member should be immediately referred to a LA attorney. See PATERNITY COMPLAINTS.

NOTE ON RESERVE SERVICEMEMBERS: Reserve Servicemembers who are activated for an extended period of active duty and who have their pay garnished directly from their civilian employer to satisfy a support obligation must provide a certified copy of the order directing their employer to withhold support payments to the Navy or Marine Corps. This is typically done for the Navy by providing a certified copy at the Navy Mobilization Processing Site (NMPS) during the activation process. The Servicemember must follow-up with their finance office at their mobilization site or directly or directly with DFAS to ensure that there is not an interruption in their support. Failure to ensure that there is not an interruption could result in the Servicemember facing penalties for arrears after mobilization. 


\section{PATERNITY COMPLAINTS}

\section{REFERENCES:}

(a) MILPERSMAN 5800-010

(b) MILPERSMAN 1754-030

(c) MCO P5800.16A (LEGADMINMAN)

POLICY: Servicemembers owe the same duty of support to minor children regardless of whether the child was born during the marriage or out of marriage.

DETERMINATION OF PATERNITY: The Department of the Navy does not determine paternity disputes; determining paternity is a matter solely for state courts. If a Servicemember questions paternity, they should seek legal advice from a legal assistance (LA) attorney BEFORE to signing their name on the child's birth certificate.

SUPPORT ORDERS: Servicemembers must comply with state court orders. Compliance with state court orders is required even if the Servicemember disputes paternity or believes that an official paternity determination has not been made. Servicemembers who desire to challenge a court order directing support should be referred to a legal assistance attorney.

WRITTEN PATERNITY COMPLAINTS: Upon the receipt of a written complaint of paternity, the command must interview and counsel the Servicemember in accordance with reference (a). Servicemembers receiving a paternity complaint should be referred to a legal assistance attorney.

- ADMISSION OF PATERNITY: If a Servicemember admits to being the natural father of the child he should be counseled on the obligation to provide support. If there is not a court order, the support should be made in accordance with service specific support guidelines found in references (b) and (c), or enter into a voluntary written agreement with the mother of the child. If the Servicemember now becomes eligible for a housing allowance or one at the with dependents rate, then the personnel office will require written acknowledgement of paternity.

- DENIAL OF PATERNITY: If the Servicemember denies paternity, the Servicemember should be counseled on the obligations under references (b) and (c), and the implication of making a false official statement under the Uniform Code of Military Justice, but no further action should be taken. The Servicemember cannot be compelled to take a DNA test. The Servicemember should be referred to a LA attorney.

ADMINISTRATIVE OR DISCIPLINARY ACTION: After a state court order determining paternity or an admission of paternity, and the Servicemember continues to fail to provide support in accordance with references (b) and (c), a court order or a mutual agreement, administrative or disciplinary action may be warranted. See ADMINISTRATIVE and DISCIPLINARY OPTIONS. 


\section{INDEBTEDNESS COMPLAINTS}

\section{REFERENCES:}

(a) DoD Dir 1344.09

(b) DoD Inst 1344.12

(c) MILPERSMAN 7000-020

(d) MCO P5800.16A (LEGADMINMAN, Chapter 16)

(e) UCMJ, Article 134

(f) MILPERSMAN 1910-140

POLICY: Servicemembers are expected to pay their just financial obligations in a proper and timely manner. However, there is no internal Department of Defense (DoD) authority to adjudicate disputed claims or enforce settlements of private claims against Servicemembers.

COMPLAINTS: In accordance with references (a), (b) and (c) or (d), upon receipt of a complaint of a Servicemember failing to pay their debt, the command should counsel the Servicemember on his or her obligations. Servicemembers who receive debt complaints against them should be referred to a legal assistance attorney and the Command Financial Specialist. Commands cannot arbitrate disputed claims and shall not indicate to a complainant what, if any action was taken against the Servicemember. The command response will depend on whether the complainant is a debt collector, creditor or non-creditor:

- DEBT COLLECTOR: A debt collector is a person or entity regularly engaged in the collection of debts, such as collection agencies and law firms. Debt collectors are prohibited by the Fair Debt Collection Practices Act (FDCPA) from contacting third parties, including the Servicemember's command, to collect a debt that has not been reduced to a judgment, unless the Servicemember has consented to such contact after the delinquency has occurred. Most indebtedness complaints from debt collectors should be returned without action using the sample letter in references (c) or (d). Commands should report all FDCPA call violations to their base staff judge advocate or the local legal assistance office.

- CREDITORS: A creditor is a person or entity that extends credit, such as car loans, bank loans and credit cards. Creditors must certify compliance with the DoD Standards of Fairness and if subject to the Federal Trade Commission (FTC) regulations, must certify compliance with the Truth in Lending Act and other FTC regulations before the command can act on a complaint from a creditor. Command assistance to creditors should be limited to administrative referral of correspondence to the Servicemember and counseling the Servicemember regarding financial obligations. Command should respond to creditors using the sample letter in references (c) or (d).

- NON-CREDITORS: A non-creditor is an entity that did not extend credit but to whom the money is owed, such as a supermarket or a landlord to whom the Servicemember wrote a now bounced check. Commands should respond to non-creditors using a letter substantially similar to the letters in reference (a) or (c).

DOCUMENTING THE MEMBER'S FAILURE TO PAY: Commands should use a page 13 for Sailors or a page 11 for Marines with reoccurring unpaid debt problems.

DISCIPLINARY AND ADMINISTRATIVE ACTON: Disciplinary action may be initiated when there has been a dishonorable failure to pay just debts or maintain checking funds under reference (e). A Servicemember may be administratively separated when there is a pattern of failing to pay just debts and the Servicemember had violated a written counseling to that effect. See reference (f). 
INVOLUNTARY ALLOTMENT APPLICATIONS: Involuntary allotment application should be processed with the Defense Finance Accounting Services (DFAS) form 2653 in accordance with reference (b). 


\section{REFERENCES:}

(a) SECNAVINST 1752.3B (series)

(b) DoD Dir 6400.1-M-1

(c) 10 U.S.C. $§ 1058$

(d) OPNAVINST 1752.1B (series)

(e) OPNAVINST 1752.2B (series)

(f) MCO 5300.17 (series)

(g) 18 U.S.C. $\$ 921$

(h) MILPERSMAN 1910-162

(i) 18 USC $\S 922(\mathrm{~g})$

\section{POTENTIAL REPORTING REQUIREMENTS:}

- Commands must comply with all reporting requirements in enclosure (2) of reference (a).

- Commands must report all major criminal offenses to Naval Criminal Investigative Service.

- In accordance with Type Commander and Echelon II requirements, commands must report all incidents involving officers. See OFFICER MISCONDUCT.

\section{NOTIFICATION TO FAMILY ADVOCACY REPRESENTATIVE:}

- Navy commands shall notify the Family Advocacy Representative (FAR) of all allegations of spouse or child abuse, the FAR will notify Navy Personnel Command (BUPERS) when allegations of child sexual abuse are made.

- Marine Commands shall notify the command Family Advocacy Officer and/or the Family Advocacy Program Manager and Marine and Family Services.

TRACK THE CASE: Appoint the XO or a responsible command representative to work with the Family Advocacy Program (FAP) and provide command input on the case disposition.

CASE DISPOSITION: The Family Advocacy Incident Determination Committee (IDC) replaced the Case Review Committee (CRC). The IDC will make a determination of whether an incident meets the Department of Defense criteria for abuse. If an incident is determined to be abuse, the case will be sent to the Clinical Case Staff Meeting (CCSM) to generate treatment recommendations, which will then be forwarded to the command. Commanding Officers have sole discretion over disciplinary action; Family Advocacy review does not preclude or limit command disciplinary action. See ADMINISTRATIVE AND DISCIPLINARY OPTIONS.

\section{FORMAL REVIEW OF IDC DETERMINATIONS:}

- USN: IDC determinations can be appealed to the IDC and then to a Headquarters Review Team at BUPERS. Appeals must be in writing and normally filed within 30 days of the advisement of the IDC's determination. Appeals can be filed by the alleged offender, victim or the command of either. In cases involving children, the non-offending parent may appeal because of: 1) newly discovered evidence, 2) fraud upon the IDC, 3) a voting member of the IDC was absent, 4) a Guilty or Not Guilty finding after a full trial on the merits that is contrary to IDC's determination or 5) plain legal or factual error.

- USMC: IDC determinations can be appealed to the installation IDC. Appeals must be in writing and normally filed within 10 days of the advisement of the IDC's determination. 
Appeals can be filed by a substantiated offender, victim, a person legally responsible for the victim, or either spouse where the incident was unsubstantiated, for the following grounds: 1) newly discovered information, 2) failure to substantially follow correct procedures or 3 ) not guilty/guilty findings after a full trial on the merits that is contrary to IDC's findings.

TREATMENT OF VICTIMS: Commands should coordinate the treatment of victims with the Victim/Witness Assistance Program.

INTERVENTION: Commands should ensure the appropriate actions are taken to provide for the protection for victims during the investigation and processing of FAP cases, such as: the issuance of military protective orders (MPOs), coordination with local child protective services, or issuance of an order barring alleged perpetrators from Navy installations. See LAW ENFORCEMENT CIVILIAN JURISDICTION.

MILITARY PROTECTIVE ORDERS: A MPO is an order requiring a Servicemember to "stay away" from complainant or victim. MPOs should be issued whenever it is likely or foreseeable that further incident will arise. A MPO should be issued in writing when possible. MPOs must be temporary in nature, but may be renewed, and should be in force until FAP counselors have an opportunity to intervene. Commanding Officers should consult with a Judge Advocate before issuing a MPO.

INTERVIEWING OR QUESTIONING SUSPECTED OFFENDERS: Commands should not interview or question suspected offenders until after coordination with the appropriate law enforcement agency (NCIS, CID, or civilian) has completed their investigation.

ALCOHOL RELATED INCIDENTS: For alcohol related incidents, after the law enforcement investigation is complete, the Drug and Alcohol Programs Advisor (DAPA) should conduct an alcohol abuse screening.

MANDATORY PROCESSING: FAP rehabilitation failure cases must be processed for administrative separation under reference $(\mathrm{h})$. Administrative separation processing is also mandatory for sexual misconduct and violent misconduct involving conduct which caused or could have caused death or serious bodily injury. See ADMINISTRATIVE SEPARATIONS.

FIREARMS AND AMMUNITION POSSESSION: In accordance with reference (i), also known as the "Lautenberg Amendment," if a Servicemember is convicted at Special or General CourtsMartial or in any civilian court of crime of domestic violence, then the Servicemember is not permitted to possess firearms or handle ammunition, even in the line of duty. Commanding Officers should consult a Judge Advocate for further information. 
SECTION XVI:

STANDARDS OF CONDUCT

AND

ETHICAL CONDUCT 


\section{GUIDELINES FOR ETHICAL CONDUCT}

\section{REFERENCES:}

(a) 5 C.F.R. $\S 2635$

(b) DoD 5500.07-R (JER)

(c) MCO P5800.16A, Chapter 11

\section{BASIC OBLIGATIONS OF PUBLIC SERVICE:}

- Public service is a public trust, requiring employees to place loyalty to the Constitution, the law and ethical principles above private gain.

- Employees shall not hold financial interest that conflict with the conscientious performance of duty.

- Employees shall not hold financial transactions using nonpublic Government information or allow the improper use of such information to further any private interest.

- An employee shall not solicit or accept any gift or other item of monetary value from any person or entity seeking official action from, doing business with, or conducting activities regulated by the employee's agency, or whose interests may be substantially affected by the performance or nonperformance of the employee's duties.

- Employees shall put forth honest effort in the performance of their duties.

- Employees shall not make unauthorized commitments or promises (knowingly) of any kind purporting to bind the Government.

- Employees shall not use the public office for private gain.

- Employees shall act impartially and shall not give preferential treatment to any private organization or individual.

- Employees shall protect and conserve Federal property and shall not use it for anything other than authorized activities.

- Employees shall not engage in outside employment or activities, including seeking or negotiating for employment, that conflict with official Government duties and responsibilities.

- Employees shall disclose waste, fraud, abuse, and corruption to appropriate authorities.

- Employees shall satisfy in good faith their obligation as citizens, including all just financial obligations, especially those - such as Federal, State, or local taxes - that are imposed by the law.

- Employees shall adhere to all laws and regulations that provide equal opportunity for all Americans regardless of race, color, religion, sex, national origin, age, or handicap.

- Employees shall endeavor to avoid any actions creating the appearance that they are violating the law or the standards of conduct. 


\section{COMMERCIAL DEALINGS BETWEEN SERVICEMEMBERS}

\section{REFERENCES:}

(a) DoD 5500.07-R §5-409 (JER)

(b) US Navy Regulations. Art. 1111

SENIOR TO JUNIOR: On or off duty, a Servicemember or civilian employee cannot solicit or sell to personnel who are junior in rank, grade or position, or to the family members of such personnel. Included in this prohibition are sales of insurance, stocks, mutual funds, cosmetics, household supplies, vitamins, real estate or any other goods or services.

EXCEPTIONS: Absent coercion/intimidation, the sale or lease of noncommercial personal or real property and commercial sales solicited and made in a retail establishment during off-duty employment are not prohibited. Sales made because a junior approaches the senior and requests the sale to be made are not prohibited, absent coercion/intimidation by the senior.

SPOUSES AND OTHER HOUSEHOLD MEMBERS: Servicemembers must seek an opinion from an ethics counselor (usually the Staff Judge Advocate for a General Court-Martial Convening Authority) if a spouse or household member is soliciting sales to junior personnel or other families. The Servicemember should be counseled that such sales activities are to be avoided where it may cause actual or perceived partiality or unfairness, involve the actual or apparent use of rank/position for personal gain or otherwise undermine discipline, morale or authority. 


\section{CONFLICTS OF INTEREST}

REFERENCES:

(a) 18 U.S.C. $\S 208$

(b) DoD 5500.07-R (JER), Section 5-100

OFFICIAL ACTIONS THAT HAVE A DIRECT AND PREDICTABLE EFFECT ON PRIVATE FINANCIAL INTERESTS: Officers, enlisted Servicemembers and civilian employees are prohibited from participating personally and substantially in an official capacity in any particular matter in which they or any person whose interests are imputed to them have a financial interest, if the particular matter will have a direct and predictable effect on that interest.

IMPUTED INTERESTS: The interest of a spouse, child, general partner, organization in which the employee serves (i.e., as a director or trustee), or anyone with whom the employee is seeking or negotiating future employment, are imputed to the employee.

\section{WHEN A CONFLICT EXISTS OR MAY EVEN REMOTELY EXIST:}

- Seek the opinion of an Ethics Counselor (Usually the Staff Judge Advocate for a General Court-Martial Convening Authority or the Office of the General Counsel).

- Disqualify yourself and do not participate or take further action on the matter.

- Provide written notice of the particular conflict to your superior officer.

- Request a waiver, disqualification, reassignment or limitation of duties.

PUBLIC FINANCIAL DISCLOSURE REPORT (SF-278): All flag/general officers must file:

- When promoted, annually thereafter and upon termination.

- Ensure it is reviewed by an Ethics Counselor for potential conflicts of interest.

- Ensure any necessary remediation is made for conflicts disclosed.

- This document is available to the public.

\section{CONFIDENTIAL FINANCIAL DISCLOSURE REPORT (OGE-450 or OGE-450A):}

The following personnel are required to file:

- Commanders of Navy shore installations with 500 or more military and civilian personnel.

- All Commanding and Executive Officers, heads and deputy heads of Army, Air Force, and Marine Corps installations, bases, air stations or activities.

- All personnel who participate personally and substantially in contracting or procurement, regulating or auditing any non-Federal entity or other activities having a direct and substantial economic impact on the interests of any non-Federal entity.

Any person whose official responsibilities require personal and substantial participation in contracting or procurement must:

- File the OGE-450 or OGE-450A upon assuming the covered position and annually thereafter; and

- Ensure it is reviewed by an Ethics Counselor for conflicts and remediation if necessary. The information contained in the OGE-450 will be kept confidential.

JOB HUNTING: When seeking outside employment the employee must disqualify himself/herself from any official action that could possibly affect the financial interests of the prospective employer. This disqualification must be in writing and sent to the employee's supervisor. The disqualification can be revoked if either party rejects possible employment. 
RESERVE NOTE: Reserve personnel must also be mindful of the conflict of interest unique to reserve component personnel. Reserve personnel are prohibited from performing their reserve component duties in the same location in which they are also employed in the Government Civil Service. Additionally, reserve component personnel who in their civilian lives are employed by a Government contractor must ensure that their service in a particular reserve billet would not present a conflict of interest in which the reserve Servicemember could be placed in a situation in which the reserve Servicemember makes decisions that can affect the reserve Servicemember's civilian employer. 


\section{FUNDRAISING}

REFERENCES:

(a) DoD 5500.07-R §3-210, 3-211 (JER) (Chapter 3)

(b) DoDI 5035.01

(c) OPNAVINST 1754.5B (series)

(d) MCO 5760.4C (series)

(e) BUPERSINST 1710.11C (series)

(f) 5 C.F.R. $\S 2635.808$

OFFICIAL ENDORSEMENT: Commands may officially endorse fundraising efforts of:

- The Combined Federal Campaign (CFC);

- Emergency and disaster appeals approved by the Office of Personnel Management (OPM);

- Army Emergency Relief;

- Navy-Marine Corps Relief Society; and

- Air Force Assistance Fund, including:

- Air Force Enlisted Foundation, Inc.;

- Air Force Village;

- Air Force Aid Society;

- General and Mrs. Curtis E. LeMay Foundation.

- Other organizations composed primarily of DoD employees or their dependents, when fundraising among their own members for the benefit of welfare funds for their own members or their dependents, when approved by the head of the DoD Component command or organization after consultation with the Designated Agency Ethics Office or designee. This includes most morale, welfare, and recreation programs, regardless of funding sources.

OFFICIAL SUPPORT: Commands may officially support (vice endorse) a charitable fundraising event sponsored by a non-Federal entity if certain criteria of reference (a) are met. Such support is limited to logistical support, such as the use of DoD facilities and equipment on a limited basis.

WORKSPACE SOLICITATIONS: Solicitation within the workplace is authorized only for approved organizations with official endorsement. Solicitations must be conducted in such a way as to ensure all contributions are voluntary.

The following coercive practices are prohibited:

- Solicitations by supervisors;

- Setting 100 percent participation goals, mandatory personal goals, or quotas;

- Using contributor or non-contributor lists for any purpose other than routine collection and forwarding of pledges; and

- Counseling or grading of individuals based on their failure to contribute to any fundraising effort.

\section{FUNDRAISING BY MILITARY AFFILIATED PRIVATE ORGANIZATIONS ANDIOR SPOUSE}

CLUBS: Sales of merchandise or services is authorized, but should be limited to occasional sales and not be frequent or continuous. Competition with Navy Resale activities should be minimized. Gambling and/or raffles and lotteries for charity are permitted when the activities are held by organizations composed primarily of DoD employees or their dependents for the benefit of welfare funds for their own members or for the benefit of other DoD employees or their 
dependents, subject to the limitations of local law an subsections 3-210 and 3-211 or reference (a), when approved by the Head of DoD Component or designee.

See PRIVATE ORGANIZATIONS AND SPOUSE CLUBS, BIRTHDAY BALL FUNDRAISING, and GAMBLING.

RAFFLES: Raffles are only authorized for Navy and Marine Corps Relief.

BINGO: Bingo games are only authorized for Morale Welfare and Recreation (MWR) programs. [See Reference (f)].

SOLICITING CONTRIBUTIONS FROM OUTSIDE SOURCES: Soliciting contributions from outside sources, such as non-DoD employees and local merchants, is prohibited for any and all fundraising activities, especially for fundraising offering tours of installations or rides in military vehicle, ships or aircraft.

USE OF RANK, OFFICIAL TITLE AND POSITION: Rank, official title and position may be used when conducting fundraising in official capacity for approved organizations. Only grade and military service may be used in connection with activities performed in personal capacity.

PERSONAL FUNDRAISING ACTIVITIES: In a private capacity, the following fundraising activities are prohibited:

- Solicitations in the work place;

- Solicitations of subordinates; and

- Solicitations from prohibited sources.

See GIFTS FROM OUTSIDE SOURCES.

\section{MARINE CORPS FUNDRAISING RESTRICTIONS:}

- Fundraising events are authorized for Marine Corps Community Services (MCCS) MWR activities per reference (a). These events shall be limited to authorized users of these activities and the funds raised must be for the benefit of the activities and their authorized users. Fundraising activities shall be conducted entirely on Marine Corps installations. Any gambling, including lottery, pool or game of chance for money or property, is strictly prohibited.

- Individual Marine units on DoD installations may hold fundraising events to augment their own unit funds subject to local regulations. They should first receive permission from the local MCCS and comply with the above requirements. 


\section{BIRTHDAY BALL FUNDRAISING}

\section{REFERENCES:}

(a) MCO 7040.11A (series)

(b) MCO P1700.27B (series)

(c) DoD 5500.07-R (JER)

(d) MCO $5760.4 \mathrm{C}$ (series)

(e) MCO P5800.16A (series) (LEGADMINMAN)

USMC BIRTHDAY BALLS: The USMC Birthday Ball is a two-tiered event, which has an official and unofficial function with separate sources of funding, as set forth in reference (a). A limited use of appropriated funds for the official portion is authorized for expenses such as: transportation, printing, publication and official ceremonial photos. However, guest of honor and cake expenses must not be paid for with appropriated funds.

Funding for unofficial portions of USMC Birthday Balls:

Non-appropriated funds (NAF) fundraising must have Marine Corps Community Services (MCCS) oversight, and:

- Gambling, including lotteries, pools or games of chance for money or property, is strictly prohibited as per reference (b).

- Monte Carlo games and activities are authorized if they award nonmonetary prizes. No reimbursement shall be made to patrons for unused or accumulated tickets, chips, etc. Further, these events must be conducted entirely on the sponsoring installation and international agreements apply overseas.

- Units may not conduct raffles for fundraising. However, reference (b) contemplates units using raffles for raising funds for MCCS.

Fundraising: For either informal unit funds or via MCCS fundraising, see FUNDRAISING.

Gifts and donations cannot be solicited except among unit members. Unsolicited donations must be accepted as provided in chapter 12 of reference (e).

USN BIRTHDAY BALLS: Because of restrictions that apply to official functions, units should conduct Navy Balls as unofficial events that are coordinated by a private volunteer committee. If an unofficial committee is used, such a committee is a non-Federal entity (NFE), with attendant JER consequences. Section 3-301 of reference (c), allows DoD employees to become members of and participate in the management of NFEs in their personal capacity, provided they act exclusively outside the scope of their official position.

- Always consult a Judge Advocate when undertaking any fundraising activity. 


\section{GAMBLING}

\section{REFERENCES:}

(a) 5 C.F.R. $\S 735.201$

(b) DoD 5500.07-R (JER)

(c) 20 U.S.C. $\$ 107 a(5)$

(d) 32 C.F.R. Part 4

(e) BUPERINST 1710.11 (series)

PROHIBITION: DoD employees shall not participate in any gambling activity prohibited by reference (a) on federally-owned or leased property or while on duty for the federal government, except:

- Activities necessitated by a DoD employee's law enforcement duties;

- Activities by organizations composed primarily of DoD employees or their dependents for the benefit of welfare funds for their own members or for the benefit other DoD employees or their dependents, when approved by the Head of the DoD Component or designee, subject to the limitations of local law and subsections 3-210 and 3-211 of reference (b);

- Private wagers among DoD employees if based on a personal relationship and transacted entirely within assigned federal government living quarters and within the limitation of local laws; or

- Purchase of lottery tickets authorized by any state from blind vendors licensed to operate vending facilities in accordance with reference (c).

ENFORCEMENT: Gambling with a subordinate may be a violation of Articles 133 and 134 of the Uniform Code of Military Justice. Gambling may be prohibited by Federal Government building and grounds regulations, such as, reference (d), which prohibits gambling in the Pentagon.

Use of government resources to prepare or further such activities is prohibited.

MWR BINGO AND NAVY RELIEF RAFFLES: Are permitted when conducted in accordance applicable directives, see FUNDRAISING.

GAMBLING IN GOVERNMENT QUARTERS: Small wages (e.g., card games, pools on sporting events), based on a personal relationship, transacted entirely within assigned government quarters (but not onboard ships) and not in violation of local law are permissible. Participants may not engage in gambling if it would violate Navy Regulations (Gambling with Subordinates), when contrary to local law or the service fraternization policies, see Fraternization. 


\section{GIFTS BETWEEN EMPLOYEES}

\section{REFERENCES:}

(a) DoD 5500.07-R (JER), Section 2-100 and 2-203

(b) 5 C.F.R. $\S 2635.304(c)(1)$

GENERAL RULE: A junior may not offer, give, make a donation or solicit contributions for a gift to a senior in the same chain of command and the senior may not accept such a gift.

\section{EXCEPTIONS TO THE GENERAL RULE:}

- Token gifts of a nominal value (less than $\$ 10.00$ ) may be given on non-frequent, occasional basis (e.g., a junior may give a superior a bag of candy when returning from vacation).

- Food and refreshments shared in the office.

- Reasonable personal hospitality at a residence or a gift in return for such hospitality (e.g., a junior could invite a superior to dinner).

- On special infrequent occasions -- such as childbirth, marriage, retirement, change of command, etc. -- a gift appropriate for the occasion may be given.

GROUP GIFTS: Authorized for special infrequent occasions (e.g., change of command or retirement). The advice of an Ethics Counselor should be sought. Total cost cannot exceed $\$ 300$ for the entire gift. All contributions must be voluntary. No more than $\$ 10.00$ may be solicited from a single person; however, individuals can choose to contribute more.

Creative attempts to avoid the $\$ 300$ maximum should be avoided (e.g., an organization should not be divided into different components solely to avoid the $\$ 300$ maximum by buying components of a larger gift).

\section{A SUPERIOR MAY NOT COERCE A SUBORDINATE TO CONTRIBUTE OR PROVIDE A GIFT (THIS TYPICALLY IS WHERE MANY INSPECTOR GENERAL CALLS COME FROM).}




\section{GIFTS FROM OUTSIDE SOURCES}

REFERENCES:

(a) DoD 5500.07-R (JER), Section 2-100

(b) SECNAVINST 4001.2J (series)

(c) SECNAVINST $1650.1 \mathrm{H}$ (series)

(d) U.S. Constitution: Article I, §9, Clause 8

(e) OPNAVINST 4001.1F (series)

(f) 5 C.F.R. §2635.201-205

(g) SECDEF Memo of 16 May 13

GENERAL RULE: Federal employees are forbidden from soliciting, coercing or accepting gifts from a "prohibited source" and gifts offered because of the employee's official position. Gifts to family members or a designee are "imputed" to the employee.

"PROHIBITED SOURCES": Any entity or person who is seeking official action from a federal employee or a federal agent; is doing or seeking to do business with the agency; or is regulated or substantially affected by the agency.

DEFINITION OF "GIFT": Anything of monetary value. Items exempted from the definition, and therefore not considered gifts:

- Modest refreshments that are not offered as part of a meal (the "coffee and donut rule");

- Greeting cards;

- Widely available discounts available to the public, all government employees or all military personnel;

- Prizes won in contests or events; including random drawings, which are open to the public; and

- Items for which you pay fair market value (if you pay for it, it's not a gift).

COMMON EXCEPTIONS TO THE GENERAL RULE PROHIBITING ACCEPTANCE OF A GIFT: In all cases, and especially with regard to the exceptions listed below, an employee is prohibited from requesting, soliciting or coercing a gift; allowing or creating the appearance of bribery or graft or accepting gifts so frequently that it creates an appearance of impropriety.

- Gifts worth less than $\$ 20.00$ per occasion. No more than $\$ 50.00$ worth of gifts from any one source per calendar year. Reference (g) allows enlisted members, E- 6 and below, to receive gifts in excess of $\$ 20$ in value when received from charitable, tax-exempt organizations;

- Gifts given because of a bona fide personal relationship;

- Awards for meritorious service. Must typically be non-cash and worth less than $\$ 200.00$;

- Gifts based on outside employment, such as approved moonlighting job or due to a spouse's employment;

- Free attendance at an event when employee is speaking on behalf of the federal agency;

- Free attendance at "widely attended gatherings" where attendance is deemed by a supervisor to be in the interests of the agency; and

- Check reference (f) for other exceptions.

FOREIGN GIFTS: Gifts from foreign governments may be accepted if proper diplomacy requires:

- Gifts with a fair market value (FMV) less than $\$ 375$ may be kept by the employee. 
- Gifts with a FMV over $\$ 350$ may be accepted on behalf of Department of the Navy and processed in accordance with reference (c).

PROCUREMENT (CONTRACTING) OFFICIALS: Anyone in a procurement position or who has ultimate responsibility for procurement should see their Ethics Counselor (Staff Judge Advocate for the General Courts-Martial Convening Authority) before accepting any gift.

FINANCIAL DISCLOSURES: Combined gifts worth more than $\$ 350$ from the same source in a calendar year must be reported by financial disclosure filers on their annual report.

NEVER ASSUME: Past practice or custom in an organization to accept certain gifts is not a defense. ASK THE ETHICS COUNSELOR.

CIVIL AND CRIMINAL PENALTIES EXIST FOR VIOLATIONS OF THESE RULES. 


\section{USE OF GOVERNMENT RESOURCES}

REFERENCES:

(a) DoD 5500.07-R (JER), §2-100 and §2-301

(b) DoD Dir 4500.56

(c) 31 USC $\$ 1344$

PREVENT MISUSE OF GOVERNMENT PROPERTY: Government property may not be utilized for private or personal purposes.

EXCEPTION: Limited personal use of Government resources may be permitted when:

- No adverse effect on performance of official duties;

- Use is of reasonable duration and frequency and use is during personal time;

- Serves a legitimate public interest;

- Does not reflect adversely on the Department of Defense (DoD) or the command; and

- Creates no significant additional cost to DoD or the command.

PREVENT MISUSE OF GOVERNMENT TIME: While receiving pay, unless the Servicemember is in an authorized leave or liberty status, all hours should be dedicated to government work. Superiors cannot order junior personnel to perform personal tasks which benefit the superior (e.g., order to perform unofficial "taxi" services for the CO's spouse).

AVOID "APPEARANCE" PROBLEMS: For both government property and time, Servicemembers must not create the appearance of misuse or impropriety (e.g., using government vehicle at a "drive-thru" restaurant, even on official travel).

GOVERNMENT VEHICLES: Government vehicles may not be used to transport employees between their home and work, reference (c). Local directives should be consulted for further definition of authorized and prohibited uses.

RENTAL VEHICLES: See TRAVEL BENEFITS.

GOVERNMENT AIRCRAFT: DoD guidelines concerning the use of government aircraft and air travel state that official travel should normally be accomplished using commercial transportation. Use of Military Air is a particularly sensitive area. It is highly recommended to consult policy guidelines to ensure correct use, see reference (b) and TRAVEL BENEFITS.

GIGS OR BARGES: Commanders should avoid misuse or even the appearance of gigs and barges, recreational use is not authorized. Gigs and barges may be used in support of foreign relations, community relations and crew morale and welfare. It is highly recommended that you seek advice from an Ethics Counselor (normally the Staff Judge Advocate for a General CourtsMartial Convening Authority) concerning gigs and barge issues. 


\section{OUTSIDE EMPLOYMENT}

\section{REFERENCES:}

(a) DoD 5500.07-R (JER), §2-206 and §2-303

(b) MILPERSMAN 5370-010

\section{COMMANDING OFFICERS MAY REQUIRE MEMBERS TO REPORT OUTSIDE} EMPLOYMENT AND PROHIBIT IT WHEN THERE IS A CONFLICT:

Command policy should be promulgated to ensure outside employment will not interfere or conflict with military duties. Case by case determination should be made. (Note: Financial disclosure filers must have advance approval for outside employment with a prohibited source.)

\section{POTENTIAL CONFLICTS:}

- Interference with official duties or time;

- Employment by a defense contractor/prohibited source, see CONFLICTS OF INTEREST;

- Appearances of impropriety;

- Dual compensation: Second salary paid from U.S. Treasury or appropriated funds;

- Involvement in any matter in which the United States is an interested party or has a substantial interest;

- Employment that will detract from readiness or pose a security risk; and

- Employment that prejudices good order and discipline or is service discrediting, see COMMERCIAL DEALINGS BETWEEN SERVICEMEMBERS.

QUESTIONABLE SITUATIONS SHOULD BE DISCUSSED WITH AN ETHICS COUNSELOR. 


\section{REFERENCES:}

(a) DoDI 1325.06

(b) DoD Dir 1344.10

(c) OPNAVINST 1620.1B (series)

(d) DoD 5500.07-R (JER), Ch 6

(e) MCO 5370.7B (series)

ALLOWABLE AND PROHIBITED POLITICAL ACTIVITIES: Political activities that are specifically allowed activities are: voting, bumper stickers, and non-leadership and out-ofuniform participation in political events. Political activities that are prohibited include: use of contemptuous language, recruiting membership in a criminal gang, participation in a leadership role or in uniform at political events. See reference (a) and enclosure (1) of reference (e) for more information on political activities.

COMMANDING OFFICER'S ANALYSIS: A Commanding Officer (CO) may prohibit, limit, or control, the political expression of a member when there "is a clear danger to loyalty, discipline or morale of military personnel or there is a material interference with the accomplishment of the military mission." See FREEDOM OF EXPRESSION.

WEARING UNIFORMS AT POLITICAL RALLIES: Service members are prohibited from wearing uniforms at any political activity, such as speeches, rallies, interviews, picket lines, marches or assemblies, if they know that a purpose of the activity supports personal or partisan views on political, social, economic or religious issues, except as authorized in advance by the CO.

RIGHT TO DIRECTLY CONTACT CONGRESS: No person may restrict any Servicemember from communicating with Congress in the Servicemember's personal or private capacity, see CONGRESSIONAL INQUIRIES.

RESERVE NOTE: Reserve Servicemembers who decide to run for political office as a civilian must be careful about how they advertise their military career as a campaign qualification or about using pictures of themselves in their military uniform in their campaign pamphlets, publications, advertising or communications. The reserve Servicemember must avoid implicitly or explicitly giving the impression that his or her candidacy is endorsed by the United States Navy, United States Marine Corps or the United States Government. Additionally, reserve component Servicemembers must also review and follow the restrictions that apply when it is appropriate or not appropriate for reserve personnel to wear their uniform. 


\section{PRIVATE ORGANIZATIONS AND SPOUSES CLUBS}

\section{REFERENCES:}

(a) DoD Dir 1000.11

(b) DoD Inst 1000.15

(c) DoD Inst 7600.6

(d) DoD Dir 1000.26E

(e) OPNAVINST 1700.7E (series)

(f) OPNAVINST 1700.9E (series)

(g) OPNAVINST 5760.CE (series)

(h) OPNAVINST 1710.11

(i) MCO 1700.26C (series)

(j) CNICINST 11000.1

(k) OPNAVINST1754.5B

STATUS OF PRIVATE ORGANIZATIONS: Private organizations are non-federal entities (NFEs) or Non-Appropriated Fund Activities (NAFIs) and are not entitled to the same level of support official entities. The nature and amount of support varies depending on the organization. Applicable regulations must be consulted to determine what level of support is authorized for any particular group.

PRIVATE ORGANIZATIONS: Private organizations that are NFEs include: Spouse Clubs, Boy Scouts, Girl Scouts, Navy League, Sea Cadets, athletic clubs, local school organizations, command organizations and social funds, such as: First Class Association or Chiefs' Mess and Wardroom.

NO DISCRIMINATION: Private organizations must be denied support if they discriminate in membership practices based upon race, sex, religion, etc.

CREATION OF PRIVATE ORGANIZATION: In order to create a private organization, founders must obtain written approval from the installation Commanding Officer (CO) to operate on an installation; organizations must have a constitution, by-laws, charter or other authorization document approved by the CO. Organizations cannot state or imply sponsorship of the Department of Defense (DoD) or Department of the Navy (DON), and should not use DoD, DON or other installation name or seal unless authorized.

PERIODIC REVIEW: Installation COs must conduct periodic reviews of all private organizations operating on base.

FUNDING AND SUPPORT: Private organizations are generally self-sustaining, primarily through dues, contributions, service charges, fees or special assessment of members. Limited fundraising activities conducted on the base may be permissible, under certain circumstances and controls. An Ethics Counselor (normally the Staff Judge Advocate for the General CourtsMartial Convening Authority) should be consulted. Minimal logistical support is authorized, dependent on the type of private organization and the authority under which it is organized. No direct financial support for a NAFI is allowed except as specifically authorized by the Secretary of the Navy.

Under certain circumstances, government resources may be used by private organizations on a "not to interfere" basis. Before approving "not to interfere" support for a NFE a Staff Judge Advocate should be consulted. 
SPOUSES CLUBS: Known as "Family Support Groups" (FSGs), Spouses Clubs enjoy the ability to receive official command support. FSGs may use the command's name in their name (e.g., Family Support Group of USS MCFAUL).

FAMILY READINESS GROUPS (FRGS): FRGs can receive additional command support due to their status, see reference (j). A FRG is a private organization, closely affiliated with the command, comprised of family members, Servicemembers and civilians associated with the command and its personnel, who support the flow of information, provide practical tools for adjusting to Navy deployments and separation and serve as a link between the command and Sailors' families. FRGs can help plan, coordinate, and conduct informational, care-taking, morale-building and social activities to enhance preparedness, command mission readiness and increase the resiliency and well-being of Servicemembers and their families. Installation COs may permit properly approved FRGs, which meet the requirements of reference (j), to operate on Navy installations. Individual commands may provide limited logistical support, such as access to command spaces, use of equipment and command representatives for FRG events, based on the criteria listed in reference (k). Expenditure of Navy appropriated and nonappropriated funds is generally not authorized for FRG social activities, including provision of food and beverages. Questions regarding specific events should be referred to a Judge Advocate or Office of General Counsel attorney in the chain of command. It is important to review reference (j), as well as the FRG handbook to ensure full compliance. 


\section{TRAVEL BENEFITS}

\section{REFERENCES:}

(a) DoD 5500.07-R (JER), Chapter 4

(b) FY2002 National Defense Authorization Act, §1116, 28 Dec 01

(c) Joint Federal Travel Regulations (JFTR)

(d) 31 U.S.C. $§ 1353$

(e) DoD Dir 4500.56

ACCEPTING TRAVEL FROM A NON-FEDERAL SOURCE: Official travel by DoD employees should normally be funded by the Government. Unsolicited official travel benefits from nonFederal sources may be accepted for attendance in an official capacity at a meeting or similar event. Acceptance must be approved in writing and an Ethics Counselor (normally the Staff Judge Advocate for a General Courts-Martial Convening Authority) must be consulted.

INCIDENTAL BENEFITS: Federal employees are allowed to retain promotional items, earned while on official travel, for personal use. These promotional items include frequent flier miles, upgrades and access to carrier clubs and facilities, in accordance with reference (b).

FREQUENT FLYER MILES: As described above, reference (b) now allows Servicemembers to keep frequent flyer miles from official travel for personal use. Frequent flyer miles can also be used on official travel for upgrades.

ON THE SPOT UPGRADES: Servicemembers may accept upgrades (even to first class) as long as official title and position are not basis for upgrade, see reference (a). Because of the possible appearance of impropriety, Servicemembers should avoid first-class travel in uniform.

OVER-BOOKING: If involuntarily bumped, Servicemembers may not keep free tickets or any other benefit received for personal use. If a Servicemember voluntarily gives up their seat and receives free tickets or another benefit, they may keep them for personal use. However, the volunteering may not result in an increase of expense to the government or additional per diem and the extra time may not be charged or received on travel claims.

RENTAL VEHICLES: Where public transport is not available, rental cars may be used to obtain suitable meals, visit drug stores, barber shops, cleaning establishments and similar places required for sustenance, comfort or health, section U3415 of reference (c). In all other respects, rules applicable to use of Government vehicles apply to use of rental cars. Use of rental vehicles for personal entertainment purposes is not authorized.

GOVERNMENT AIRCRAFT: See USE OF GOVERNMENT RESOURCES. 


\section{REFERENCES:}

(a) 10 U.S.C. $\$ 2261$

(b) SECNAVINST 7042.7K (series)

Command Coins can be purchased using three different sources of funds:

APPROPRIATED FUNDS: Appropriated funds may be used to purchase items intended for retention and/or recruitment. The item must cost $\$ 50$ or less and the command must document the justification for each item issued. Appropriated funds may also be used to purchase items for the recognition of Servicemembers for specific achievement, outstanding accomplishment, or a unique achievement that contributes to command effectiveness. These items are considered awards.

OFFICIAL REPRESENTATION FUNDS (ORF): Reference (b) provides that ORF may be used to purchase gifts and mementoes having a command/unit, Navy, or uniquely American or geographic theme, to be presented to specific classes of individuals such as foreign dignitaries or prominent citizens. ORF may therefore be used to purchase command/unit coins for presentation to only those groups of individuals listed in reference (b). Cost limitations are associated with the various types of recipients. Check reference (b) before purchasing/gifting the coin(s). An ORF coin record should be kept, to include the recipient and the reason for the presentation.

PERSONAL FUNDS: A commander may purchase coins with their own funds and are not bound by the restrictions noted above. Issuances of these coins are considered a gift and are subject to the gift rules.

DO NOT MIX COINS FROM DIFFERENT FUNDING SOURCES. 


\section{GLOSSARY OF COMMON ACRONYMS USED IN THIS PUBLICATION}

\begin{tabular}{|c|c|}
\hline ADSEP: & Administrative Separation \\
\hline ADT: & Active Duty for Training \\
\hline AFDCB: & Armed Forces Disciplinary Control Board \\
\hline $\mathrm{BAH}:$ & Basic Allowance for Housing \\
\hline BCA: & Body Composition Assessment \\
\hline BCD: & Bad Conduct Discharge \\
\hline BMC: & Branch Medical Clinic \\
\hline BOI: & Board of Inquiry \\
\hline BUPERS: & Bureau of Personnel (Navy Personnel Command) \\
\hline CA: & Convening Authority \\
\hline CAAC: & Counseling and Assistance Center \\
\hline CCSM: & Clinical Case Staff Meeting \\
\hline CFC: & Combined Federal Campaign \\
\hline CFR: & Code of Federal Regulations \\
\hline CNP: & Chief of Navy Personnel \\
\hline Cl: & Command Investigation \\
\hline CMC: & Command Master Chief \\
\hline CMC: & Commandant of the Marine Corps \\
\hline CNIC: & Commander, Naval Installations Command \\
\hline CNO: & Chief of Naval Operations \\
\hline CO: & Commanding Officer \\
\hline COl: & Courts of Inquiry \\
\hline CONUS: & Continental United States \\
\hline CRA: & Credit Reporting Agency \\
\hline CRC: & Case Review Committee \\
\hline DAEO: & Designated Agency Ethics Official \\
\hline DAPA: & Drug and Alcohol Program Advisor \\
\hline DC M\&RA: & Deputy Commandant of the Marine Corps for Manpower and Reserve Affairs \\
\hline DC: & Defense Counsel \\
\hline DD: & Dishonorable Discharge \\
\hline DFAS: & Defense Finance and Accounting Service \\
\hline DFC: & Detachment for Cause \\
\hline DoD: & Department of Defense \\
\hline DoDD: & Department of Defense Directive \\
\hline DoDI: & Department of Defense Instruction \\
\hline DON: & Department of the Navy \\
\hline DONCIO: & Department of the Navy Chief Information Officer \\
\hline DRB: & Disciplinary Review Board \\
\hline EAOS: & End of Active Obligated Service \\
\hline EAS: & End of Active Service \\
\hline EMI: & Extra Military Instruction \\
\hline EO: & Equal Opportunity \\
\hline EVAL: & Evaluation \\
\hline FAA: & Federal Aviation Administration \\
\hline FAP: & Family Advocacy Program \\
\hline FAR: & Family Advocacy Representative \\
\hline FFM: & Frequent Flyer Miles \\
\hline FITREP: & Fitness Report \\
\hline
\end{tabular}




\begin{tabular}{|c|c|}
\hline FJA: & Fleet Judge Advocate \\
\hline FMBE: & Navy Appropriations Matters Office \\
\hline FMV: & Fair Market Value \\
\hline FOIA: & Freedom of Information Act \\
\hline FRG: & Family Readiness Group \\
\hline FTC: & Federal Trade Commission \\
\hline GCM: & General Court Martial \\
\hline GCMCA: & General Court Martial Convening Authority \\
\hline GMT: & General Military Training \\
\hline HIPAA: & Health Insurance Portability and Accountability Act \\
\hline HON: & Honorable Characterization of Service \\
\hline GEN: & General (Under Honorable Conditions) Characterization of Service \\
\hline IAW: & In Accordance With \\
\hline ICO: & Installation Commanding Officer \\
\hline IDA: & Initial Denial Authority \\
\hline IDC: & Initial Determination Committee \\
\hline IDT: & Inactive Duty for Training \\
\hline IG: & Inspector General \\
\hline 10: & Investigating Officer \\
\hline IRR: & Individual Ready Reserve \\
\hline ISIC: & Immediate Superior in Command \\
\hline JAGMAN: & Judge Advocate General's Manual \\
\hline JAD: & Office of the Staff Judge Advocate for the Commandant of the Marine Corps \\
\hline JER: & Joint Ethics Regulation \\
\hline LA: & Legal Assistance \\
\hline LOD: & Line of Duty \\
\hline LODI: & Line of Duty Investigation \\
\hline LOT: & Letter of Transmittal \\
\hline LR: & Litigation Report \\
\hline LSSS: & Legal Services Support Section (USMC) \\
\hline MARADMIN: & Marine Corps message \\
\hline MARCORSEF & DMAN: Marine Corps Separation Manual \\
\hline MCCS: & Marine Corps Community Service \\
\hline MClO: & Military Criminal Investigative Office \\
\hline MCM: & Manual for Courts Martial \\
\hline MEP: & Military Entrance Processing \\
\hline MHE: & Mental Health Evaluation \\
\hline MHP: & Mental Health Provider \\
\hline MILPERSMAI & V: Military Personnel Manual \\
\hline MJ: & Military Judge \\
\hline MPO: & Military Protective Order \\
\hline MSRRA: & Military Spouses Residency Relief Act \\
\hline MTF: & Medical Treatment Facility \\
\hline MWR: & Morale, Welfare, and Recreation \\
\hline NAF: & Non Appropriated Funds \\
\hline NAFI: & Non Appropriated Federal Activity \\
\hline NAVADMIN: & Naval message \\
\hline NAVPERSCO & M: Navy Personnel Command \\
\hline NCIS: & Naval Criminal Investigative Service \\
\hline NDAA: & National Defense Authorization Act \\
\hline NDSL: & Navy Drug Screening Laboratory \\
\hline
\end{tabular}




\begin{tabular}{|c|c|}
\hline NJP: & Non Judicial Punishment \\
\hline NLT: & Not Later Than \\
\hline NMPS: & Navy Mobilization Processing Site \\
\hline NOSC: & Navy Operational Support Center \\
\hline NSCDA: & National Security Case Disposition Authority \\
\hline OCA: & Original Classification Authority \\
\hline OCONUS: & Outside the Continental United States \\
\hline OGC: & Office of the General Counsel \\
\hline OIC: & Officer in Charge \\
\hline OJAG: & Office of the Judge Advocate General \\
\hline OLA: & Office of Legislative Affairs \\
\hline OPM: & Office of Personnel Management \\
\hline OPNAVINST: & OPNAV Instruction \\
\hline OPREP: & Operational Report \\
\hline ORF: & Official Representation Funds \\
\hline OSD: & Office of the Secretary of Defense \\
\hline OTH: & Other than Honorable Characterization of Service \\
\hline PA: & Public Affairs \\
\hline PCA: & Posse Commitatus Act \\
\hline PCS: & Permanent Change of Station \\
\hline PFA: & Physical Fitness Ássessment \\
\hline PI: & Preliminary Inquiry \\
\hline PMO: & Priority Material Office \\
\hline MCO: & Marine Corps Order \\
\hline POA: & Power of Attorney \\
\hline PRD: & Projected Rotation Date \\
\hline PSD: & Personnel Support Detachment \\
\hline PTA: & Pre-Trial Agreement \\
\hline PTC: & Pre-Trial Confinement \\
\hline PTR: & Pre-Trial Restraint \\
\hline PTSD: & Post Traumatic Stress Syndrome \\
\hline RCM: & Rule for Court Martial \\
\hline RLSO: & Region Legal Service Office \\
\hline SA: & Separation Authority \\
\hline SACO: & Substance Abuse Control Officer \\
\hline SAPR: & Sexual Assault Prevention and Response \\
\hline SARP: & Substance Abuse Rehabilitation Program \\
\hline SCM: & Summary Court Martial \\
\hline SCRA: & Service Members Civil Relief Act \\
\hline SECDEF: & Secretary of Defense \\
\hline SECNAV: & Secretary of the Navy \\
\hline SECNAVINST & Secretary of the Navy Instruction \\
\hline SELRES: & Selected Reserve \\
\hline SGLI: & Service Members Group Life Insurance \\
\hline SILT: & Separation In Lieu of Trial \\
\hline SITREP: & Situational Report \\
\hline SJA: & Staff Judge Advocate \\
\hline SOFA: & Status of Forces Agreement \\
\hline SOP: & Standard Operating Procedure \\
\hline SOPA: & Senior Officer Present Afloat \\
\hline SPCM: & Special Court Martial \\
\hline
\end{tabular}


SPCMCA: Special Court Martial Convening Authority

SSN: $\quad$ Social Security Number

TAD: $\quad$ Temporary Additional Duty

TBI: $\quad$ Traumatic Brain Injury

TC: $\quad$ Trial Counsel

TYCOM: $\quad$ Type Commander

UCMJ: $\quad$ Uniform Code of Military Justice

UPC: $\quad$ Urinalysis Program Coordinator

USC: $\quad$ United States Code

USCG: $\quad$ United States Coast Guard

USCIS: $\quad$ United States Citizen and Immigration Service

USDAO: $\quad$ United States Defense Attaché Office

USERRA: Uniformed Services Employment and Reemployment Rights Act

VLC: Victim's Legal Counsel

VTC: $\quad$ Video Tele Conference

XO: $\quad$ Executive Officer

XOI: $\quad$ Executive Officer Inquiry 


\section{APPENDIX}
A. COMMANDING OFFICER (CO) SEARCH AND SEIZURE CHECKLIST
B. OVERVIEW OF THE MILITARY JUSTICE SYSTEM
C. COURT-MARTIAL MAXIMUM PUNISHMENT CHART
D. CONVENING AUTHORITY LIMITATIONS ON FINDINGS MODIFICATIONS
E. CONVENING AUTHORITY LIMITATIONS ON SENTENCING MODIFICATIONS
F. NJP PUNISHMENT LIMITATIONS CHART
G. USE OF POSITIVE URINANLYSIS RESULTS
H. HANDING SEXUAL HARASSMENT ALLEGATIONS
I. HANDING FRATERNIZATION ALLEGATIONS
J. COMPLAINTS OF WRONG COMMANDING OFFICER CHECKLIST
K. EXECUTIVE OFFICER INQUIRY (XOI) GUIDE
L. DELIVERY OF PERSONNEL
M. SERVICE OF PROCESS 


\section{COMMANDING OFFICER (CO) SEARCH AND SEIZURE CHECKLIST}

I. Finding the existence of probable cause to order a search, what should the CO know before making the authorization? The following considerations are provided to aid in the determination:

a. Find out the name and duty station of the applicant requesting a search authorization

b. Administer an oath to the person requesting the search authorization. A recommended format for the oath is set forth below:

"Do you solemnly swear (or affirm) that the information you are about to provide is true to the best of your knowledge and belief, so help you god?"

c. What is the location and description of the premises, object, or person to be searched? Ask the following:

i. Is the person or area one over which the $\mathrm{CO}$ has jurisdiction?

ii. Is the person or place described with particularity?

d. What facts indicate that the place to be searched and property to be seized is actually located on the person or in the place indicated?

e. Who is the source of the information?

i. If the source is a person other than the applicant for the search authorization who is before the CO, see Part II.

ii. If the source is the person before the $\mathrm{CO}$ asking for the search authorization, the following should be asked:

1. What training has the person had in investigating offenses of the type in question or in identifying the particular type of evidence?

2. Is there any further information that will provide grounds for the search for, and seizure of, the property in question?

3. Is the person withholding any information that may affect the CO's decision on the request to grant a search authorization?

f. Once the $\mathrm{CO}$ is satisfied as to the reliability of the information and that of the person from whom it is received, the $\mathrm{CO}$ may entertain reasonable belief that the items are where they are said to be and a search may be authorized.

g. The search authorization should reflect something similar to the following:

\section{Appendix (A)}


"I (CO's name, rank, position) find that probable cause exists for the issuance of an authorization to search (name specific location or person) for the following items: (specific description of items sought); and I authorize (name of person to conduct the search) to search (name specific location or person) for those items and to seize them if found."

\section{SEARCH AUTHORIZATIONS: INFORMANT ADDENDUM}

a. When the applicant for the search authorization is not the informant who provided the facts which serve as the basis for the request, a CO must first determine what forms the basis of the informant's information. The facts provided by the informant must be specific enough to be acted upon.

b. The CO must then determine the informant's reliability. The following questions may help a $\mathrm{CO}$ ascertain the reliability of an informant:

i. How long has the applicant for the search authorization known the informant?

ii. Has the informant provided information in the past?

iii. Has the provided information always proven correct in the past? Almost always? Never?

iv. Has the informant ever provided any false or misleading information?

v. (If a drug case) Has the informant ever identified drugs in the presence of the applicant?

vi. Has any prior information resulted in conviction? Acquittal? Are there any cases still awaiting trial?

vii. What other situational background information was provided by the informant that substantiates reliability of the information provided (e.g., accurate descriptions, credible timelines, actual personal knowledge/observation, etc.)?

c. The following questions may help a CO ascertain the reliability of the information:

i. Does the applicant for the search authorization possess other information from known reliable sources, which indicates what the informant says is true?

ii. Does the CO possess information which indicates what the information says is true?

\section{Appendix (A)}




\section{SEARCHES: DESCRIBE WHAT TO LOOK FOR AND WHERE TO LOOK}

a. Requirement of specificity: No valid search authorization will exist unless the place to be searched and the items to be sought are particularly described.

b. Description of the place of the person to be searched:

i. Persons: Always include all known facts about the individual, such as name, rank, social security number when necessary for identification purposes, and unit. If the suspect's name is unknown, include a personal description, places frequented, known associates, make/model of auto, usual attire, etc.

ii. Places: be as specific as possible, with great effort to prevent the area which is being authorized for search from being too broad, giving rise to the possible claim that the search is just an illegal "fishing expedition." On the other hand, the place described should not be so narrowly detailed so as to exclude logical locations where there is probable cause to believe evidence may be found in a given location (e.g., describing one drawer in a chest of drawers instead of stating the entire chest and all drawers.) 


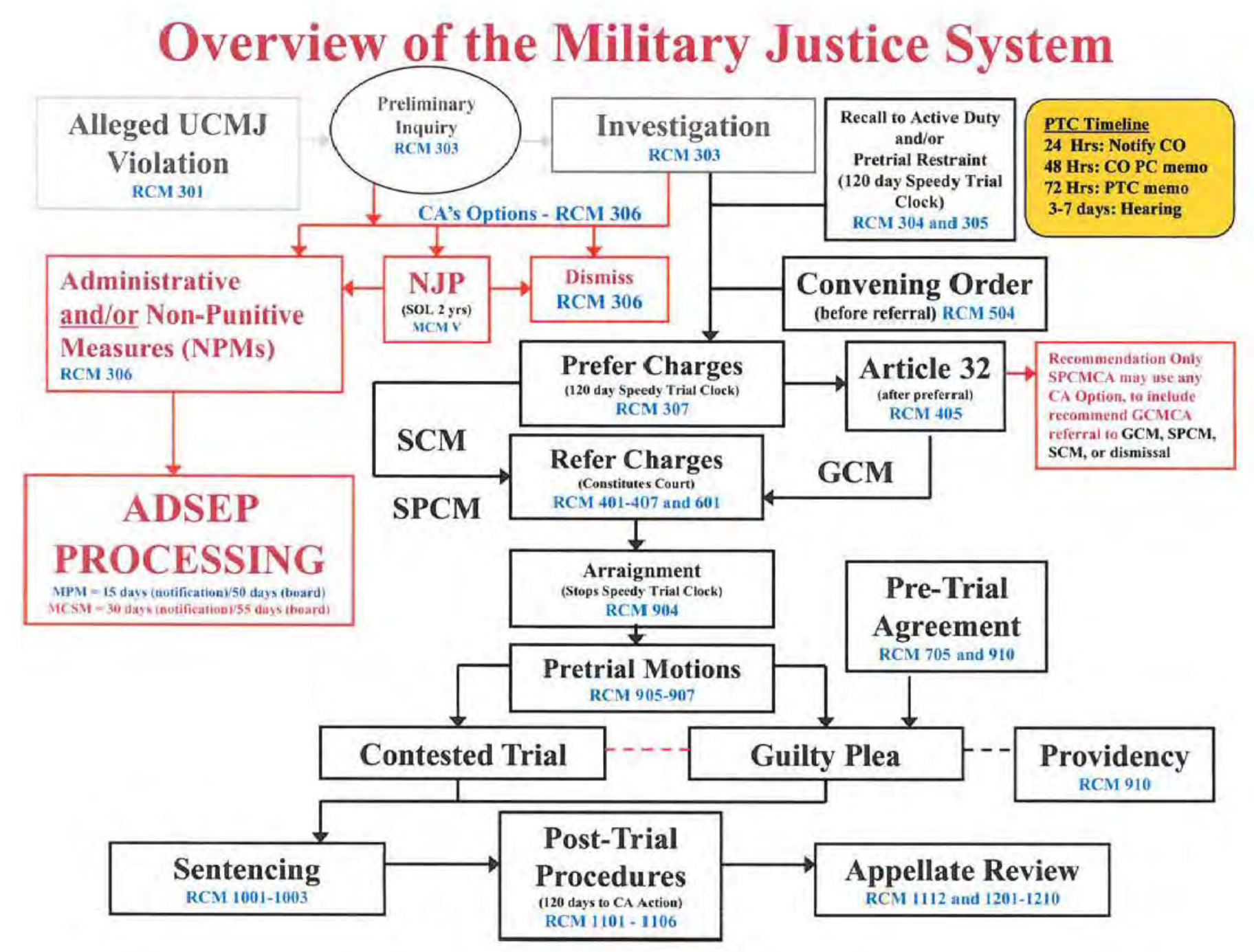




\section{MAXIMUM PUNISHMENT CHART}

\begin{tabular}{|c|c|c|c|c|c|c|c|}
\hline \multirow[t]{2}{*}{ Punishment } & \multicolumn{2}{|c|}{ SCM } & \multicolumn{2}{|l|}{ SPCM } & \multicolumn{3}{|c|}{ GCM } \\
\hline & $\begin{array}{l}E-4 \& \\
\text { below }\end{array}$ & E-5 \& above & EM's & O's \& WO's & EM's & WO's & O's \\
\hline 1. Death & NO & NO & NO & NO & YES $(* 1)$ & YES $\left(1^{*}\right)$ & YES $(* 1)$ \\
\hline 2. Dismissal & NO & NO & NO & NO & NO & NO & YES \\
\hline 3. Dishonorable Discharge & NO & NO & NO & NO & YES & YES & NO \\
\hline 4. Bad-Conduct Discharge & NO & NO & YES & NO & YES & NO & NO \\
\hline 5. Confinement & 30 days & NO & 12 mos. & NO & YES & YES & YES \\
\hline 6. Restriction & 60 days & 60 days & 60 days & 60 days & 60 days & 60 days & 60 days \\
\hline $\begin{array}{l}\text { 7. Hard Labor Without } \\
\text { Confinement }\end{array}$ & 45 days & NO & 90 days & NO & 3 mos. & NO & NO \\
\hline $\begin{array}{l}\text { 8. Forfeiture of all Pay and } \\
\text { Allowances }\end{array}$ & NO & NO & NO & NO & YES & YES & YES \\
\hline $\begin{array}{l}\text { 9. Forfeiture of two-thirds } \\
\text { pay per month }\end{array}$ & $1 \mathrm{mo} \cdot\left({ }^{*} 2\right)$ & $1 \mathrm{mo} .(* 2)$ & $12 \mathrm{mos}$. & 12 mos. & YES & YES & YES \\
\hline 10. Fine & $\operatorname{YES}(* 3 / * 4)$ & $\operatorname{YES}(* 3 / * 4)$ & YES $(* 3)$ & YES $(* 3)$ & YES & YES & YES \\
\hline $\begin{array}{l}\text { 11. Reduction to next } \\
\text { inferior rate }\end{array}$ & YES & YES & YES & NO & YES & NO & NO \\
\hline $\begin{array}{l}12 \text { Reduction to lowest } \\
\text { paygrade }\end{array}$ & YES & NO & YES & NO & YES & NO & NO \\
\hline 13. Reprimand & YES & YES & YES & YES & YES & YES & YES \\
\hline
\end{tabular}

ALL PUNISHMENTS ARE LIMITED BY THE MAXIMUM ALLOWABLE FOR THE UCMJ ARTICLES VIOLATED AS WELL AS THE TYPE OF COURTMARTIAL THE CASE IS REFERRED TO.

(*1) Where authorized or mandatory

(*2) May extend payment up to two months - MJM 10-F-2.e

$\left({ }^{\star} 3\right)$ If given, a fine or a fine and forfeiture combination may not exceed the maximum amount of forfeitures which may be adjudged in a case.

(*4) AT SCM, a fine may not be combined with forfeitures

\section{Appendix (C)}




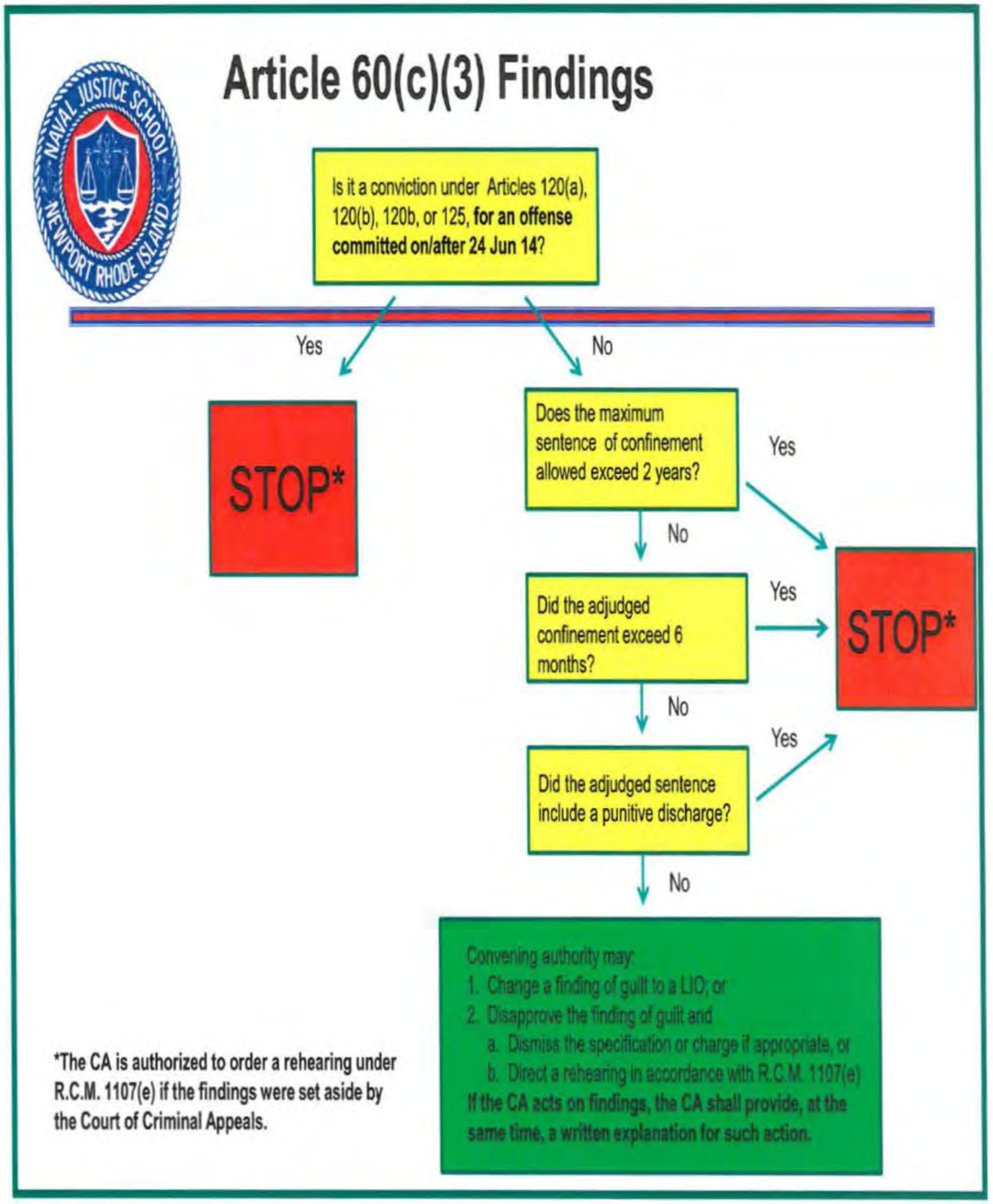

Appendix (D) 


\section{Article 60(c)(2) Sentence}

General Rule*: For offenses committed onlafter 24 June 2014 - regardless of the offenses charged - the CA may not disapprove, commute, or suspend in whole or in part" an adjudged sentence of confinement for more than 6 months or a punitive discharge, unless a below exception applies:

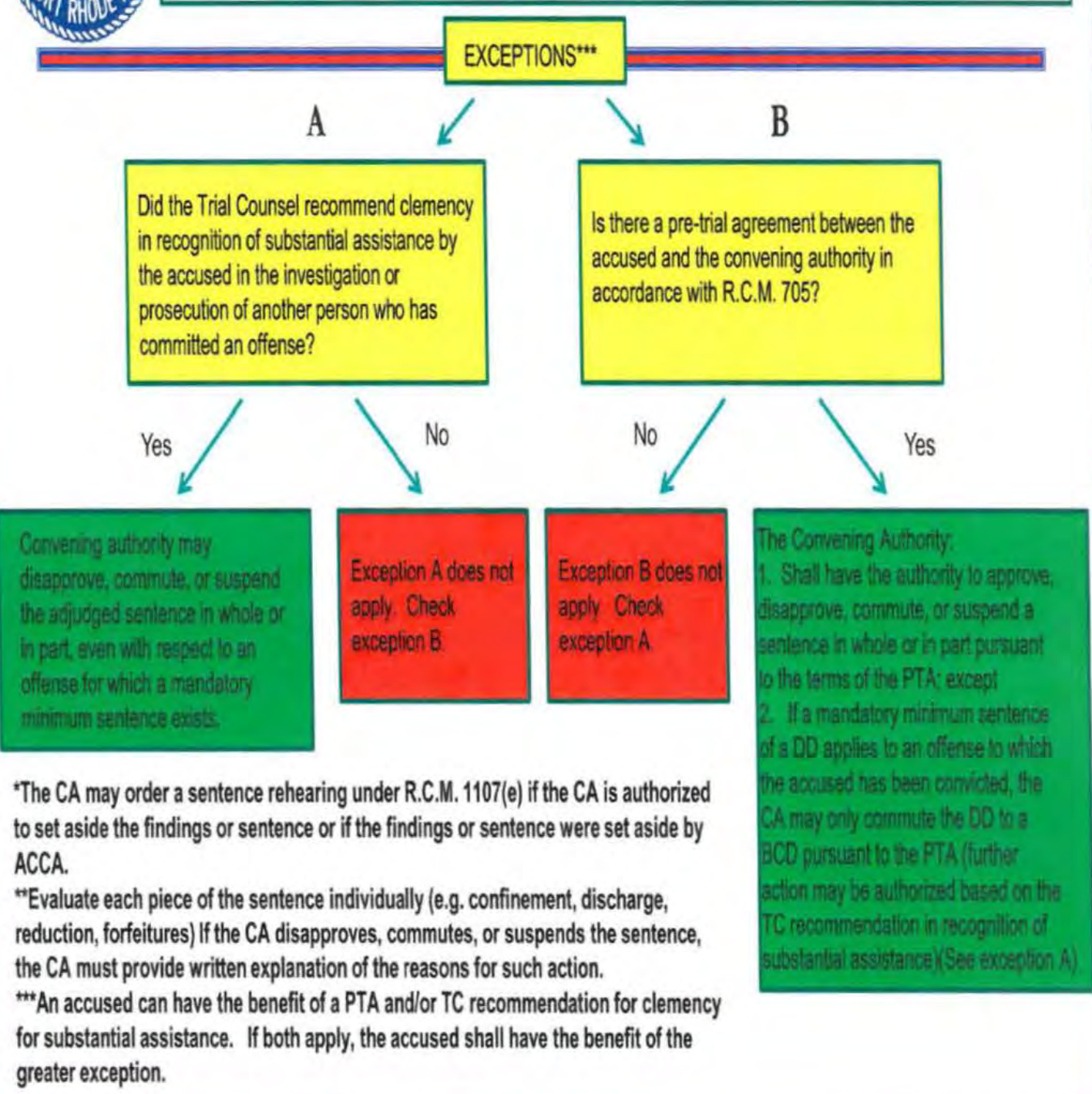

\section{Appendix (E)}


ARTICLE 15 PUNISHMENT LIMITATIONS

\begin{tabular}{|c|c|c|c|c|c|c|c|c|c|}
\hline $\begin{array}{l}\text { Imposed } \\
\text { By }\end{array}$ & $\begin{array}{l}\text { Imposed } \\
\text { On }\end{array}$ & $\begin{array}{c}\text { Bread \& Water } \\
\text { or DIMRATS } \\
\text { (1) }\end{array}$ & $\begin{array}{l}\text { Correctional } \\
\text { Custody } \\
\text { (2) }\end{array}$ & $\begin{array}{c}\text { Arrest in } \\
\text { Quarters } \\
\text { (3) }\end{array}$ & $\begin{array}{c}\text { Forfeitures } \\
\text { (4\&5) }\end{array}$ & $\begin{array}{c}\text { Reduction } \\
\text { (4\&6) }\end{array}$ & $\begin{array}{c}\text { Extra } \\
\text { Duties } \\
\text { (7) }\end{array}$ & $\begin{array}{c}\text { Restriction } \\
\text { (7) }\end{array}$ & $\begin{array}{l}\text { Reprimand or } \\
\text { Admonition } \\
\text { (4) }\end{array}$ \\
\hline \multirow{3}{*}{$\begin{array}{l}\text { Flags/Generals } \\
\text { in Command }\end{array}$} & Officers & No & No & 30 Days & $\begin{array}{l}1 / 2 \text { of } 1 \mathrm{Mo} \text {. } \\
\text { For } 2 \mathrm{Mos} \text {. }\end{array}$ & No & No & 60 Days & Yes \\
\hline & $\begin{array}{c}E-4 \text { to } \\
E-9\end{array}$ & No & No & No & $\begin{array}{l}\mathrm{y} / \text { of } 1 \mathrm{Mo} \text {. } \\
\text { For } 2 \mathrm{Mos} \text {. }\end{array}$ & 1 Grade & 45 Days & 60 Days & Yes \\
\hline & $\begin{array}{c}E-1 \text { to } \\
E-3\end{array}$ & 3 Days & 30 Days & No & $\begin{array}{l}\mathrm{Y} / 2 \text { of } 1 \mathrm{Mo} . \\
\text { For } 2 \mathrm{Mos} \text {. }\end{array}$ & 1 Grade & 45 Days & 60 Days & Yes \\
\hline \multirow{3}{*}{0.4 to 0.6} & Officers & No & No & No & No & No & No & 30 Days & Yes \\
\hline & $\begin{array}{c}E-4 \text { to } \\
\text { Eg }\end{array}$ & No & No & No & $\begin{array}{l}\mathrm{Y} \text { of } 1 \mathrm{Mo} . \\
\text { For } 2 \mathrm{Mos} \text {. }\end{array}$ & 1 Grade & 45 Days & 60 Days & Yes \\
\hline & $\begin{array}{c}E-1 \text { to } \\
E-3\end{array}$ & 3 Days & 30 Days & No & $\begin{array}{l}\mathrm{Y} \text { of } 1 \mathrm{MO} \text {. } \\
\text { For } 2 \mathrm{MOS}\end{array}$ & 1 Grade & 45 Days & 60 Days & Yes \\
\hline \multirow{3}{*}{$\begin{array}{c}\text { 0-3 / Below \& } \\
\text { OICs (8) }\end{array}$} & Officers & No & No & No & No & No & No & 15 Days & Yes \\
\hline & $\begin{array}{c}E-4 \text { to } \\
E-9\end{array}$ & No & No & No & 7 Days & 1 Grade & 14 Days & 14 Days & Yes \\
\hline & $\begin{array}{c}E-1 \text { to } \\
E-3\end{array}$ & 3 Days & 7 Days & No & 7 Days & 1 Grade & 14 Days & 14 Days & Yes \\
\hline
\end{tabular}

(1) May be awarded only if attached to or embarked in a vessel and may not be combined with other restraint punishment or extra duties.

(2) May not be combined with restriction or extra duties.

(3) May not be combined with restriction.

(4) May be imposed in addition to or in lieu of all other punishments.

(5) Shall be expressed in whole dollar amounts only.

(6) Navy CPOs (E-7 to E-9) may not be reduced at NJP; Marine Corps NCOs (E-6 to E-9) may not be reduced at NJP (Check directives relating to promotion).

(7) Restriction and extra duties may be combined to run concurrently, but the combination may not exceed the maximum possible for extra duties.

(8) OICs regardless of rank have NJP authority over enlisted personnel only. OIC's and Marine CC may only reduce personnel within their promotion authority.

(9) Restriction imposed upon commissioned and warrant officers may not exceed 15 days when imposed by a CO below the grade of MAJ or LCDR (JAGMAN 0111a)

\section{Appendix (F)}


USE OF DRUG URINALYSIS RESULTS

FROM DOD CERTIFIED DRUG LABS*

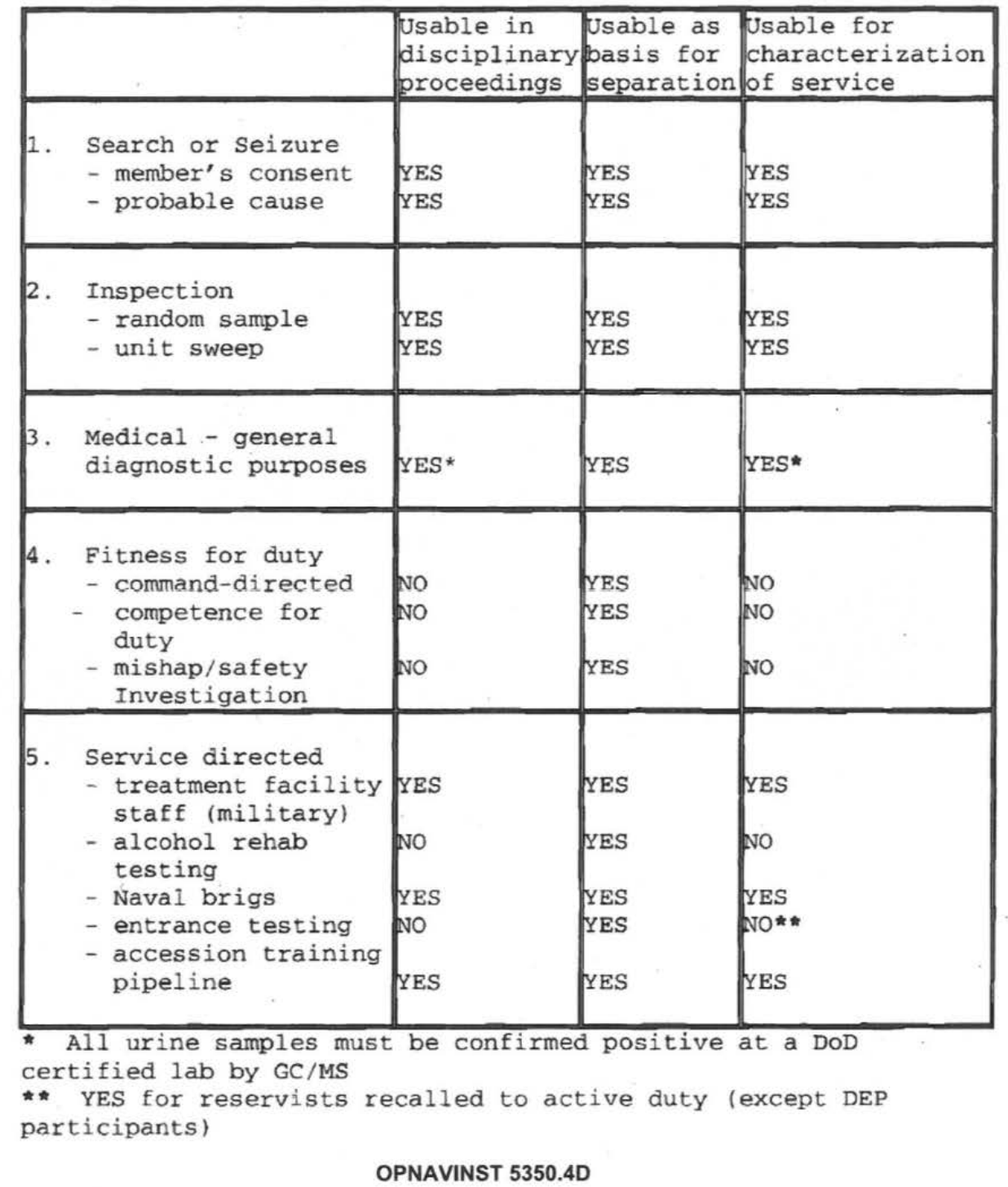

\section{Appendix (G)}




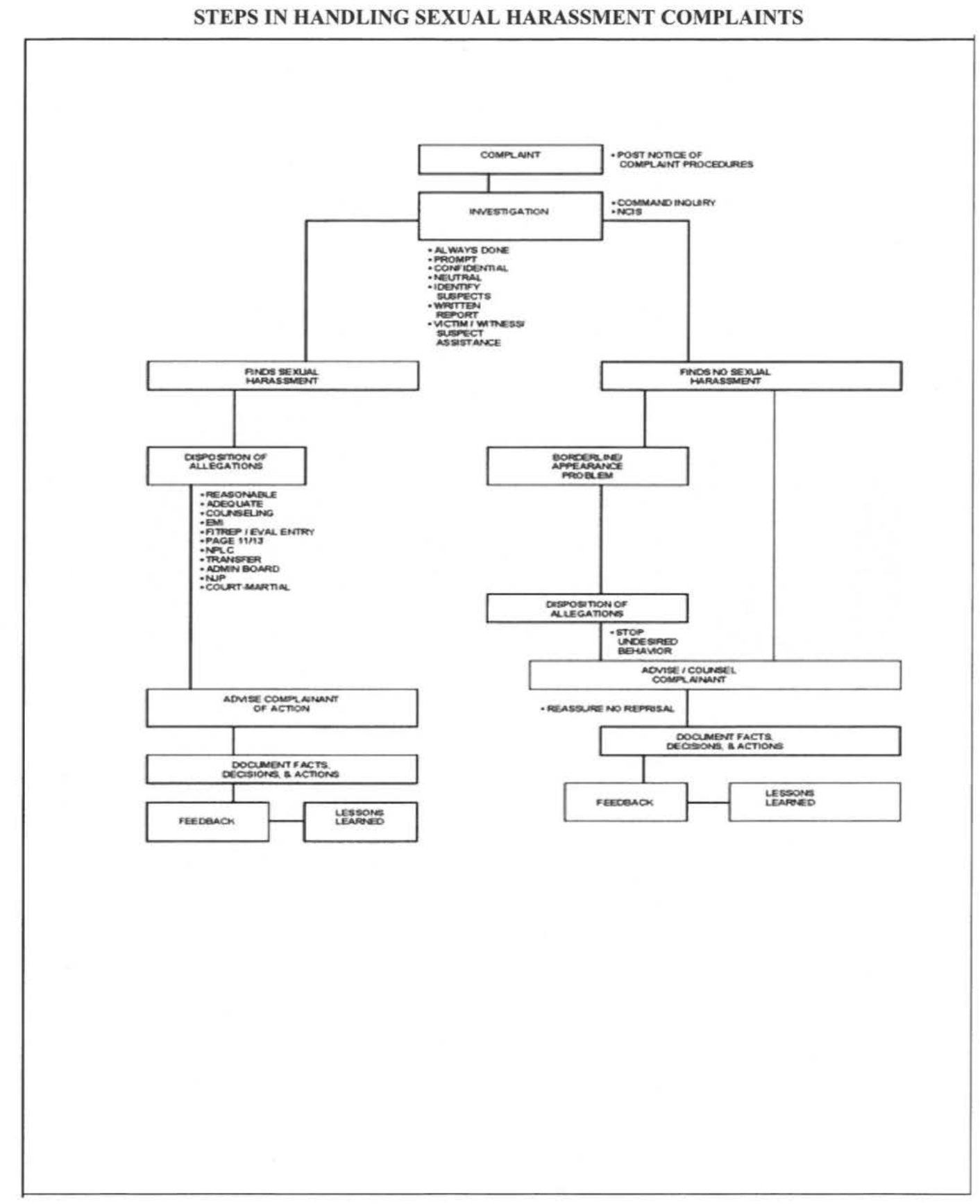

Appendix (H) 
HANDLING FRATERNIZATION ALLEGATIONS

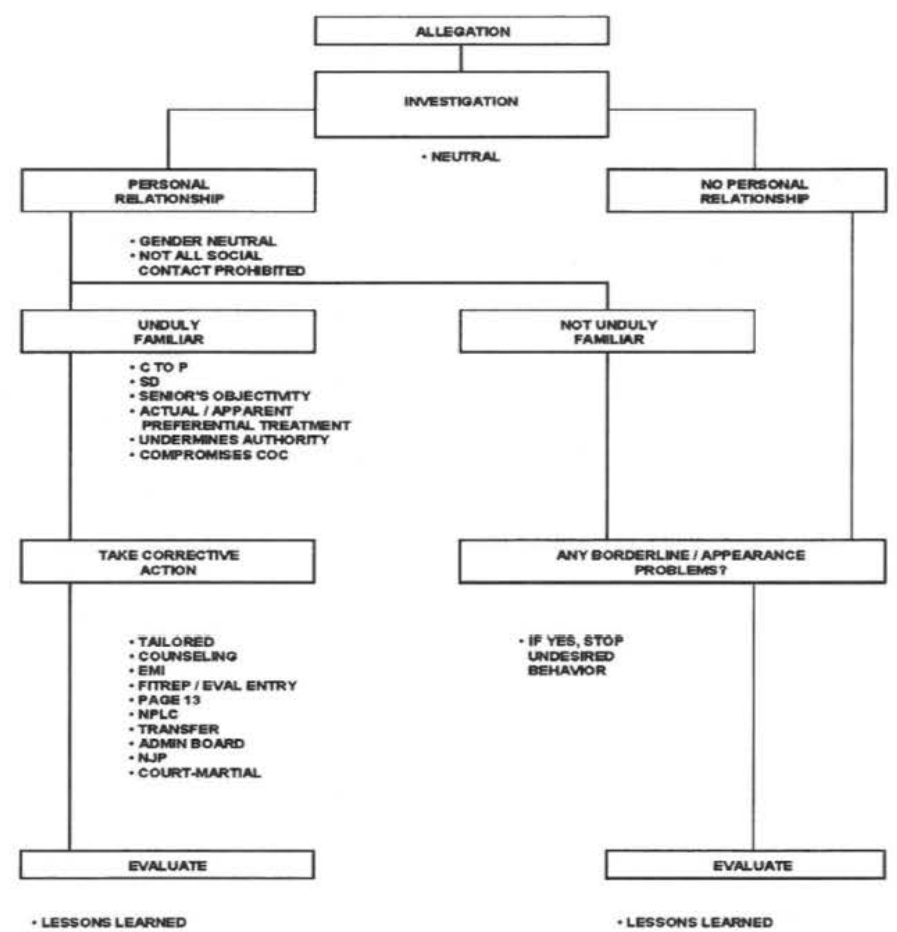

Appendix (I) 


\section{COMPLAINTS OF WRONG - COMMANDING OFFICER CHECKLIST}

${ }^{*}$ All references are to the Judge Advocate General Manual (JAGMAN) unless otherwise noted.

Complainant Name: ; Date Received:

1. Complaint is properly forwarded? ( $\$ 0306 \mathrm{~d}$; NAVREG 1150)

a. Addressed to proper commanding officer (for Article 1150 complaints) or to proper general court-martial convening authority (for Article 138 complaints) via intermediate endorsers. If not, readdress and forward back to the complainant or to the proper intermediate endorser, including the respondent.

b. Is the respondent named in the complaint the proper respondent? ( $\$ 0305 \mathrm{~b}$; NAVREG 1150)

c. Have intermediate endorsers added additional information adverse to the information provided by the complainant? If so, has the complainant had an opportunity to review and rebut the new information?

2. Complaint timely, or is it submitted late? Is the late submission justified? (§ 0306a). If not, complaint may still be processed or it may be returned to complainant. $(\S 0307 \mathrm{~b}(2))$ without action.

3. Complainant does not join more than one respondent? (§ $0306 \mathrm{~g})$. If it does, the complaint may still be processed as two complaints of wrong, one against each proper respondent, or it may be returned to the complainant as defective. (§0306g) The same concept applies to a single complaint from two or more complainants.

4. Complaint is in the proper format? (§ 0306c, Appendix A-3-a). If not, obtain missing information and forward to the proper disposition authority or return the complaint to the complainant as defective. (§0307b(2))

a. Complaint includes:

i. Complainant and respondent's name and identifying information?

ii. Includes the date wrong discovered and number of days between discovery and complaint submission?

iii. If there is a submission delay, is it explained?

iv. Complaint complete with all enclosures and endorsements?

v. Complaint certified as "true and accurate" and signed, witnessed, and dated?

5. Complaint alleges a wrong that is a proper subject of a complaint of wrongs? (§0303f, 0304a)

a. Not regarding recommendations only?

b. Not regarding general service policies?

c. Not wrongs that have another procedure for disposition that provides notice, right to rebut/hearing, and review by a superior? (e.g., NJP, ADSEP boards, courtsmartial, etc.)

d. Complaint makes a proper request for relief? (§ 0305)

\section{Appendix (J)}




\section{EXECUTIVE OFFICER'S INQUIRY (XOI)}

1. Obtain the report chit, all written statements and other documentary and physical evidence relating to the alleged offenses from the legal officer.

2. Call in the accused and all reasonably available witnesses who can testify about either the alleged offense or evidence in extenuation, mitigation, or aggravation concerning the alleged offense.

3. Inform the accused that the commanding officer $(\mathrm{CO})$ is contemplating the imposition of non-judicial punishment (NJP) and that this (XOI) is an informal hearing before possible NJP.

4. Describe the specific offense(s) to the accused, including the specific article(s) of the Uniform Code of Military Justice that the accused allegedly violated.

5. If applicable, advise the accused he/she has the right to refuse NJP. (An accused can never refuse $\mathrm{XOI}$ ).

6. Advise the accused that he/she does not have to make a statement regarding the offense(s) and that any statement made by him/her can be used as evidence against him/her at XOI and NJP.

a. NOTE: If it is reasonably foreseeable that the accused's statements during XOI may be considered for introduction in a later court-martial, an explanation of rights and a waiver - in the format of Appendix A-1-M of the JAGMAN - will have to be obtained from the accused during the hearing, before proceeding further.

7. Ask the accused what happened.

a. If the accused admits guilt, the accused should be allowed to offer evidence in extenuation and mitigation.

i. Then ask any witnesses to testify about any related matters in extenuation and mitigation or aggravation.

b. If the accused denies guilt, the accused should be asked for his/her version of the facts.

i. Ask the witnesses to testify about the alleged offense(s).

ii. Inform the accused of any other evidence against him/her concerning the alleged offense(s).

iii. Allow the accused to rebut if he/she chooses.

iv. Ask the witnesses to testify on any matters in extenuation and mitigation or aggravation.

8. Ask the accused if he/she would like to make a final statement.

\section{Appendix (K)}


9. If the $\mathrm{CO}$ has given the $\mathrm{XO}$ authority to dismiss the case or specific charges and dismissal is warranted, either dismiss the case outright or dismiss unsupported charges. (Such action does not preclude later NJP or court-martial for the dismissed offense(s). The XO may also impose non-punitive measures. If NJP is warranted, the XO will indicate this on the report chit and return all materials to the legal officer, who will forward the case to the CO. 


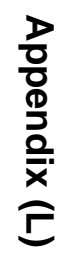

벙

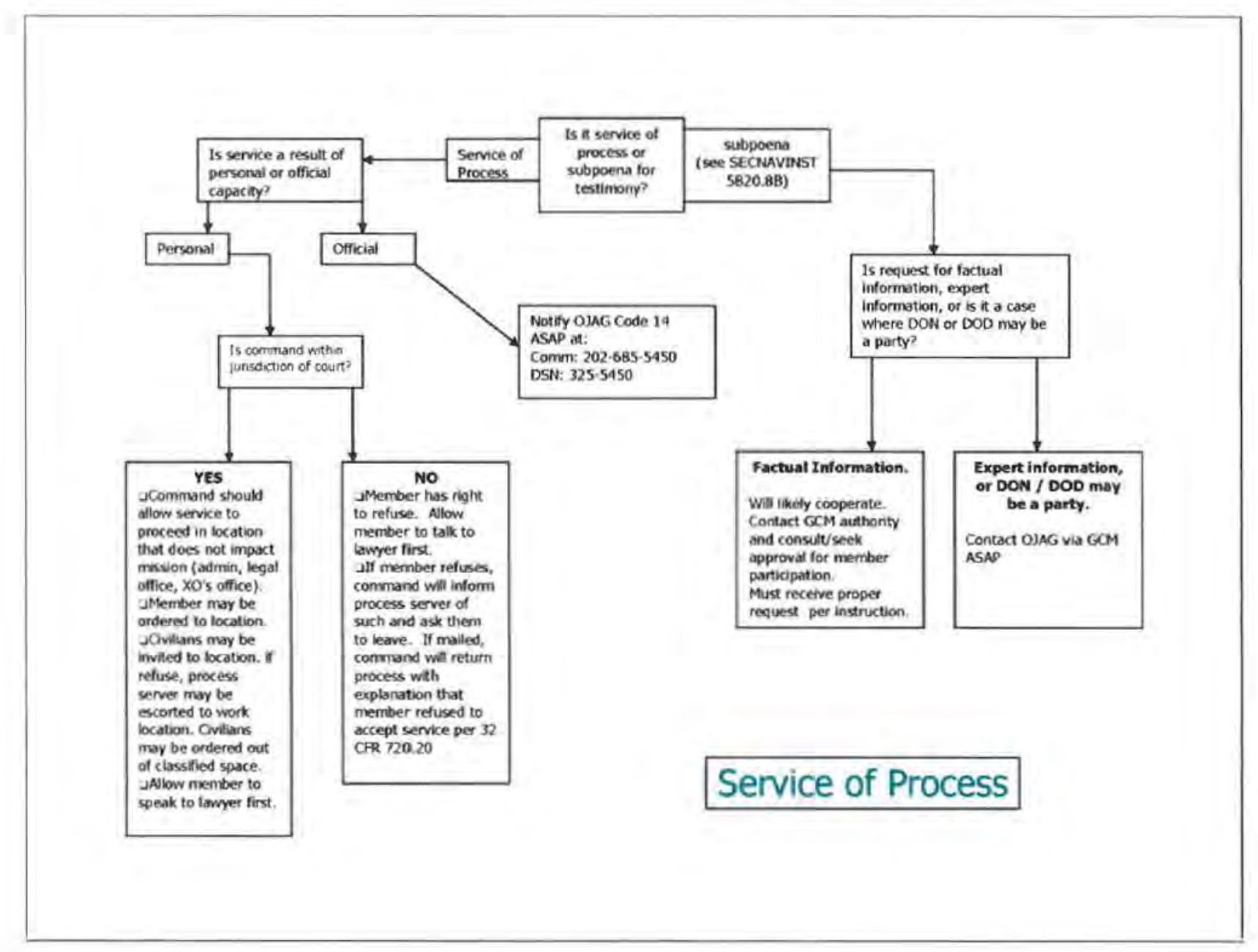




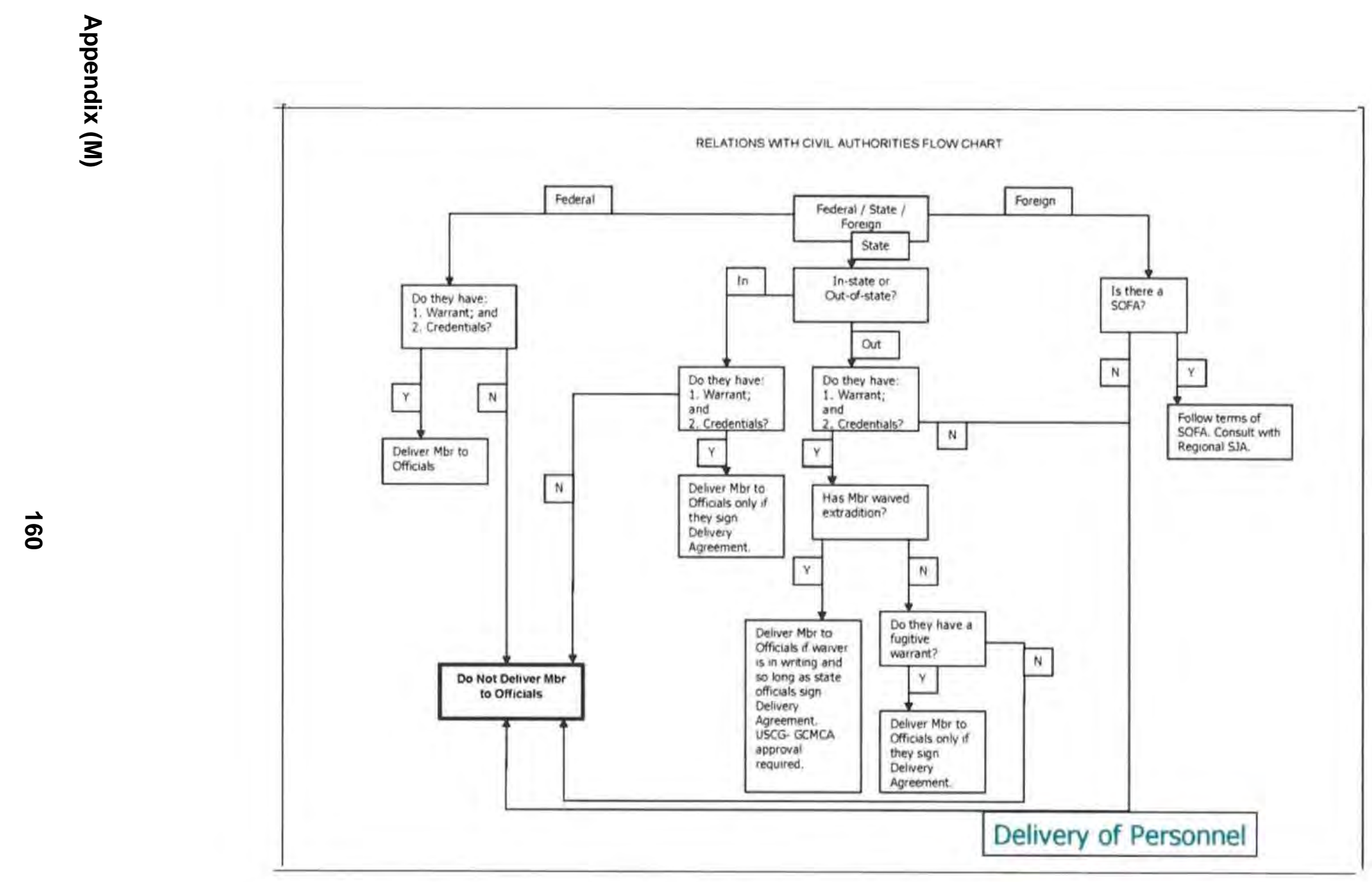

